\title{
The role of prefrontal cortex in working-memory capacity, executive attention, and general fluid intelligence: An individual-differences perspective
}

\author{
MICHAEL J. KANE \\ University of North Carolina, Greensboro, North Carolina \\ and \\ RANDALL W. ENGLE \\ Georgia Institute of Technology, Atlanta, Georgia
}

\begin{abstract}
We provide an "executive-attention" framework for organizing the cognitive neuroscience research on the constructs of working-memory capacity (WMC), general fluid intelligence, and prefrontal cortex (PFC) function. Rather than provide a novel theory of PFC function, we synthesize a wealth of singlecell, brain-imaging, and neuropsychological research through the lens of our theory of normal individual differences in WMC and attention control (Engle, Kane, \& Tuholski, 1999; Engle, Tuholski, Laughlin, \& Conway, 1999). Our critical review confirms the prevalent view that dorsolateral PFC circuitry is critical to executive-attention functions. Moreover, although the dorsolateral PFC is but one critical structure in a network of anterior and posterior "attention control" areas, it does have a unique executiveattention role in actively maintaining access to stimulus representations and goals in interference-rich contexts. Our review suggests the utility of an executive-attention framework for guiding future research on both PFC function and cognitive control.
\end{abstract}

... the frontal lobes ... with their associated sensory centres, form the substrata of those psychical processes which lie at the foundation of the higher intellectual operations. (Ferrier, 1886, p. 467)

Different individuals, under apparently the same conditions, show differences in the degree of attention... . [A]s a suggestion of the meaning of these general, individual conditions, we might surmise such things as ... the frontal lobes or some function thereof, "mental constitution" or organization; or "intellective energy." (Woodrow, 1916, p. 285)

Life definitely reveals two categories of people-artists and thinkers. . . In the artist the activity of the cerebral hemispheres flowing through the whole mass, involve least of all the frontal lobes, concentrating chiefly on the remaining parts; in the thinkers, however, the converse is true. (Pavlov, 1941, p. 113)

The frontal lobes reach their phylogenetic and ontogenetic peak in adult Homo sapiens, where they occupy be-

This work was supported by Grants F49620-93-1-0336and F4962097-1 from the Air Force Office of Scientific Research and Grant RO1HD27490-01A1 from the National Institute of Child Health and Human Development. We are indebted to Alan Baddeley, Todd Braver, Andrew Conway, John Duncan, Timothy Salthouse, and Jeffrey Toth for their helpful comments on earlier versions of this manuscript. Correspondence concerning this article should be sent either to M. J. Kane, Department of Psychology, P. O. Box 26164, University of North Carolina at Greensboro, Greensboro, NC 27402-6164, or to R. W. Engle, School of Psychology, Georgia Institute of Technology, Atlanta, GA 30332-0170 (e-mail: mjkane@uncg.edu or randall.engle@ psych.gatech.edu). tween $30 \%$ and $40 \%$ of the neocortical area (see, e.g., Brodmann, 1925; Damasio, 1991; Fuster, 1988; GoldmanRakic, 1987). Such evolutionary and physical prominence has led many theorists to assign the highest of cognitive capabilities, and even the highest qualities of humanity itself, to the frontal cortex (e.g., Goldstein, 1936, 1944; Halstead, 1947; Rylander, 1939). However, early clinical research on patients with frontal lobe damage indicated that such injury did not affect intelligence, at least as broadly defined by IQ test batteries (e.g., Ackerly, 1937; Hebb, 1939, 1945; Hebb \& Penfield, 1940). Such null findings stand in stark contrast to the everyday cognitive difficulties reported by many patients with frontal damage, particularly by those with damage to the prefrontal cortex (PFC; see, e.g., J. M. Harlow, 1848; Lezak, 1983; Luria, 1966; Shallice \& Burgess, 1991a, 1991b).

Indeed, a more recent body of clinical observations and experimental research suggests that PFC injury and disease creates a formidable array of cognitive deficits. Such deficits include (but are not limited to) problems of attention, motor control, spatial orientation, short-term memory, temporal and source memory, metamemory, associative learning, creativity, perseveration, and reasoning (for reviews, see Fuster, 1988; Goldman-Rakic, 1987; A. C. Roberts, Robbins, \& Weiskrantz, 1998; Stuss \& Benson, 1984; Wise, Murray, \& Gerfen, 1996).

In the sections that follow, we will critically and comprehensively review evidence that general working-memory (WM) and executive-attentionfunctions are subserved 
by neural circuits centered in and passing through the PFC. There is broad agreement in the literature that PFC circuits, and perhaps dorsolateral prefrontal cortex (dPFC) cells in particular, are critical for WM functions. From our perspective, the role of dPFC in WM is to maintain information in a highly active, easily accessible state. This maintenance is particularly important in the presence of interference, and it may be crucial in blocking the effects of distraction. Moreover, as we have argued elsewhere (e.g., Engle, 2001, 2002; Engle, Tuholski, Laughlin, \& Conway, 1999), we view WM capacity, or the capability for executive attention, as the psychological core of the statistical construct of general fluid intelligence, or psychometric $G f$. In this review, then, we will also evaluate evidence suggesting the importance of the dPFC to general fluid ability. We will further speculate that, because dPFC is critical to WM capacity and to Gf, normal individual differences in WM capacity and in Gf may be mediated by normal individual differences in dPFC functioning (see also Engle, Kane, \& Tuholski, 1999; Engle \& Oransky, 1999).

As the quotes that began this paper may suggest, we do not claim to present a novel theory of PFC function, but rather we present an organizing framework for reviewing prior research and suggesting fruitful avenues for future work. Indeed, the lens through which we examine the literature has much in common with several prominent views of dPFC function, particularly those of Baddeley (1996), Dempster (1991, 1992), Duncan (1993, 1995), Fuster (1988, 1996), Goldman-Rakic (1987), Malmo (1942), E. K. Miller \& Cohen (2001), R. J. Roberts and Pennington (1996), Shallice and Burgess (1991b), Shimamura (2000), Smith and Jonides (1997), and Stuss, Shallice, Alexander, and Picton (1995). Our contribution here is novel, however, not just in the comprehensiveness of the review, but also in providing a unified perspective on four broad, overlapping constructs: WM capacity, attention control, fluid intelligence, and PFC function. Relations within only a subset of these constructs have been explored in detail before-for example, among attention, intelligence, and PFC (Dempster, 1991, 1992; Duncan, 1993, 1995). Moreover, although aspects of WM function have long been linked to the PFC (see, e.g., Jacobsen, 1935, 1936), the individual-differences construct of WM capacity has not.

To summarize our view, the WM construct is assumed to be a hierarchical system involving short-term-memory (STM) representational components plus a general, executive-attention component (see Baddeley \& Hitch, 1974; Baddeley \& Logie, 1999; Cowan, 1995, 1999). "Span" tasks that reflect WM capacity are thought to reflect the contributions of both STM and executiveattention components (see, e.g., Daneman \& Carpenter, 1980; Turner \& Engle, 1989). However, the covariation among WM-span tasks and tasks of higher order cognition reflects primarily the executive-attention component in the system, and less the STM components. Normal in- dividual differences in WM span are widely found to correlate with many facets of higher order cognition, including language comprehension, reasoning, and Gf. We believe that these correlations are driven by individual differences in executive attention. Thus, when we use the term "WM capacity," which we do for historical reasons, we are really referring to the capability of the executiveattention component of the WM system.

By executive attention, we mean a capability whereby memory representations are maintained in a highly active state in the presence of interference, and these representations may reflect action plans, goal states, or taskrelevant stimuli in the environment. Critical to our view is that, while the active maintenance of information can be useful in many situations, it is most necessary under conditions of interference or response competition. This is because in the absence of interference, task-relevant information, goals, or response plans may be easily retrieved from long-term memory (LTM) as needed. Under interference-rich conditions, however, incorrect information and response tendencies are likely to be retrieved. Such contexts therefore set the occasion for relying on active maintenance of information.

We further suggest that individual differences in executive attention may also reflect the capability to prevent attentional focus from being captured by mental or environmental distractors, and thus drawn away from the actively maintained target information. In interferencerich contexts, a loss of focus on the representation of target information will result in its returning to baseline activation levels and its being difficult to recover from LTM. Thus, active maintenance and distractor blocking are interdependent features of executive attention that we argue form the core of the WM capacity and Gf constructs. We also hope to persuade the reader that these dual features of executive attention are dependent on dPFC structures.

We highlight here that our attentional view of WM capacity differs significantly from traditional notions of STM or WM emphasizing how large WM capacity is, or how much WM can hold (see, e.g., Daneman \& Carpenter, 1980; G. A. Miller, 1956). The dependent measure in most WM-span tasks is, indeed, the amount of information that can be recalled in a particular context. Nonetheless, we emphasize the importance of WM capacity for maintaining access to even a single stimulus, goal, or response production in contexts providing potent interference. As we hope to make evident below, WM theories that focus on the size of WM capacity do not allow for the predictions or data that are accommodated by our framework.

Below, we will critically review the evidence linking WM capacity and executive attention to the dPFC. However, we will first summarize the recent behavioral research linking WM capacity, attention control, and fluid ability that informs our framework. Subsequently, we will briefly review the difficulties in localizing WM 
functions to PFC circuitry, including considerations of anatomy and physiology, empirical methods, and individual differences.

\section{INDIVIDUAL DIFFERENCES IN WORKING-MEMORY CAPACITY AND EXECUTIVE CONTROL}

It is beyond the scope of this paper to review comprehensively the WM and intelligenceliteratures upon which our framework is based (we refer the interested reader to Conway \& Kane, 2001; Engle, 2001; Engle, Kane, \& Tuholski, 1999; Engle, Tuholski, et al., 1999). However, much of the research linking WM capacity, attention control, and Gf is relatively recent, and so we will briefly elaborate on our framework by reviewing the evidence linking these constructs.

Much of the relevant research has used span tasks as an index of WM capacity. WM-span tasks typically require subjects to maintain short lists of items in memory while simultaneously processing other information, such as reading sentences or solving equations (see, e.g., Daneman \& Carpenter, 1980; Turner \& Engle, 1989). Thus, the critical task-a memory-span test-is embedded within a secondary, processing task. Parametric and psychometric research has demonstrated that WM-span tasks are reliable and valid measures of the WM capacity construct (e.g., Engle, Tuholski, et al., 1999; Klein \& Fiss, 1999). Moreover, individual differences in knowledge, processing abilities, or strategies used during the span task do not impact the correlations between span scores and complex cognitive measures (Conway \& Engle, 1996; Engle, Cantor, \& Carullo, 1992; Engle, Nations, \& Cantor, 1990).

Most importantly here, structural-equation-modeling studies show that latent variables representing the common variance among WM-span tasks correlate between .60 and .80 with latent variables comprising reasoning and Gf tasks (Conway, Cowan, Bunting, Therriault, \& Minkoff, 2002; Engle, Tuholski, et al., 1999; Kail \& Hall, 2001; Kyllonen \& Christal, 1990; Süß, Oberauer, Wittman, Wilhelm, \& Schulze, 2002). In contrast, consider STM tasks such as word and digit span, which require immediate memory but do not include additional processing. These STM tasks, despite their shared variance with and surface similarity to WM-span tasks, do not demonstrate significant links to fluid ability after the contributions of WM are controlled for (Conway et al., 2002; Engle, Tuholski, et al., 1999). Thus, a considerable body of research now shows that the skills and strategies related to either simple processing or simple retention cannot account for the WM span $\times$ ability relation.

We have therefore proposed that WM is a system consisting of STM and executive-attention components. Moreover, only the general, executive-attention element of the WM system, the capability of which we call "WM capacity," drives the predictive power of WM-span tasks
(Engle, 2001,2002; Engle, Kane, \& Tuholski, 1999; Engle, Tuholski, et al., 1999). In this view, WM-span tasks involve most of the processes required by STM tasks, represented by the shared variance that is evident between WM and STM constructs. ${ }^{1}$ In addition, WM tasks make greater demands on attention control than do STM tasks, because WM tasks present a secondary task to interfere with the primary retention task. We therefore view information maintenance in the presence of interference as the critical control function of WM capacity, and as the primary mechanism linking WM capacity with higher order cognitive ability.

Quasi-experimental work has provided more direct evidence for an attentional mechanism of WM capacity, and one that is particularly relevant to interference. Such research has typically examined differences in attentioncontrol capabilities between extreme groups of high-and low-WM-capacity subjects (or between individuals of high and low intelligence). For example, individuals with low WM spans are more susceptible than those with high spans to various forms of LTM interference, such as fan-effect, output, retroactive, and proactive interference (Conway \& Engle, 1994; Kane \& Engle, 2000; Rosen \& Engle, 1997, 1998). The same appears to be true for Gf, at least with respect to proactive and output interference (Borkowski, 1965; Dempster \& Corkill, 1999; E. Miller, 1984; Phillips, 1997, 1999).

Even outside of traditional memory-tasks contexts, low-span/low-ability individuals demonstrate greater vulnerability to interference than do high-span/highability individuals in conditions that present potent competition between task goals and habitual responses. For example, in dichotic-listening tasks, subjects must shadow the message from one ear and ignore the message from the other ear. Here, low spans are over three times as likely as high spans to notice their names in the distractor channel, with $65 \%$ versus $20 \%$ of low versus high spans noticing, respectively (Conway, Cowan, \& Bunting, 2001). Thus, high spans were better able than low spans to resist the lure of the powerful orienting cue of their names being called, in the service of the novel task goal. Significant span differences are also seen in the antisaccade task, which presents subjects with a conflict between task goals and visual orienting cues (Kane, Bleckley, Conway, \& Engle, 2001). In this task, subjects saw an attention-capturing visual cue in the periphery and had to move their eyes and attention away from the cue, in the opposite direction, in order to detect a target stimulus there. In comparison with high spans, low spans erroneously made more eye movements toward the cue, corrected these errors more slowly, and were slower to identify the target stimuli. As in dichotic listening, high spans outperformed low spans in a task in which a novel goal had to be kept accessible in order to bias responding away from habit. However, high and low spans performed identically in a prosaccade condition in which subjects could reflexively look toward the cue to identify the target. ${ }^{2}$ 
When one considers tasks that demand novel responses in the presence of conflict, the Stroop task inevitably comes to mind (see MacLeod, 1991, for a review). In the Stroop task, subjects name the colors in which words or word-like stimuli are presented. When the color and the word conflict, as in the case of the word RED appearing in green, color naming is slowed (and more error prone) than when the word or word-like stimulus is unrelated to the color (e.g., PIN, or XXX, in green), or when the color and word match (e.g., GREEN in green). In fact, successful performance on the Stroop task correlates modestly with Gf measures (see, e.g., Dempster \& Corkill, 1999; Pati \& Dash, 1990; Valentine, 1975) and varies significantly with WM span (Kane \& Engle, in press). With respect to Gf, Boone (1999) found that, after age was controlled for, full-scale IQ accounted for $13 \%$ of Stroop variance. Kane, Sanchez, and Engle (1999) found that a single Gf measure correlated with Stroop interference at $r=-.49$.

With respect to WM span, Kane and Engle (in press) predicted that it should best predict Stroop interference when memory-maintenance demands were maximized. They did this by presenting high proportions of congruent trials, in which the color and the word matched (e.g., RED presented in red). Kane and Engle (in press) reasoned that Stroop tasks that include many congruent stimuli should put a premium on keeping the novel task goal active and accessible in comparison with a task that presents only incongruent stimuli. This is because, on congruent trials, the word dimension leads to the same response as the color dimension, and so "accurate" responding can occur despite one's acting according to habit and failing to act according to the goal. In such contexts, responses on rare incongruent trials should be especially sensitive to successful goal maintenance; if the goal is lost over many congruent trials, error will be likely on an incongruent trial. Indeed, in two experiments, we found that when $75 \%$ of trials were congruent, low spans committed $55 \%$ and $100 \%$ more word-naming errors on incongruent trials than did high spans.

Our findings from dichotic-listening, antisaccade, and Stroop tasks provide strong preliminary evidence for span-related differences in goal neglect due to failed WM maintenance in the presence of interference. Perhaps the best evidence for a similar link between fluid intelligence and failed goal maintenance comes from the work of Duncan and his colleagues (e.g., Duncan, Emslie, Williams, Johnson, \& Freer, 1996; Duncan, Johnson, Swales, \& Freer, 1997). In Duncan's “attention-switching”"task, subjects monitor one of two stimulus streams on a computer screen for the appearance of letters. Periodically, an abstract cue (a "+" or a "-") is presented between the two streams, indicating that subjects should either continue monitoring the same stream or switch to monitoring the other. Subjects who reliably switch their attention on cue tend to score substantially higher on the Cattell Culture Fair Test of Gf (Institute for Personality and Ability Testing, 1973), with $r$ s ranging from approximately .40 to 65 . In fact, whereas almost no individuals with Cattell scores above the population mean fail to switch, nearly all individuals with scores below one standard deviation of the mean fail to switch (for similar findings from related tasks, see Arthur, Barrett, \& Doverspike, 1990; Kahneman, Ben-Ishai, \& Lotan, 1973; McKenna, Duncan, \& Brown, 1986). Thus, like WM capacity, Gf is a good predictor of the ability to maintain stimulus or goal information in an accessible state, particularly in the presence of interference from distractors or habit.

\section{COMPLEXITIES OF MAPPING WORKING-MEMORY CAPACITY AND Gf ONTO THE PFC}

Having briefly described the recent evidence linking WM capacity and executive attention to Gf, we now turn to the significant difficulties that arise when an attempt is made to map such executive-attention functions onto a particular brain structure. Perhaps the most obvious obstacle to applying localization-of-function research to the PFC is that the PFC is a structurally and functionally heterogeneous brain region (see, e.g., Barbas \& Pandya, 1991; Fuster, 1980; Goldman-Rakic, 1987). Thus, we will hereafter focus our discussion on the dorsolateral region of the PFC, which has been the region most strongly (but not uniquely) associated with general cognitive functioning (see, e.g., Goldman-Rakic, 1987). The dorsolateral region roughly surrounds the principal sulcus, inferior convexity, and arcuate sulcus in the macaque monkey (Barbas \& Pandya, 1991; Goldman-Rakic, 1987). By most accounts, it occupies some combination of Brodmann's areas and Walker's areas 46, 9, and 10, in humans and macaques, respectively (e.g., Goldman-Rakic, 1987; Pandya \& Yeterian, 1999; Petrides \& Pandya, 1994).

Limiting our focus to the dPFC does not solve our localization problem, however. This is because the $\mathrm{dPFC}$ is massively interconnected with other cortical and subcortical brain areas, as is the PFC as a whole (see, e.g., Barbas \& Mesulam, 1981, 1985; Chow \& Cummings, 1999; Fuster, 1980, 1989; Goldman-Rakic, 1987; Nauta, 1964, 1972; Pandya \& Yeterian, 1990). When considered in the context of human neuropsychology, these bidirectional projections pose an obvious problem for localizing any single function to one locus within the circuit. That is, physical damage to any link in a series of neural connections may manifest itself similarly at a behavioral level. Moreover, typical PFC damage in humans, whether from trauma or from disease, is rather widespread at both cortical and subcortical levels (see Fuster, 1980; Petrides, 1989). More precise mapping of cognitive functions to brain structure, however, is allowed by several in vivo methodologies, such as positron emission tomography (PET) and functional magnetic resonance imaging (f MRI) (for reviews, see Posner \& Raichle, 1994; Raichle, 1994). These techniques, particularly advances in event-related fMRI, hold great promise in revealing brain-behavior relations, but the results must still be interpreted with some caution, particularly those from older studies (see Sarter, Bernston, \& Cacioppo, 1996; Sergent, 1994; R. P. Woods, 1996). 
In addition to recent imaging work, extensive research with macaques has helped isolate the necessary and sufficient brain areas for some behavioral tasks. This work has allowed researchers either to preexperimentally deactivate circumscribed brain sites through surgical lesions or to deactivate and reactivate these areas through cooling methods, electrical stimulation, or by manipulating specific neurotransmitters (for a review, see GoldmanRakic, 1987). Nevertheless, with regard to understanding human prefrontal function, the few limitations to nonhuman research are serious ones. First, a relatively narrow breadth of tasks can reasonably be explored with monkeys, and sample sizes are necessarily quite small. Second, monkeys require hundreds, if not thousands, of trials to learn many of these tasks. It is therefore not clear whether the monkey brain that is lesioned after learning is the same brain that existed before learning (O'Reilly, Braver, \& Cohen, 1997).

The difficulties discussed above have been noted previously by other authors. However, our theoretical framework also raises the important possibility, not considered before, that dPFC damage might have different consequences depending upon premorbid individual differences in WM capacity and Gf. If WM capacity, executive attention, and fluid intelligence all reflect a common mechanism, and if this mechanism is mediated by the prefrontal cortex, then any study of prefrontal function will be complicated by the confluence of individual differences and task demands. Thus, whether cognitive deficits on a task are observed after damage to dPFC will depend on premorbid individual differences in WM capacity/Gf and on whether that task involves sufficient interference to require, or be sensitive to, executive processing.

For example, in some tasks in which high-span individuals outperform low spans (e.g., in verbal fluency, proactive interference, and visual selective-attention tasks), adding a secondary load task hurts the performance of only the high spans, turning them into functional low spans. Counterintuitively, the performance of low spans is unaffected by the secondary task (see, e.g., Bleckley, 2001; Kane \& Engle, 2000; Rosen \& Engle, 1997). Such findings suggest that, in some contexts, high spans engage attentional processing to achieve their superior performance, whereas low spans do not, and so only high spans suffer when attention is taxed by the secondary task. Low spans, because of their limited executive-attention capabilities, tend to rely more on automatic processing, whereas high spans rely more on attentional processing within the same task. We therefore propose that in high-WM-capacity/Gf individuals, PFC damage, like an attentionalload, will lead to greater behavioral deficits than will similar damage in low-WM-capacity/Gf individuals. In effect, dPFC damage, like a secondary attentionalload, should make a former high-span individual perform like a low-span individual, whereas in many cases low spans should be relatively unaffected. ${ }^{3}$

Despite the interpretive complexities outlined above, we are optimistic that the data from a convergence of methods provide at least a crude framework for an un- derstanding of the role of the dPFC in WM capacity, executive attention, and Gf. We will attempt to specify this framework throughout by proposing that the common variance among WM capacity/executive attention, $G f$, and $d P F C$ functioning is the degree to which a task requires that a memory representation be maintained in a highly active state. Moreover, individual differences in this common construct will most readily be observed in task situations involving interference and distraction.

\section{CONVERGING MODELS OF PFC INVOLVEMENT IN WORKING-MEMORY CAPACITY}

Before beginning our review of the relevant empirical findings, we will highlight two recent views of PFC and WM function that have had a major impact on our perspective. As discussed previously, Duncan and his colleagues have argued that Gf reflects an executive attentional capability that, when deficient, may result in "goal neglect" in some contexts (e.g., Duncan, 1990, 1993, 1995; Duncan et al., 1996). Similar to the supervisory attention system of Shallice (1988; Norman \& Shallice, 1986), this view holds that abstract (hierarchical) goal representations guide behavior when the environment elicits no particular response or a contextually inappropriate response. When goal states are neglected in these contexts, or, as we would argue, when they are not actively maintained by $W M$, behavior will appear disorganized, perseverative, or otherwise inappropriate. Critically, according to Duncan $(1990,1993,1995)$, the attentional "goal-weighting" capability that allows for coherent, goal-directed behavior is central to psychometric Gf and relies heavily on PFC circuits for effective functioning.

We see an important parallel here between Duncan's $(1990,1993,1995)$ theory and the more formal model of executive and PFC function proposed by Cohen and his colleagues (e.g., Braver \& Cohen, 2000; Cohen \& ServanSchreiber, 1992; E. K. Miller \& Cohen, 2001; O’Reilly, Braver, \& Cohen, 1999). Specifically, Cohen's model implements the control capabilities of the PFC as the ability to maintain context information (or task demands) in an active state. Moreover, the active maintenance of task demands has the effect of reducing competition from distractors through lateral inhibition. This is precisely the kind of maintenance function we have emphasized as critical to understanding WM capacity and Gf (see also R. J. Roberts \& Pennington, 1996). Cohen and colleagues further suggest that the WM system is a distributed one, specifically involving PFC, anterior cingulate, hippocampal complex, and posterior sensory and motor cortex. The PFC is the critical component in active maintenance amid interference (Cohen, Braver, \& O’Reilly, 1996, 1998; O'Reilly et al., 1999).

According to the Cohen model, different cortical structures evolved complementary specialties in order that the whole brain could best accommodate varied and dynamic processing demands. Posterior sensory and motor cortex evolved to allow slow, integrative learning 
using widely distributed representations. In contrast, the hippocampus and PFC developed to operate on more discrete representations. The hippocampus rapidly learns arbitrary information and associations by episodically binding stimulus and context information. PFC dynamically maintains and updates goal information to bias processing in networked areas and to retrieve goal-relevant information from those areas as needed. Thus, "controlled" or executive processing emerges from the interactions among these complementary brain regions.

Critically, from our perspective, the PFC is what allows for active maintenance and interference control in the Cohen model (Cohen et al., 1998; E. K. Miller \& Cohen, 2001; O'Reilly et al., 1999). Specifically, interference control arises from the interaction of two separate mechanisms. First, PFC representations are strongly interconnected and so recurrent excitation leads to their sustained activity (see also Dehaene \& Changeux, 1989). Such recurrent excitation alone, however, would have the side effect of making PFC activity difficult to rapidly shift and update, which is clearly not the case. Second, Cohen and colleagues therefore propose that dopamine circuits between PFC and midbrain areas (e.g., ventral tegmental area, or VTA) also serve a "gating" role (see Braver \& Cohen, 2000). That is, descending fibers from the PFC may block task-irrelevant representations from interfering with active maintenance. Given that the PFC controls the release of dopamine from VTA, it can bias the signals from other brain areas back to itself. For example, the PFC may signal dopamine release to increase the signal strength from other brain areas when updating is necessary (e.g., after completion of a goal). Or, the PFC may signal dopamine release to increase activity in inhibitory loops when updating is not necessary (e.g., before completion of a goal). Although this proposal is somewhat speculative at this time, it provides a biologically plausible implementation of the maintenance and blocking/inhibition functions of WM capacity that we review here (see also Kimberg, D'Esposito, \& Farah, 1997; Luciana, Depue, Arbisi, \& Leon, 1992).

\section{WORKING-MEMORY CAPACITY AND THE PREFRONTAL CORTEX}

In this section, we comprehensively review the evidence that the dPFC is central to the executive-attention processes of the WM system. Our discussion will first focus on findings from tasks in the traditional Baddeley and Hitch (1974) approach to WM. In these executiveattention tasks, subjects must maintain information in memory while simultaneously processing additional information. We will then consider the research that has isolated other executive functions, such as maintaining information while focusing and switching attention. Finally, we will review evidence for dPFC involvement in the performance of psychometric tests that reflect Gf.

It is difficult to define an appropriate subject sample (or samples) with which to study dPFC function, and any such decision is open to some criticism. Our own choices were influenced by two main goals: to provide a rather complete review of the relevant empirical work, and also to keep the size of this potentially mammoth literature manageable. In the sections that follow, then, we primarily review studies using the following subject samples: (1) nonhuman primates with surgical brain lesions (or temporary deactivation of brain regions); (2) adult humans with brain damage due to stroke, tumors or tumor resection, aneurysm repair surgery, or penetrating head wounds; and, finally, (3) healthy adult humans studied with various brain-imaging techniques. Although a review of related research with neuropsychiatric or developmental populations is clearly relevant to present purposes, we must leave it to other authors (see, e.g., Diamond, 1990, 1991; Pennington, 1994; R. J. Roberts \& Pennington, 1996; West, 1996).

\section{Working-Memory Capacity}

A significant volume of research relevant to our conception of WM capacity has been conducted with nonhuman primates as subjects, and so we begin our discussion there. Data have come primarily from three classes of macaque subject groups. They are those with surgical lesions to circumscribed brain areas, those with implants that temporarily deactivate brain areas through cooling or electrical current, and those with electrode implants to allow for single-cell recordings. Following our review of this monkey research, we will discuss the corresponding work with human patients and with healthy human adults.

\section{Nonhuman Primate Research}

The WM capacity of macaque monkeys is inferred from delay tasks, with "delay" referring to the interval imposed between presentation of a stimulus and testing of a subject's memory for it. Since Jacobsen's $(1935,1936)$ demonstration that delay-task performance is highly sensitive to PFC damage, the delay tasks most commonly employed in this research domain have been the delayedresponse task, the delayed-alternation task, the delayed matching-to-sample task, and the selflexternallyordered memory task (for reviews, see Funahashi \& Kubota, 1994; Goldman-Rakic, 1987, 1995; Petrides, 1995). In each task, the subject must remember spatial or object information across a delay and must update the memory representation of that information from trial to trial, particularly because the same stimuli may repeat across trials.

More specifically, on each trial of the delayed-response task, the monkey views two or more possible spatial locations while one is randomly "baited" or otherwise deemed relevant. After a delay, in which the locations are typically removed from view, the monkey is rewarded for recalling the relevant location, evidenced either by reaching or by an eye-movement response. In the delayedalternation task, the monkey views two possible spatial locations (or two objects), one of which is baited out of the monkey's view; here, baiting is always contingent upon the previously baited location or object. That is, if on one trial the monkey is rewarded for selecting one location or object, on the next trial it will be rewarded for 
selecting the opposite location or object. Critically, a delay is imposed between successive responses. In the delayed matching-to-sample task, the monkey views a sample object that is then removed from view for some time. At test, the monkey views two objects, one of which is the sample, and it is rewarded for responding to the sample. The delayed matching-to-sample task is particularly interesting with respect to our executive-attention framework. It not only requires monkeys to maintain information across a delay, but it also forces them to inhibit their natural tendency to respond to novel stimuli in the environment. Finally, in the self/externally ordered memory task, the monkey views series of sample objects, or series of sample locations, and must choose a sample on each trial that had not yet been chosen on any previous trial. Here, then, monkeys must maintain and update a representation of previously selected objects in order to avoid responding to them in the future.

These delay tasks may appear to have more in common with STM tasks than with WM-span tasks. That is, they involve only information storage and do not additionally demand simultaneous processing of other information, as do human WM-capacity tasks (although the delayed matching-to-sample task does additionally require monkeys to withhold a prepotent response). Recall that, whereas WM-capacity tasks require people to study and recall stimulus lists while processing unrelated information, STM tasks do not, and only WM-span tasks consistently correlate with measures of complex cognitive ability (see, e.g., Daneman \& Carpenter, 1980; Engle, Tuholski, et al., 1999; Turner \& Engle, 1989).

However, we note that in the delay tasks with monkeys, attentional focus is typically drawn away from the to-be-recalled stimuli during the delay. This is done either by placing an opaque physical barrier between the subject and the stimuli, thus requiring eye fixation on a nontarget location, or by requiring a maintained reaching response to a nontarget location (see, e.g., Funahashi, Bruce, \& Goldman-Rakic, 1989; H. F. Harlow, Davis, Settlage, \& Meyer, 1952; Niki, 1974b). Such distractions are not present in human STM tasks, such as digit-span tasks, in which recall is tested immediately. Thus, delay tasks do seem analogous to human WM-capacity tasks, in that successful performance on the task requires that information about the stimulus be maintained for use in the presence of distracting elements in the environment, as well as in the presence of interference from prior-trial information at retrieval.

When the opaque physical barrier is placed between the monkey and the stimuli, or when a maintained response is required to a location other than that of the stimuli, the monkey is distracted by other elements in the environment. That is, the monkey may simply "think" about something other than the stimuli. And, while "thinking" about something else, the monkey loses the previously highly active representation of the target stimulus. Indeed, in healthy monkeys, illuminating the testing chamber during the delay reduces memory performance in comparison with darkened delays (see, e.g.,
D'Amato \& O'Neill, 1971; Harper \& White, 1997; Salmon \& D'Amato, 1981; Worsham \& D'Amato, 1973). This is presumably because illumination allows visual distraction during the delay, whereas darkness minimizes it. Therefore, the presence of a distraction during the delay, and the potential for retrieval interference from the repetition of stimuli and locations across trials, make these delay tasks reasonable analogues of human WM-capacity tasks. We should also note, in this regard, that the task demands required to tap a particular construct in adult humans (here, WM capacity) may be quite different from those required to tap that construct in nonhuman primates, or even in human children (see Engle, Kane, \& Tuholski, 1999; Engle, Tuholski, et al., 1999).

To return to the PFC literature, dorsolateral prefrontal areas-particularly those anterior to the arcuate sulcus and surrounding the principal sulcus - are critical to normal performance in all of the delay tasks described above (see Goldman-Rakic, 1987; Rosenkilde, 1979). Accuracy drops to near-chance levels in monkeys with lesions to Walker's areas 9, 10, and 46, even with delays of mere seconds (see, e.g., Battig, Rosvold, \& Mishkin, 1960; Funahashi, Bruce, \& Goldman-Rakic, 1993; Goldman \& Rosvold, 1970; Goldman, Rosvold, Vest, \& Galkin, 1971; Mishkin \& Pribram, 1955, 1956; Oscar-Berman, 1975; Pribram \& Mishkin, 1956; W. A. Wilson, 1962; but see Petrides, 1995). Similarly, macaques with temporary dorsolateral "lesions" brought about by cortical cooling or electrical current show significant delay-task impairments (see, e.g., Bauer \& Fuster, 1976; Fuster \& Bauer, 1974; Quintana \& Fuster, 1993; Shindy, Posley, \& Fuster, 1994; Stamm, 1961; Stamm \& Rosen, 1973). However, lesions to many other brain areas, even in more ventral or superior PFC, often do not produce such deficits (see, e.g., Goldman et al., 1971; Mishkin \& Pribram, 1955, 1956; Oscar-Berman, 1975; Pohl, 1973; but see, e.g., Battig et al., 1960; Rosvold \& Delgado, 1956; Zola-Morgan \& Squire, 1985).

Single-unit recordings from dPFC cells indicate significant neural populations whose firing is concomitant with delay periods. That is, they begin firing when the cue information either appears or disappears, and they continue firing during the delay until a response is initiated. Such cells seem to hold cue-related information "on line" during the delay (see, e.g., Fuster, 1973; Fuster \& Alexander, 1973; Fuster, Bauer, \& Jervey, 1985; Kikuchi-Yorioka \& Sawaguchi, 2000; Kojima \& Goldman-Rakic, 1982, 1984; Kubota \& Niki, 1971; Kubota, Tonoike, \& Mikami, 1980; E. K. Miller, Erickson, \& Desimone, 1996; Niki, 1974a, 1974b, 1974c; Niki \& Watanabe, 1976; Quintana, Yajeya, \& Fuster, 1988; Romo, Brody, Hernández, \& Lemus, 1999; Rosenkilde, Bauer, \& Fuster, 1981).

Moreover, at least for cells within the principal sulcus region of $\mathrm{dPFC}$ in the monkey, circumscribed "memory fields" can be seen. Analogous to visual-system neurons with distinct receptive fields, many principal sulcus cells respond preferentially to stimuli in specific regions of space. These cells are particularly active during the encoding and delay-maintenance of stimuli in their preferred 
locations (see, e.g., Batuev, Shaefer, \& Orlov, 1985; Funahashi et al., 1989; Funahashi, Bruce, \& GoldmanRakic, 1990; Rainer, Asaad, \& Miller, 1998; F. A. W. Wilson, O'Scalaidhe, \& Goldman-Rakic, 1993). Delayperiod specificity is not limited to the spatial domain, however. Objects may also elicit selectivity in dPFC cells (Rainer et al., 1998): In a delayed matching-to-sample task, monkeys responded when a specific sample object, appearing with two distractors, was repeated in the same location. The sample stimulus was consistent across trials within a trial block, but it varied between blocks. Thus, in a context in which both object and location information was relevant to correct responding, objectspecific and location-specific maintenance cells were identified. (As we will discuss later, however, more dPFC cells were identified as responding generally to both object and location dimensions than as responding specifically to only the object or only the location dimension; see also Rao, Rainer, \& Miller, 1997.) Interestingly, object-specific cells fired above baseline even during the delays between trials, within a block, suggesting that the object-specific cells were maintaining the identity of that trial block's sample stimulus in order to help guide attention to the sample among the distractors.

Our arguments about the WM-as opposed to the STM-demands of these delay tasks is further supported by an important experiment by Malmo (1942). Monkeys with large dorsolateral lesions performed at chance level in the delayed-response task if a light was kept on during a $10-$ sec delay, as is typical. The lit conditions presumably allowed subjects to attend to other objects in the environment. However, if the lights were turned off during the delay, thus minimizing distraction from other visual stimuli, the PFC monkeys were virtually unimpaired. These findings strongly suggest that the dPFC maintains memory representations in the presence of environmental distractions that may switch focus away from the active maintenance of that representation. When focus is briefly shifted, interference may make retrieval of recent stimuli or task demands much more time-consuming and error prone.

Indeed, Bartus and LaVere (1977) also found that interstimulus delays are much less important to dPFC-related memory deficits than is the presence of distraction during the delay. Monkeys with dPFC lesions were compared with unoperated monkeys. On a traditional delayed-memory task, lesioned monkeys performed at chance with a 10 -sec delay, but normally with a 0 -sec delay, replicating previous findings. Subjects were also tested in a combined delayed-memory/delayed matching-to-sample task. Here, the monkeys viewed two stimuli for $500 \mathrm{msec}$, one to the right and one to the left, each consisting of a pattern of three illuminated lights. Eight patterns were arbitrarily but consistently defined as targets and eight were defined as distractors. On each trial, the monkey was rewarded for pulling a lever on the same side as the target pattern and ignoring the lever on the side of the distractor pattern.

When the target and distractor patterns were presented together for 1,000 msec, and until responding was permitted, the lesioned and nonlesioned monkeys performed equally well, requiring an average of 60-70 trials to reach a $90 \%$ accuracy criterion. The groups also performed equivalently when a 500-msec blank interval was inserted between the target display and the response. The dPFC-lesioned monkeys were significantly impaired, however, in a second condition that presented additional distractors during the delay. Here, the target and distractor patterns appeared together for $500 \mathrm{msec}$, followed by a brief presentation of two distractor patterns. Responses were not permitted until after the distractors appeared. In this condition, in which distractor patterns intervened between stimulus and response, normal monkeys again took only about 60 trials to reach criterion. Monkeys with dPFC lesions, in contrast, took an average of over 220 trials to do so. Consistent with Malmo's (1942) findings, then, monkeys with lesions to the dPFC were particularly impaired in remembering target information when attention was drawn away from the target during even a very brief delay. Without the maintained activation of target information, and with proactive interference from prior trials impairing LTM retrieval, monkeys cannot perform delayed-memory tasks without intact dPFC.

Finally, we note that several brain areas that are anatomically networked with the dPFC also are important to delay-task success. For example, lesions to nuclei of the basal ganglia and thalamus, to hippocampal regions, or to some parietal and temporal cortex areas produce delay performance deficits; moreover, single-unit recordings and imaging data from these structures indicate delay-period activity in a considerable number of cells (see, e.g., Alexander \& Fuster, 1973; Batuev et al., 1985; Baylis \& Rolls, 1987; Friedman \& Goldman Rakic, 1988; Koch \& Fuster, 1989; Shindy et al., 1994; Watanabe \& Niki, 1985; Zola-Morgan \& Squire, 1985). These findings of posterior and subcortical participation in delaytask performance make good sense. First, these various structures are neurally interconnected, and second, virtually no cognitive task is performed by a single brain region. Complex tasks such as those tapping WM capacity appear to involve integrated circuits that work in concert to solve behavioral problems involving immediate memory (see Goldman-Rakic, 1987).

However, we also emphasize that recent evidence suggests that, for cells in posterior areas, firing during the delay is significantly disrupted if distractor stimuli are presented prior to the target (Constantinidis \& Steinmetz, 1996; E. K. Miller \& Desimone, 1994; E. K. Miller, Li, $\&$ Desimone, 1993). Such disruption is not seen in delayresponsive dPFC cells (di Pellegrino \& Wise, 1993a, 1993b;E. K. Miller et al., 1996). These data suggest, again, that dPFC cells are uniquely critical to retaining information across delays when interference and distraction are present (Bartus \& LaVere, 1977; Malmo, 1942). Without dPFC activity, the presence of a salient distractor causes target representations to be lost from active memory, and the buildup of proactive interference across trials makes these representations more difficult to retrieve from LTM. Therefore, even though posterior and subcortical brain areas are important to some aspects of delay-task 
performance, the dorsolateral PFC appears to be special in its role of maintaining the activation of memory representations in the presence of interference, when shifts of attention away from targets may lead to a loss of their rapid accessibility.

\section{Human Research}

Memory-span tasks. As far as we know, only one case study and one experiment have tested human patients with PFC damage on complex WM-span tests that require subjects to remember words while also reading unrelated sentences (Daneman \& Carpenter, 1980). Results were mixed. In the case report, a patient with a severe head injury to the left frontal lobe was able to attain simple digit span scores of 4 and 5 (with visual and auditory stimuli, respectively). However, the patient was unable to recall any of the smallest sets of two words in the sentence span task (Van der Linden, Coyette, \& Seron, 1992). Thus, the frontal damage appeared to impair recall most severely in a WM task. Given that this was a case study, however, we have no premorbid assessment or control condition with which to compare these STM and WM scores. A controlled experiment comparing lobectomy patients with frontal cortex damage $(n=12)$ with those with temporal cortex damage $(n=50)$ and with healthy controls $(n=17)$ revealed no significant differences among groups on the sentence span task (Frisk \& Milner, 1990). However, for the frontal patients, the rank-order correlation between extent of damage and various scores from the span task ranged from $r=.34$ to $r=.38$, indicating that less frontal damage was associated with higher span scores. Although these correlations were not significant $(p<$ .05 ), perhaps due to the small sample size, they are consistent with recent data collected from healthy adult volunteers (Raz, Briggs, Marks, \& Acker, 1999). In that study, a composite measure of WM span correlated modestly with individuals' dorsolateral PFC volume corrected for height, as measured by MRI $(r=.29)$. WM span scores did not correlate significantly with volume of fusiform gyrus $(r=.16)$, inferior temporal lobe $(r=.06)$, or occipital cortex $(r=-.13)$.

Delayed-memory tasks. Human patients with PFC damage also show clear deficits on delay tasks that are similar to those exhibited by brain-lesioned macaques (Baldo \& Shimamura, 2000; Bechara, Damasio, Tranel, \& Anderson, 1998; Chorover \& Cole, 1966; Dubois et al., 1995; Freedman \& Oscar-Berman, 1986; Ptito, Crane, Leonard, Amsel, \& Caramanos, 1995). ${ }^{4}$ For example, in computer-presented delayed-response and delayedalternation tasks with 15 -sec delays, frontal patients with unilateral stroke damage showed significant impairments compared with posterior-damaged and non-braindamaged controls (Verin et al., 1993). In the delayedresponse task, no control patients made errors, only 2 of the 10 posterior patients made errors, yet 7 of the 10 frontal patients made errors. Ferreira et al. (1998) tested mixedetiology patients in a computerized delayed-response task with 500-msec versus 10-sec delays. Eight patients with unilateral frontal lesions (most including $\mathrm{dPFC}$ ) and
10 patients with unilateral inferior temporal lesions were each compared with patients in an age-matched, healthy control group. On each trial, 12 randomly arranged blue squares appeared, and then 2 to 5 of the squares turned red for 2-3.5 sec. These red squares were the targets for that trial. After the delay, during which the screen was black, all 12 squares reappeared. The subjects then touched the target squares in any order. All groups performed equivalently on the 500-msec delay trials. Although ceiling effects may have limited the sensitivity of the test, only the frontal patients showed a significant decrease in memory on 10-sec delay trials. Frontal patients appeared to have great difficulties recalling target sets larger than two items on long-delay trials, whereas temporal patients were unimpaired across all set sizes.

Brain-imaging studies of healthy humans performing delay tasks have principally employed delayed matchingto-sample tasks. However, they have provided less clear results than those described above for lesion studies (for other reviews of this literature, see Haxby, Petit, Ungerleider, \& Courtney, 2000; Jonides et al., 1996; McCarthy, 1995). On one hand, imaging studies with delayed matching-to-sample tasks using human faces as stimuli have shown increasing dPFC activity across increasing delays (e.g., from 1 to $21 \mathrm{sec}$ ). ${ }^{5}$ Structural equation modeling suggests that the loci of increased activity occur bilaterally, between dPFC (Brodmann 46) and anterior cingulate (Brodmann 24) circuits, and between more ventral PFC (Brodmann 47) and posterior areas 21 and 37 (McIntosh, Grady, Haxby, Ungerleider, \& Horwitz, 1996; see also Courtney, Ungerleider, Keil, \& Haxby, 1996, 1997; Grady et al., 1998; Haxby, Ungerleider, Horwitz, Rapoport, \& Grady, 1995).

On the other hand, PET studies of delay tasks with object stimuli (primarily novel shapes) or with spatial stimuli often show very little prefrontal activation. When PFC activation is seen at all, it is most often centered in Broca's area, more ventral PFC areas, and/or around premotor cortex and supplementary motor areas (see, e.g., Awh et al., 1996; Dupont et al., 1993; Jonides et al., 1993; Rowe, Toni, Josephs, Frackowiak, \& Passingham, 2000; ${ }^{6}$ Smith, Jonides, \& Koeppe, 1996; Smith et al., 1995).

We would explain such discrepant findings by noting that the delays in most of the "negative" studies were too brief to necessitate dPFC involvement. Study-test intervals were typically as short as $3 \mathrm{sec}$ or less. Although the nonhuman primate literature suggests prefrontal involvement across very brief delays, humans may be able to perform such brief-delay tasks with minimal use of executive attention - and thus of the $\mathrm{dPFC}$ - especially with verbally codable stimuli (see Engle, Tuholski, et al., 1999). Indeed, in PET and fMRI studies of delayedresponse tasks using relatively long delays, dPFC activation does consistently occur (Baker, Frith, Frackowiak, \& Dolan, 1996; Barch et al., 1997; D’Esposito, Ballard, Zarahn, \& Aguirre, 2000; Fiez et al., 1996; Goldberg, Berman, Randolph, Gold, \& Weinberger, 1996; Rypma \& D'Esposito, 1999; Swartz, Halgren, Fuster, \& Mandelkern, 1994). Four studies showing significant dPFC ac- 
tivation, even with relatively short delays, have used tasks that are more demanding. For example, delayed alternation and delayed response requirements were combined into a single task (Gold, Berman, Randolph, Goldberg, \& Weinberger, 1996), or subjects had to maintain multiple stimuli at once (Prabhakaran, Narayanan, Zhao, \& Gabrieli, 2000; Rypma, Prabhakaran, Desmond, Glover, \& Gabrieli, 1999; Stern et al., 2000). ${ }^{7}$

Furthermore, as we noted previously, most delayedmemory experiments with macaques present some kind of distractor during the delay, and none of the "negative" human studies drew attention away from the target stimuli between study and test. Given that subjects were neither distracted nor required to process new information during the delay, these brief-delay tasks were closer to STM tasks than to WM-capacity tasks. That is, these tasks may allow insight into the brain areas involved in the short-term storage component of the WM system, such as those involving more ventral/ventrolateral PFC areas (see Owen, Evans, \& Petrides, 1996; Petrides, 1989). They probably do not provide much information about the circuits underlying WM capacity/executive attention. Indeed, delay tasks that require manipulation of the target information during the delay, such as alphabetizing a group of random letters, demonstrate increased delay-period $\mathrm{dPFC}$ activity relative to tasks not requiring such manipulation (D'Esposito, Postle, Ballard, \& Lease, 1999; Postle \& D'Esposito, 2000). Moreover, the dPFC areas that are sensitive to manipulation requirements do not appear to be particularly sensitive to changes in memory load, as indexed by delay-period activity across increasing sizes of memory sets (Jha \& McCarthy, 2000; Postle, Berger, \& D'Esposito, 1999; but see Postle \& D’Esposito, 2000).

$\boldsymbol{n}$-Back tasks. Simultaneous storage and manipulation of information is clearly required by the emerging "gold-standard" task in imaging studies of WM, the $n$-back task (Kirchner, 1958; Mackworth, 1959). Accordingly, the $n$-back task consistently shows dPFC involvement. For example, in one PET study using the 3back task, subjects responded to each stimulus object in a continuous sequence only if it matched the item seen three items ago (Smith et al., 1996, Experiment 2). In another condition, subjects responded to the stimulus if it appeared in a location that was occupied three items ago. Thus, in both conditions subjects had to selectively maintain information about prior stimuli as they encoded each new stimulus. Dorsolateral areas 46 and 9 showed increased bilateral activation in both object and spatial 3back conditions compared with control conditions (for similar PET results, see Petrides, Alivisatos, Meyer, \& Evans, 1993; Schumacher et al., 1996).

Research using fMRI techniques has provided converging evidence of the activation of dPFC areas during $n$-back performance. Cohen et al. (1994) presented subjects with a 2-back task with letter stimuli and a 1-sec interstimulus interval (ISI). In comparison with a control task in which subjects responded any time they saw the letter $X$, the 2-back task produced significant activa- tion in PFC areas 46, 9, and 10 (and also in more inferior areas 45 and 47, and in anterior cingulate). In two experiments, Braver et al. (1997) showed linearly increasing activity in dorsolateral areas 9 and 46 as WM load increased from a 1-back, to a 2-back, to a 3-back task. (Increased activity was also seen in PFC areas 44 and 45.) In their Experiment 2, which utilized whole-brain scans, significant memory-related activity was additionally detected in posterior frontal (Brodmann 4 and 6) and posterior parietal (Brodmann 40/7) cortices, and in the caudate nucleus of the basal ganglia. Thus, as expected, $\mathrm{dPFC}$ and regions anatomically networked to it showed significant increases in activation as WM load increased (see also Honey, Bullmore, \& Sharma, 2000; Jonides et al., 1997; Martinkauppi, Rämä, Aronen, Korvenoja, \& Carlson, 2000; Nyström et al., 2000; Pfefferbaum et al., 2001; Seidman et al., 1998). Moreover, this dPFC activation is maintained at a constant rate throughout ISIs between 10 and $20 \mathrm{sec}$ (Cohen et al., 1997).

Many $n$-back studies elicit bilateral, and roughly symmetrical, dPFC activation (e.g., Braver et al., 2001; Braver et al., 1997; Cohen et al., 1994; Martinkauppiet al., 2000; Seidman et al., 1998; Smith et al., 1996). However, McCarthy and colleagues have found that dPFC activation varies between object and spatial WM tasks (McCarthy et al., 1994; McCarthy et al., 1996). ${ }^{8}$ Here, when subjects monitored a stimulus stream for repetitions of objects, both hemispheres showed significant dPFC activation, with higher levels in the left hemisphere than in the right (but for the opposite result, see Callicott et al., 1999). When subjects monitored a stimulus stream for repetitions of locations, only right-hemisphere dPFC activation was significant. Somewhat consistent findings were reported from a multisite, multiscanner study in which a spatial 2-back task produced slightly to substantially greater right than left hemisphere activity, depending upon how data were pooled (Casey et al., 1998). Likewise, in a paced task resembling the $n$-back task, in which multiple stimulus locations had to be continuously tracked, increasing memory load was associated with greater increases in right than in left dPFC activity (Diwadkar, Carpenter, \& Just, 2000).

Although the domain generality of dPFC activity in the $n$-back task remains controversial, recent work has suggested that the inconsistent findings of lateralization in spatial versus object tasks may result largely from normal individual differences. D'Esposito, Ballard, Aguirre, and Zarahn (1998) examined patterns of lateralization in spatial versus object 2-back tasks across individual subjects. Half of the subjects showed either bilateral dPFC activation during both tasks or matching unilateral dPFC activation in both tasks, consistent with the prior findings of similar lateralization in object and spatial tasks. However, the other half of the subjects showed bilateral activation in one of the tasks (most often the verbal task) and unilateral activation in the other, which was somewhat more consistent with the McCarthy group's findings (McCarthy et al., 1994; McCarthy et al., 1996). We note, however, that no subjects showed uniquely right hemi- 
sphere activation in one task and uniquely left hemisphere activation in the other. Similarly, Postle, Stern, Rosen, and Corkin (2000, Experiment 1) found that exactly half of their subjects showed greater dPFC activation in spatial than in object $n$-back tasks. No evidence was found across their three experiments for systematic differences between spatial and object tasks in the anatomical loci of dPFC activity.

Finally, in tasks combining location and identity retention, Jansma, Ramsey, Coppola, and Kahn (2000) in an $n$-back task, and Postle and D'Esposito (1999) in a delayed-memory task, found load/delay-specific dorsolateral PFC activity in $83 \%$ and in $100 \%$ of their subjects, respectively. In the $n$-back study, three subjects showed left-lateralized activity, three showed right-lateralized activity, and four showed bilateral activity. In the delayedmemory study, four of five subjects showed bilateral activity for spatial delays and three of five showed bilateral activity for object delays. In both studies, there was much greater variability between subjects within a domain (object vs. spatial) than between domains within a subject. Indeed, a recent behavioral study found performance on verbal, object, and location $n$-back tasks to correlate with $r$ s between .50 and .80 , indicating considerable shared variance among these tasks (Hartley, Speer, Jonides, Reuter-Lorenz, \& Smith, 2001). ${ }^{9}$ It appears that further individual-differences work will be important to our future understanding of the laterality of WM-related brain activity during $n$-back and delayed-memory tasks (for more on this controversy, see Goldman-Rakic, 2000; E. K. Miller, 2000; Postle \& D'Esposito, 2000).

For now, however, our reading of the imaging work discussed thus far is that the preponderance of the evidence supports some overlapping neural substrate for spatial and object WM capacity (see also the reviews by D'Esposito, Aguirre, et al., 1998; Owen, 1997). As evidenced by delay tasks with brain-injured patients and by imaging studies with healthy human subjects, the dorsolateral PFC is significantly involved in memory tasks that require subjects to maintain information in memory in the presence of interference, especially if attentional focus is temporarily drawn away from target information by distractors or by the processing/manipulation of other targets.

\section{Executive Attention Research}

As summarized previously, individual differences in WM capacity among healthy adults reliably predict individual differences in rather "molecular" executiveattention tasks such as Stroop, antisaccade, and dichotic listening tasks (for reviews, see Conway \& Kane, 2001; Engle, 2001; Engle, Kane, \& Tuholski, 1999). Thus, we consider the constructs of WM capacity and executive attention to be largely overlapping, if not isomorphic (see also Baddeley, 1996; Engle, 1996). One might expect, then, that the brain structures that support WM capacity should be similar or identical to those that support executive-attentioncapabilities. Faculties of WM capacity appear to rely on the $\mathrm{dPFC}$, as was described in the preced- ing sections, and so this brain region should be important to executive attention. We will now review the empirical evidence supporting such a link between executive attention and dPFC, specifically with respect to attentional focusing and switching in the presence of interference.

Much of the relevant research on the neuroscience of attention was motivated by the work of Mesulam (1981) and Posner and colleagues (e.g., Posner, 1988; Posner \& Peterson, 1990). Their theories, and others since, argued that attention is not a unitary construct, but rather that it encompasses multiple processes subserved by interdependent biological substrates. These include posterior parietal cortex, thalamus, anterior cingulate, and PFC (for reviews, see Desimone \& Duncan, 1995; Parasuraman, 1998; van Zomeren \& Brouwer, 1994). We do not attempt to argue here that all dimensions of attention are prefrontal, nor do we argue that all dimensions of attention are related to WM capacity. This is clearly not the case. Rather, we suggest only that the aspects of executive control that are the focus of this paper-namely, the ability to maintain focus on a representation or goal and to block distraction, all in the presence of interferenceis heavily reliant on dorsolateral prefrontal structures.

The importance of the dPFC to such aspects of executive attention, and the relevant experimental findings reviewed below, were anticipated by the research and case reports of Luria and his Soviet colleagues (e.g., Luria, 1966; Luria, Karpov, \& Yarbuss, 1966; Luria, Pribram, \& Homskaya, 1964). These works demonstrated that patients with PFC damage had a number of attentioncontrol deficits. They had difficulty maintaining a preparatory set during a novel task, particularly if the task demands conflicted with habitual responses (e.g., tapping a finger once when the experimenter tapped twice, and tapping a finger twice when the experimenter tapped once). They also failed to disengage attention from previously relevant stimuli and responses (e.g., in attempting to draw alternating circles and crosses, they often drew one circle followed by a sequence of crosses only).

In the sections that follow, we will discuss in detail the executive-attentiondeficits that appear to accompany dPFC damage. In addition, we will review neuroimaging data suggesting the importance of the dPFC to these attentioncontrol functions in normal, healthy subjects. Note, however, that in some of these research domains there have been relatively few empirical investigations to date, and so some caution is required.

\section{Dual-Task Interference}

A small but growing body of studies has examined the role of the dPFC in divided attention-that is, in keeping multiple task demands active simultaneously or in close alternation, and they have done so using a variety of tasks. For example, in an fMRI study, 6 healthy righthanded subjects performed two different tasks, one verbal and one spatial, either singly or simultaneously (D'Esposito et al., 1995). Performance of either task alone activated only central and posterior cortex areas compared 
with a resting-state baseline. No dPFC activation was evident, even when the spatial task was presented at a faster rate to increase its difficulty. When the two tasks were performed simultaneously, however, dPFC areas (9/46) and anterior cingulate were significantly activated (with 4 of 6 subjects showing primarily right PFC activation). Note that actual performance on the spatial task in the dual-task condition matched that in the fast-rate, singletask condition, indicating that the dPFC activation did not merely result from an increase in task difficulty.

Under PET, Corbetta, Miezin, Dobmeyer, Shulman, \& Peterson (1991) had subjects divide their attention among multiple stimulus attributes in order to detect a change in one of the attributes. Right dPFC and anterior cingulate areas were significantly activated above a resting-state baseline. Similar findings were reported by Johannsen et al. (1997) with elderly adults. Right dPFC areas (but not anterior cingulate) showed increased activity when the subjects simultaneously attended to both visual and tactile stimuli, compared with when they focused attention to either visual or tactile stimuli. Parietal areas (Brodmann 40) showed less activation under divided attention than under focused attention. Finally, Iidaka, Anderson, Kapur, Cabeza, and Craik (2000) examined PET activation during paired-associate learning and retrieval. At the same time, subjects performed either a simple response-time task (pressing a key whenever they heard a tone) or a choiceresponse time task (pressing one key for high tones and another for low tones). dPFC activity increased bilaterally when either encoding or retrieval of the list was paired with the more complex secondary task compared with the simple task. In contrast, ventrolateral PFC activity decreased under the demanding dual-task conditions.

Other imaging studies, however, have demonstrated reduced or unchanged dPFC activation under dual-task versus single-task conditions. It appears that the essential variable here is whether or not the individual tasks themselves rely heavily on dPFC. For example, Goldberg et al. (1998) presented subjects with the Wisconsin Card Sorting Task (WCST) as the primary task, and a verbal shadowing task as the secondary task. The WCST, as evidenced by imaging work, consistently activates dPFC bilaterally, along with various posterior brain areas (e.g., Weinberger, Berman, \& Zec, 1986; for a more detailed discussion of the WCST, see "Interference in shifting attention and set," below). Here, dual-task costs were evident in behavior and brain activity, with slower and less accurate WCST performance and with less bilateral dPFC activation under divided-attention conditions. Similar results were reported from a memory study in which subjects studied and recalled word lists that varied (at three levels) in the degree of active organization required (Fletcher, Shallice, \& Dolan, 1998). Under PET, "Level 3" lists that required the most organization on the part of the subjects differed from Levels 2 and 1 in increasing the activation of only dPFC areas 9/46. When these lists were encoded simultaneously with a de- manding finger-tapping task, only Level 3 lists were significantly impaired relative to an easy finger-tapping task. Moreover, only Level 3 lists showed a reduction in $\mathrm{dPFC}$ activation during demanding tapping versus easy tapping. As a final example, when performing two delayed matching-to-sample tasks simultaneously (one visual and one auditory), subjects demonstrated no increase in PFC activation compared with performing each task individually, despite obvious behavioral effects (Klingberg, 1998). As would be expected, however, the individual tasks demonstrated substantial dPFC activation compared with a control condition. ${ }^{10}$

Thus, as a group, the imaging findings reviewed here indicate that, for component tasks making substantial demands on dPFC, such as card sorting or delayed memory, dividing attention will lead to deficits in both behavior and $\mathrm{dPFC}$ activation. In contrast, in tasks that individually make minimal demands on dPFC, such as making simple decisions about stimulus attributes, dividing attention among the demands may call dPFC areas into action. We see an interesting parallel here to our own individual-differences research with healthy adults. In memory tasks that make substantial executive and PFC demands, such as verbal fluency and proactive interference tasks (see below for a detailed discussion), subjects of high intelligence and high WM span outperform those of low intelligence and low WM span (Kane \& Engle, 2000; E. Miller, 1984; Phillips, 1997, 1999; Rosen \& Engle, 1997). When these attention-demanding tasks are combined with secondary tasks, however, span and intelligence differences are reduced or eliminated, with only the high-span and high-intelligencegroups being hurt by the secondary task (Kane \& Engle, 2000; Kane, Peterman, Bleckley, \& Engle, 2002; Phillips, 1997; Rosen \& Engle, 1997). Dividing attention functionally makes low spans out of high spans during these already complex tasks, just as it reduces dPFC activity. The findings of increased dPFC activity when simple tasks are combined suggest that performance of high- and lowspan (and high- and low-intelligence) subjects should diverge, rather than converge, when a nonfrontal secondary task is added to a nonfrontal primary task. An obvious example of this idea is the WM-span task itself, in which the low-executive STM demand is combined with a lowexecutive processing demand.

Not only do imaging studies suggest the role of dPFC regions in divided attention, but limited behavioral work with patients also points to their importance. In one task that combined divided- and selective-attention requirements, unilateral lobectomy patients with damage to dorsolateral PFC, to dorsomedial PFC, and/or to anterior cingulate were markedly impaired (Richer et al., 1993). When these frontal patients had to search for only one predetermined target amid distractors (e.g., ":d"s among "d:"s, ".d"s, and "d."s), they performed close to normally. However, when they had to search for any of several targets (e.g., ":d”, “.d”, or “,d”) amid distractors 
(“d:", “d. .”, “d,”, “. .d”, “::d”), and so had to retain a significant amount of information in WM during search, they were significantly slower and more error prone than were the control subject groups.

Baddeley, Della Sala, Papagno, and Spinnler (1997) examined the dual-task performance of patients with PFC damage of mixed etiology. By a median split $(n=24)$, half of the patients were characterized as displaying marked "dysexecutive" behavior in their lives and in clinical interview, and half were not. The dysexecutive patients' behavior was characterized as having become more inert or more disinhibited after injury, as making a clinical interview very difficult to complete, and/or as leading to significant difficulties in living autonomously. Compared with the nondysexecutive patients, the dysexecutive patients had significantly more difficulties with a dual-task paradigm involving digit span and visuomotor tracking tasks. The nondysexecutive patients showed almost no dual-task cost when combining the tasks compared with when they performed them separately, and the dysexecutive patients showed a dramatic dual-task cost. The dualtask measure turned out to be a much more sensitive measure of dysexecutive behaviors than were several traditional "frontal tasks."

\section{Interference in Selective Attention, Memory Retrieval, and Switching Attention and Set}

By our view of WM capacity and executive attention, actively maintaining task goals may serve to reduce competition from external stimuli, information in longterm memory, and elicited or primed responses. Thus, WM capacity may act in the service of selection attention amid distractors, retrieving information from memory in the presence of interference, and of flexibly switching task sets in the presence of habitual responses and ambiguous stimuli. In the sections that follow, we therefore review the relevant literature linking interference in selection, retrieval, and set switching to the dPFC.

Interference in selective attention. Few experiments with monkeys have explicitly related selective-attention functions to the dPFC. However, dPFC involvement in resisting distraction was seen in a simple conditionalresponse task with irrelevant stimuli (Grueninger \& Pribram, 1969). Here, rhesus monkeys with bilateral resections of the dPFC viewed a $4 \times 4$ panel of illuminated squares. The monkeys were rewarded for pressing the upper left square if and only if it was simultaneously lit with the bottom right square. Subjects first learned the task to criterion with no distractors. These control trials were then interspersed with several distractor conditions. On distractor trials, distractor squares brightened or a loud buzzer sounded simultaneously with the lighting of the target squares. Monkeys with dPFC lesions were just as fast as control monkeys in the no-distractor condition. However, in all of the distractor conditions, including the buzzer condition, the dPFC-operated subjects were significantly slowed.
Although more studies have been done with human subjects, the results have not been consistent. For example, in field-dependence tasks, in which subjects must ignore some environmental cues and attend to others, patients with broad-spread frontal lobe damage are only sometimes impaired relative to patients with posterior cortical damage. Frontal patients appear to be impaired only when they must overcome the distracting effect of their own body orientation, but not when they must simply ignore irrelevant visual stimuli (Battersby, Krieger, Pollack, \& Bender, 1953; Teuber, Battersby, \& Bender, 1951; Teuber \& Mishkin, 1954; Teuber \& Weinstein, 1956; but see Yacosynski \& Davies, 1945). Moreover, in the Eriksen and Eriksen (1974) flanker task, in which tobe-identified target letters are flanked by distractor letters, patients with heterogeneous PFC damage showed no more interference from the distractors than did normal controls (Lee, Wild, Hollnagel, \& Grafman, 1999; Rafal et al., 1996). These findings may appear to be troubling from the perspective of our framework, but the field-dependence results are also difficult to interpret. The subjects all had very large lesions due to battle wounds or tumors, and damage was rarely confined to either the anterior or the posterior cortex. However, these results, along with the flanker task data, do tentatively suggest that, relative to posterior lesions, frontal lobe lesions in humans may only disrupt selective attention when the distractor stimuli are very highly salient, and/or provoke a prepotent response. As in the human individual-differences work, WM-related effects are most clearly seen in attentional tasks when a habitual response must be overcome for accurate responding.

In the Stroop (1935) task, the distractor stimulus provides a truly powerful competitor for the target, given that subjects must name the color in which a conflicting color word is printed. According to our view, prefrontal patients should show marked deficits in the Stroop task relative to healthy controls and posterior-lesioned patients. They sometimes do (e.g., Richer et al., 1993). However, the reliability of dPFC-specific deficits may depend upon specific task parameters. For example, Vendrell et al. (1995) compared patients with damage of mixed etiology in various prefrontal areas (e.g., dorsolateral, medial, orbital, anterior cingulate) to age-matched control patients on a discrete-trial computerized version of the Stroop task. Control and Stroop trials were randomly intermixed, and response times and accuracy were measured for each stimulus. Patients with right dorsolateral damage $(n=2)$, right anterior cingulate damage $(n=3)$, or both $(n=10)$ showed exaggerated Stroop effects in error rates (as did low-WM-span subjects in our own work; see Kane \& Engle, in press).

Concordant findings come from imaging studies with healthy adults in discrete-trial Stroop procedures. Here, prefrontal and anterior cingulate areas were more active than they were on control trials in which subjects named the colors of nonlinguistic stimuli (Banich et al., 2000; Bench et al., 1993; Pardo, Pardo, Janer, \& Raichle, 1990; 
Taylor, Kornblum, Lauber, Minoshima, \& Koeppe, 1997; Zysset, Müller, Lohman, \& von Cramon, 2001).

Involvement of dPFC areas is less consistent, however, in tests using standardized neuropsychological Stroop assessments that measure total response times over a long series of items presented on cards. On one hand, Perret (1974) found that patients with circumscribed PFC lesions demonstrated larger Stroop-RT effects than did control patients (see also Walker, Husain, Hodgson, Harrison, \& Kennard, 1998). On the other hand, several experiments and case studies have reported no dPFC-specific Stroop deficits (Ahola, Vilkki, \& Servo, 1996; Butters, Kaszniak, Glisky, Eslinger, \& Schacter, 1994; Corcoran \& Upton, 1993; Shallice \& Burgess, 1991a; Stuss, Floden, Alexander, Levine, \& Katz, 2001; Vilkki, Holst, Ohman, Servo, $\&$ Heiskanen, 1992). We note that healthy subjects' performance on standard neuropsychologicaladministrations of the Stroop test may be uncorrelated with their performance on discrete-trial procedures (Kindt, Bierman, \& Brosschot, 1996). We also note that these standardized, blocked Stroop procedures may show inconsistent effects because they minimize the WM demands of the task.

In discrete-trial versions, Stroop and control trials appear unpredictably, and they are often interleaved with congruent trials in which the colors and words actually match (e.g., RED displayed in red). Thus, in discrete-trial versions that include some nonconflicting, congruent stimuli, subjects should have more difficulty keeping the unusual task requirements active and accessible in WM (e.g., Cohen, Dunbar, \& McClelland, 1990; De Jong, Berendsen, \& Cools, 1999). Although the explicit task instructions and goals are the same when congruent trials are intermixed with incongruent trials, the implicit procedures that subjects follow may be quite different. When congruent trials are included in the mix, word information is unpredictably congruent or incongruent with responses. Thus, actively maintaining the ignore-the-word demands in WM should be more necessary (if not more difficult), and so lapses in goal maintenance should be more frequent.

Recall that Kane and Engle (in press) found that the relation between Stroop interference and WM capacity in healthy adults is complicated by the presence or absence of congruent trials in the design. In particular, with high proportions of congruent trials, individuals of lower WM capacity committed many more errors, by reading the word instead of naming the color, than did individuals of high-WM capacity. Thus, individuals of low WM were more likely than those of high WM to neglect the goal of the task, ignore the word, when actively maintaining the goal was made difficult by the experimental context. Such findings suggest that active goal maintenance in the presence of interference from LTM or habit, which is the essence of WM capacity, drives individual differences in the ability to block or inhibit distraction, and so may be critical to finding dPFC-related deficits in Stroop task performance.

Indeed, a recent ERP study with healthy adults found that errors in the Stroop task predictably followed a slow wave originating in $\mathrm{dPFC}$ and/or polar PFC. That is, these slow waves, which began 400-800 msec before the stimulus was presented, were more likely to precede trials on which subjects erred than to precede those on which subjects were accurate (West \& Alain, 2000b). In our view, the timing and location of this wave pattern suggests that it reflected a transient loss of goal-state information that had previously been maintained in $\mathrm{dPFC}$, and with the loss of this goal-state information came the likelihood of error. As further evidence of the validity of this idea, West and Alain (2000b) found that the slow wave was specifically tied to errors in a Stroop task with many congruent trials. It was not particularly associated with error trials in a Stroop task with few congruent trials. Thus, just as in our individual-differences study, increasing the difficulty of maintaining goal information was critical to making the Stroop measure sensitive to dPFC- and WM-related contributions to interference susceptibility and control.

These conclusions are further bolstered by fMRI data obtained during a mixed-block Stroop task in which the instructions to read the word or name the color were presented $11 \mathrm{sec}$ before each stimulus appeared (MacDonald, Cohen, Stenger, \& Carter, 2000). Half of the trials were word-reading trials and half were color-naming trials; within each trial type, half of the stimuli were incongruent and half were congruent. Over the 11-sec delay, dPFC activity steadily increased on color-naming trials only. No increase was seen on the more automatic wordreading trials. Moreover, the correlation between delayperiod dPFC activity and Stroop interference in color naming was substantial and negative $(r=-.63)$. These data indicate that dPFC acts to reduce Stroop interference by maintaining the name-the-color and/or ignorethe-word task demands in an active state. ${ }^{11}$

ERP studies with more simple stimuli also confirm that damage to the dPFC can impair selective-attention capabilities (for reviews, see Knight, 1991; Knight \& Grabowecky, 1995; Knight, Staines, Swick, \& Chao, 1999). For example, certain components of auditory- and somatosensory-evoked waveforms are greater in magnitude for frontal-lesioned patients than for healthy controls or posterior-lesioned patients (Knight, Scabini, \& Woods, 1989; Yamaguchi \& Knight, 1990). Such findings suggest that intact PFC areas normally inhibit, or "gate," the amplitude of these potentials from other cortical and subcortical areas (Skinner \& Yingling, 1977; Yingling \& Skinner, 1977). Furthermore, in dichoticlistening tasks that present subjects with target and distractor stimuli to different ears, patients with right-PFC damage show decreased target detection rates from left channels. This behavioral deficit is concomitant with an absence of the Nd component of the ERP waveform (Knight, Hillyard, Woods, \& Neville, 1981), a component that normally corresponds to auditory target detection under focused-attention conditions (see Knight, 1991). Moreover, the presence of a distractor stimulus in the "unattended" channel on trial $n$ reduces the subsequent Nd to a target channel stimulus on trial $n+1$. This occurs with both right- and left-hemisphere dPFC dam- 
age (Knight et al., 1981; D. L. Woods \& Knight, 1986). Therefore, patients with dPFC damage appear unable to maintain activation of target stimuli and/or to block distractor stimuli from gaining access to WM, and so they have greater difficulty detecting targets.

A particularly powerful demonstration of the gating function of the dPFC in a memory context was provided by an ERP study by Chao and Knight (1998). Their study also made clear the link between the attentional and immediate memory functions required by the delayedmemory tasks that we discussed earlier (e.g., Bartus \& LaVere, 1977; Malmo, 1942). Ten patients with unilateral $\mathrm{dPFC}$ lesions and 10 healthy age-matched controls were tested in an auditory delayed matching-to-sample test with a 5,000-msec delay. The sample and test stimuli consisted of real-world sounds such as coughing, dogs barking, piano notes, and dishwasher noise. In addition, half of the trials included several auditory distractor "tone pips" $(4000 \mathrm{~Hz})$ between the offset of the sample sound and the onset of the test sound. The PFC patients and the controls showed similar error rates on no-distractor trials, but the PFC patients showed significantly more errors than did the controls on distractor trials. Moreover, in comparison with the controls, the dPFC patients showed increased cortical responding to the distractor tones and decreased cortical responding to the target stimuli. Damage to dPFC disrupted the blocking of irrelevant distractors, thus impairing the ability to maintain memory for target stimuli across a delay. Or, the failure to actively maintain target representations allowed for disruptions by distractor stimuli. Just as is evidenced in delay tasks with nonhuman primates, then, the dPFC appears to be critical to selectively maintaining target information across filled intervals. This is especially true when attentional focus may be drawn away from the target by distraction, and interference from prior events impairs retrieval of the target information from LTM.

Interference in memory retrieval. With respect to interference effects on memory, proactive interference tasks require subjects to recall recently presented items while disregarding previously studied items. As more and more lists are presented, there is greater competition from prior lists, and this is reflected in the tendency for greater intrusions and fewer correctly recalled items on the subsequent lists. We have found that low-WM-span subjects are more vulnerable to proactive interference than are high-span subjects, and, furthermore, that dividing the attention of high spans increases their interference effects to the level of those of low spans (Kane \& Engle, 2000).

Luria (1971) stressed the utility of such interference tests in assessing brain-injured patients, and in fact, subsequent research with dPFC-lesioned subjects supports a connection between the dPFC and interference resistance in memory. Case reports first indicated that stroke, aneurysm repair, or traumatic damage to various PFC areas produced marked susceptibility to proactive interference. When these patients attempted to recall a short word list following as few as one or two associatively related lists, recall dropped by $50 \%$ to $90 \%$ from List 1 levels. Healthy control subjects showed recall decreases of only $15 \%$ to $30 \%$ with the same lists (Coslett, Bowers, Verfaellie, \& Heilman, 1991; Parkin, Leng, \& Stanhope, 1988; Zatorre \& McEntee, 1983; but see Simkins-Bullock, Brown, Greiffenstein, Malik, \& McGillicuddy, 1994). Volpe and Hirst (1983) also found that prefrontal patients showed more intrusions of prior-list words into their recall of subsequent lists (14\% of responses) than did healthy controls ( $1 \%$ of responses).

In experimental work with larger groups of brainlesioned subjects, frontal patients have proven highly susceptible to proactive interference, regardless of lesion laterality (Freedman \& Cermak, 1986; Jetter, Poser, Freeman, \& Markowitsch, 1986; Shimamura, Jurica, Mangels, Gershberg, \& Knight, 1995; Van der Linden, Bruyer, Roland, \& Schils, 1993; but see Janowsky, Shimamura, Kritchevsky, \& Squire, 1989). Even when these frontal patients were matched on List 1 recall to patients with nonfrontal lesions (or to healthy controls), the frontal patients had more difficulty recalling the later word lists. Interference-buildup tasks typically produce highly variable data and require large samples to detect group interactions (see, e.g., Wickens, 1970). Thus, these findings of significant frontal deficits with modest-sized patient groups are particularly noteworthy.

The few imaging studies with healthy subjects further support the idea that the dPFC is integral to combatting proactive interference. As has been indicated by ERP, PET, and brain-SPECT data, dorsolateral and anterior PFC areas are activated when subjects attempt to recall stimuli under high-interference conditions. However, these areas are not active under low-interference conditions (Dolan \& Fletcher, 1997; Uhl et al., 1990; Uhl, Podreka, \& Deecke, 1994). Furthermore, this interference-related prefrontal activity is actually stronger when subjects are unsuccessful in recalling than when they are successful (Uhl et al., 1990). Prefrontal activity may therefore represent the effort and executive attention involved in attempting to select among (and/or inhibit) highly activated response candidates (for contributions of ventrolateral PFC to interference resistance, see D'Esposito, Postle, Jonides, \& Smith, 1999; Jonides, Marshuetz, Smith, Reuter-Lorenz, \& Koeppe, 2000; Jonides, Smith, Marshuetz, \& Koeppe, 1998).

Retrieval-interference effects may also be inferred from verbal fluency tasks, in which subjects generate as many exemplars as they can from a given category, such as animals or letters beginning with $S$, within some time limit. Recall that low-WM-span and low-intelligence individuals show impaired fluency relative to high-WMspan and high-intelligence individuals (see, e.g., Phillips, 1997; Rosen \& Engle, 1997). We suggest that, particularly across long recall periods, fluency may be enhanced by selectively directing attention away from, or inhibiting, the high-probability words that were recalled earlier in the session. After a subject has exhausted the first words that easily come to mind, executive attention 
should be necessary to maintain active search and avoid repeating the recall of previously recalled, and therefore highly activated, exemplars (see Moscovitch, 1994; Perret, 1974; Rosen \& Engle, 1997). Indeed, the length of the recall period may be critical to understanding how PFC structures affect fluency.

One- and 2-min fluency tests that allow for responding primarily on automatically activated, high-probability exemplars show only small differences, if any, among patients with left frontal, right frontal, nonfrontal, or diffuse lesions (Ahola et al., 1996; Benton, 1968; Corcoran \& Upton, 1993; Joanette \& Goulet, 1986; Miceli, Caltagirone, Gainotti, Masullo, \& Silveri, 1981; Newcombe, 1969; Parkin, Bindschaedler, Harsent, \& Metzler, 1996; Shallice \& Burgess, 1991a; Upton \& Corcoran, 1995; Vilkki et al., 1992; Walker et al., 1998; but see E. Miller, 1984; Ramier \& Hecaen, 1970). Often, though, patients with frontal damage do perform more poorly than healthy control subjects on these brief recall tasks (Baldo \& Shimamura, 1998; Butters et al., 1994; Janowsky, Shimamura, Kritchevsky, \& Squire, 1989; Laiacona et al., 1989; Owen, Downes, Sahakian, Polkey, \& Robbins, 1990; Paus et al., 1991; Troyer, Moscovitch, Winocur, Alexander, \& Stuss, 1998; Tucha, Smely, \& Lange, 1999).

Fewer studies have been done with longer recall periods. However, frontal patients, particularly those with left-hemisphere damage, consistently perform significantly worse than do nonfrontal patients across 4- or 5-min recall periods (Guitton, Buchtel, \& Douglas, 1985; Jones-Gotman \& Milner, 1977; Milner, 1964; Pendleton, Heaton, Lehman, \& Hulihan, 1982; Perret, 1974; but see Bolter, Long, \& Wagner, 1983). These longduration fluency tasks should make considerable demands on selective attention and effortful memory search, as less dominant exemplars must be retrieved amid increasing interference from the already recalled, dominant exemplars.

Fluency results should be interpreted with some caution, for, as Reitan and Wolfson (1994) indicate, few studies screen subjects for dysphasic symptoms, and so dysphasic disturbances may contribute to the left-hemisphere deficits seen in the literature. However, ${ }^{133} \mathrm{Xe}$-inhalation, PET, and $\mathrm{FMRI}$ imaging data from healthy right-handed subjects corroborate the neuropsychological findings. When recall periods exceed 2 min, or when multiple recall periods are required with the same cues, both of which should increase potential for interference, both left and right dPFC areas are activated over baseline (Cuenod et al., 1995; Frith, Friston, Liddle, \& Frackowiak, 1991; Parks et al., 1988; but see Warkentin, Nilsson, Risberg, \& Karlson, 1989, for left PFC activation only). ${ }^{12}$ Thus, on balance, the data from neuropsychological and neuroimaging studies suggest that the dPFC is instrumental in fluency tasks that, we argue, require executive attention and memory-search processes, primarily due to the presence of output interference. ${ }^{13}$

Interference in shifting attention and set. Setshifting tasks represent a further class of interference task wherein prepotent response tendencies must be overcome in order for the subject to act according to goals or intentions. Here, executive attention may be required to allow rapid access to task-relevant memory representations (or action productions, or goals) while shifts of attentional focus are made. That is, keeping task-relevant information active in memory while focus is switched away and back should put a premium on executive attention, Gf, and dPFC. In addition, goal states that drive subject-initiated shifts of attention may often conflict with environmental cues or prior habit. For example, a stressed parent behind the wheel of a car may intend to shift focus away from a screaming child in the back seat and toward the oncoming traffic on the road. In such cases, optimal performance will depend on the parent's actively maintaining the goal state in WM and preventing its decay to baseline in the presence of powerful distraction. Thus, these shifts of focus should put a premium on executive attention, fluid ability, and PFC.

One might expect relevant evidence here from the testing of brain-injured patients on the WCST (Berg, 1948; Grant \& Berg, 1948; Heaton, 1981). The WCST is a complex problem-solving and set-switching task adapted from concept-formation tasks used with nonhuman primates (e.g., Zable \& Harlow, 1946) and human psychiatric patients (e.g., Weigl, 1941). Subjects in these early tasks learned to discriminate reinforced from nonreinforced stimuli on the basis of some rule (e.g., the left $o b$ ject is always rewarded regardless of identity). They then had to reverse the discrimination after reaching some learning criterion (e.g., the right object is now rewarded). Macaques and other primates with full bilateral frontal ablations demonstrated marked difficulty in reversing previously learned discriminations in comparison with posterior-lesioned and control monkeys (H. F. Harlow \& Dagnon, 1943; H. F. Harlow \& Settlage, 1948). These frontal deficits were especially pronounced as succeeding discriminations and reversals were tested (Settlage, Zable, \& Harlow, 1948).

Clinical lore and early research (e.g., Milner, 1963) supported the use of the WCST as a diagnostic tool for assessing PFC damage. However, more recent data now provide mixed support for an association between WCST performance and dPFC structures (for reviews, see Mountain \& Snow, 1993; Reitan \& Wolfson, 1994). For example, relative to patients with posterior damage, patients with PFC damage are sometimes unimpaired on the WCST (see, e.g., Anderson, Damasio, Jones, \& Tranel, 1991; Corcoran \& Upton, 1993; Grafman, Jonas, \& Salazar, 1990) and are sometimes impaired (see, e.g., Drewe, 1974; Milner, 1963; Nelson, 1976). This lack of specificity may not be surprising, given the obvious complexity of the WCST. There are many ways to pass (or fail) this test, and so one might expect multiple processes and brain areas to be involved. Indeed, Dunbar and Sussman (1995) presented a patient with damage to left temporoparietal cortex and impairment in articulatory rehearsal who obtained zero categories and committed 94 perseverative errors on the WCST. Likewise, when Dunbar and Sussman used a sec- 
ondary task to prevent healthy adults from using articulatory rehearsal during the WCST, category attainment dropped and perseverative errors increased substantially relative to baseline WCST conditions.

Nonexecutive processes notwithstanding, a more prominent and specific role for the PFC in such a setswitching task might be anticipated given the present theoretical framework. That is, WM capacity and PFC circuits should be important to preventing perseveration, or interference from a prior task set. Indeed, in a latentvariable, structural-equation modeling study with healthy undergraduates, Miyake, Friedman, Emerson, Witzki, and Howerter (2000) found that WCST performance was predicted by a latent variable derived from three simple set-switching tasks (path coefficient $=.38$; for more on such tasks, see below). Such findings suggest that in normal subjects, individual differences in WCST performance are determined, at least in part, by ability to switch task set. As further behavioral evidence of a connection between the WCST and the PFC functions of concern in this review, Lehto (1996) found that among healthy adolescents, a composite measure of WM-span tasks correlated significantly with various WCST measures, such as categories achieved $(r=.34)$, trials to completion $(r=$ $-.45)$, and perseverative errors $(r=-.35)$.

Moreover, in a recent neuropsychological study that improved upon the subject-selection criteria of many prior studies, patients with focal lesions to $\mathrm{dPFC}$ and to superior medial frontal cortex demonstrated substantial WCST deficits in comparison with patients with nonfrontal lesions and healthy controls (Stuss et al., 2000). In a subsequent version of the test, subjects were first told all the possible categories in the test, and in the final version of the test subjects were explicitly told when to switch categories. The dPFC and medial-frontal patients were significantly impaired in both of these WCST modifications. For example, even in the final version, the $\mathrm{dPFC}$ and medial groups averaged between 9 and 17 perseverative errors in 64 trials, whereas the nonfrontal groups averaged only between 1 and 3 such errors.

Neuroimaging studies, particularly those by Weinberger, Berman, and colleagues, have also indicated a prominent role for dPFC in the WCST (Berman et al., 1995; Berman, Zec, \& Weinberger, 1986; Esposito, Kirkby, Van Horn, Ellmore, \& Berman, 1999; Goldberg et al., 1998; Weinberger et al., 1986). Subjects were scanned while performing the WCST and while performing a computerized control task, in which test cards were to be sorted according to a consistent and concrete rule. That is, in the control task, the to-be-sorted test cards each displayed a number from 1 to 4 , and the four reference cards each displayed a number from 1 to 4 . Consistently across studies, the WCST evoked significant increases in bilateral blood flow to dorsolateral regions of the prefrontal cortex in comparison with the control task. In addition, broad networks of medial frontal and posterior brain areas were also activated, but somewhat less consistently across studies (see also Nagahama et al., 1996; Nagahama et al., 1999; Nagahama et al., 1998). ${ }^{14}$

Set-shifting tasks that are similar to, but less complex than, the WCST also produce deficits that are specific to dPFC damage, at least for certain kinds of shifts (see, e.g., Cicerone, Lazar, \& Shapiro, 1983; Delis, Squire, Bihrle, $\&$ Massman, 1992). That is, patients with damage to PFC are as able as healthy controls and patients with posterior lesions to develop an attentional set in responding, and subsequently to apply that set to new stimuli. For example, PFC patients can learn to respond according to shape with squares and triangles, and then shift to respond according to shape with circles and rectangles. Thus, "intradimensional" set shifting does not appear to rely on PFC. However, patients with PFC lesions are significantly impaired when they are required to shift set to an entirely new dimension, such as color (Owen et al., 1993; Owen, Roberts, Polkey, Sahakian, \& Robbins, 1991). These "extradimensional" set shifts are particularly difficult for frontal patients when the previously reinforced dimension becomes nonreinforced and the reinforced dimension is entirely new (e.g., respond to shape and ignore a superimposed line, and then switch to responding to color and ignoring shape; Owen et al., 1993). Moreover, extradimensional set shifting appears to rely on $\mathrm{dPFC}$ structures in particular. Studies of brain-lesioned marmosets (Dias, Robbins, \& Roberts, 1996a, 1996b, 1997) and imaging studies with humans (Rogers, Andrews, Grasby, Brooks, \& Robbins, 2000) have indicated that areas 9/46 (and their nonhuman analogues) are active during, and critical to, successful extradimensional shifting. ${ }^{15}$ Other kinds of shifts appear to rely more on orbitofrontal and medial frontal areas.

Thus, on balance, recent research with the WCST and its analogues indicates a strong link between shifting attentional sets and the dPFC. Although the database is considerably smaller, evidence for dPFC involvement in overcoming a previously established task set has also come from less conceptually driven tasks. These tasks tend to require switching attention among spatial locations, but most importantly, they require switching focus in opposition to interference from habit or from a powerful cue.

For example, in the antisaccade task, subjects see an abrupt-onset signal in one spatial location, and must direct attention and eyes away from this cue to the opposite side of the screen (for a review, see Everling \& Fischer, 1998). We found that successful performance on this task is linked with WM capacity, given that the goal to respond in opposition to habit must be actively maintained in the presence of a powerful elicitor of the habit (Kane et al., 2001). Antisaccade performance is likewise disrupted when WM is occupied by an attention-demanding secondary task (R. J. Roberts, Hager, \& Heron, 1994). As one might expect, then, patients with dPFC damage are also impaired in the antisaccade task relative to normal controls, patients with Parkinson's disease, and patients with 
damage to posterior frontal and nonfrontal cortex (Fukushima, Fukushima, Miyasaka, \& Yamashita, 1994; Guitton et al., 1985; Pierrot-Deseilligny, Rivaud, Gaymard, \& Agid, 1991). However, dPFC damage does not affect performance in a prosaccade condition in which the location of the cue always corresponds to the location of the upcoming target (similar to the case of our WMcapacity findings). PET imaging has also indicated that antisaccade trials increase dPFC activation relative to prosaccade trials, along with increases in some parietal, temporal, and midbrain areas (Sweeney et al., 1996). Relative to a fixation condition, prosaccade trials provoke no increase in dPFC activity. Thus, dPFC damage impairs performance, and dPFC areas are active, only when the cue always appears in a location that attracted focus away from the upcoming target. Such contexts demand that responding be in accordance with activated task goals, not environmental prompting.

In a particularly dramatic illustration of failed goal maintenance in the antisaccade task, Walker et al. (1998) presented the case study of a 62-year-old patient with stroke damage to right lateral PFC (primarily ventrolateral, but encroaching on dorsolateral areas). The patient was tested on four different occasions, between 12 and 60 weeks postinsult, on several variations of the prosaccade and antisaccade tasks. The patient made saccade errors on $100 \%$ of the antisaccade trials in every session, regardless of target hemifield, even though he understood the task and could articulate the direction of the appropriate response for each trial.

Parallel findings come from the visual analogue of the dichotic-listening task (hereafter, the Duncan task), in which subjects monitor one of two visual stimulus streams, on either the left or the right, for targets. On some trials subjects unpredictably see an abstract cue (a "+" or "-") that signals them to immediately switch their attention to the other stimulus stream (see, e.g., Duncan et al., 1996). Thus, a habitual response must be prevented, and a new task set must replace it. Moreover, because the cue is abstract, subjects must accurately maintain its meaning, or the production to rapidly retrieve its meaning from LTM, in order to respond accurately. Using this task, Duncan et al. (1996) found that, like healthy subjects of low fluid intelligence, patients with frontal lobe damage were more impaired in switching attention away from one stimulus location to another than were posterior-lesioned patients and healthy controls. These frontal patients actually showed no difficulty in initially attending to targets on either the left or the right side of fixation. However, they failed as a group to shift attention to the other side when they were cued by the abstract signal to do so. Ten of 19 normal controls switched attention successfully on every trial block, and only 3 failed to switch on any block. Similarly, 3 of 8 posterior-damaged patients switched attention successfully on every block, and only 1 failed to switch on any block. In contrast, only 1 of 10 frontal patients switched attention successfully on every block, and a full seven patients failed to switch on any block. Statistically, the posterior patients performed identically to the normal controls, whereas the frontal patients were significantly impaired relative to both other groups. Some caution is advised in interpreting these data, however, because only 3 of the 10 frontal patients had exclusively frontal damage, with the remaining 7 having widespread extrafrontal damage. ${ }^{16}$

Finally, set-shifting deficits in frontal patients were also seen in an analogue of the Stroop task. Dunbar and Sussman (1995) studied patients with frontal damage due to closed-head injury (but they had probably sustained extrafrontal damage as well). One of their experiments presented congruent, neutral, and incongruent trials in pure blocks of a picture-word Stroop task. Here, the patients demonstrated interference comparable to that found in published norms. However, another experiment presented a mixed block of picture-naming or word-reading trials that were individually precued by a tone. Thus, on the basis of the tone, which was, as in the Duncan task, an abstract task cue, the patients had to switch continually and unpredictably between task sets. Here, the patients showed dramatic error rates on incongruent trials (between $40 \%$ and $50 \%$ errors) in both picture naming and word reading.

Cognitive psychologists, outside the neuroscience domain, demonstrate increasing interest in set shifting, or "task switching," as a means of exploring the executive control of behavior (e.g., Allport, Styles, \& Hsieh, 1994; Gopher, Armony, \& Greenshpan, 2000; Los, 1999; Mayr \& Keele, 2000; Meiran, 1996). Following Jersild (1927), their experiments identified switching "costs" by comparing conditions in which simple task demands repeat with those in which they change across trials. For example, subjects may see a letter and a number paired on each trial, and on some trials they must categorize the letter and on others the number (see, e.g., Rogers \& Monsell, 1995). When two consecutive trials require different kinds of responses (e.g., letter/number), response times and error rates are higher than when two such trials require the same kind of response (e.g., number/number). This very task was presented to 12 patients with focal PFC damage and 14 control subjects matched for age and verbal intelligence (Rogers et al., 1998). PFC-related deficits were limited to those subjects with left hemisphere damage and to conditions in which task set was cued by an abstract signal. That is, in conditions presenting a concrete word cue for each trial, such as the word LETTER, above the stimuli (e.g., LETTER: $4 G \rightarrow$ NUMBER: $6 A$ ), frontal patients showed switch costs as small as those of controls. However, in conditions presenting an abstract cue for each trial, such as a red background for letter trials and a green background for number trials, left PFC patients showed costs that were three to four times larger than those for right PFC patients and controls. This abstract cuing effect is most interesting because tasks switched predictably after every two trials, making the explicit cues redundant.

Unfortunately, the limited fMRI work that has been done with such switching tasks has produced equivocal 
results. On one hand, in a task in which response mappings switched or repeated from trial to trial, responseswitching trials produced greater activation in bilateral PFC (areas 9, 6, 44, 45) than did response-repeat trials (Dove, Pollmann, Schubert, Wiggins, \& von Cramon, 2000). On the other hand, in a letter/number task similar to that used by Rogers et al. (1998) with PFC patients, no prefrontal areas were more active during task-switching trials than during task-repeat trials, despite large switch costs in the behavioral data (Kimberg, Aguirre, \& D'Esposito, 2000). Here, tasks switches were regular and predictable, just as in Rogers et al. (1998), and the provided task cues were seemingly as abstract as those used by Rogers et al. (1998; they were cued by the screen location of the stimuli). It is unclear to us how the lack of PFC activation here is to be accounted for.

In conclusion, the interference data from attentionswitching tasks are something of a mixed bag with respect to dPFC involvement. On the negative side, the "gold-standard" neuropsychological test reflecting failures to switch, or perseveration - the WCST - has been argued to be no more selective for PFC damage than for non-PFC damage. Moreover, of the two imaging studies examining task-switching paradigms from cognitive psychology, one found no switch-related PFC activity. However, on the positive side, recent brain-lesion and neuroimaging data from the WCST and WCST-like tasks offer fairly compelling evidence that dorsolateral PFC is active during, if not critical to, successful switches of set. Moreover, as evidenced by antisaccade and Duncan tasks, dPFC areas support attentional switches in space that are made in opposition to interference from habit and in concordance with an abstract cue. Finally, there is at least some preliminary evidence from task-switching paradigms that PFC damage impairs switching set in response to abstract cues.

\section{General Intelligence Research}

As we have already mentioned, clinical and experimental reports indicate that PFC injury may have little effect on intelligence as defined by broad psychometric test batteries (e.g., Ackerly, 1937; Eslinger \& Damasio, 1985; Hebb, 1939, 1945; Hebb \& Penfield, 1940; Shallice \& Burgess, 1991a; Warrington, James, \& Maciejewski, 1986). According to Duncan (1995), however, this paradox may be resolved by considering more carefully what IQ batteries such as the WAIS-R actually measure. Gf may contribute some variance to each of the various subtests in the battery, but it certainly plays a greater role in some than in others. Whereas nonverbal, figural reasoning tests such as Raven's Progressive Matrices or the Cattell Culture Fair have very high Gf loadings, WAIS-R subtests on vocabulary and information do not. The latter tests may more accurately reflect general crystallized intelligence $(\mathrm{Gc})$ or $\mathrm{Gf}$ at the time of learning but not necessarily at the time of testing. Averaging across high-Gf and low-Gf subtests in IQ batteries may thus dilute the real effect that PFC lesions have on Gf.
Duncan, Burgess, and Emslie (1995) tested three patients with frontal lobe lesions of mixed etiology. One had bilateral damage from an open head wound, one had unilateral damage due to tumor resection, and one had unilateral damage due to a white-matter infarction. These three frontal patients were matched to healthy controls for age (range, 29-56 years) and for their overall WAIS or WAIS-R scores, with scores ranging from 126 to 130 . All subjects then took the Cattell Culture Fair test as a measure of Gf. The "intelligence" of all the frontal patients was dramatically lower-22-38 points-as indicated by their Cattell scores compared with their own WAIS scores. In contrast, the controls all showed equivalent or higher scores on the Cattell test than on the WAIS. Moreover, the frontal patients' Culture Fair IQs were three standard deviations below those of their WAIS-matched controls. A group of patients with parietal damage, and lower mean WAIS scores than the frontal patients or controls, demonstrated no discrepancy between their WAIS and Cattell scores. Although based on few subjects, the Duncan et al. (1995) findings suggest the useful research strategy of matching subject groups on their conventional IQ scores (or, even better, on Gc measures) and then testing for PFC-related deficits that are specific to Gf-loaded tasks.

Waltz et al. (1999) took a different but equally interesting approach. They tested six patients with focal frontal damage and six patients with focal temporal damage on different categories of problems adapted from Raven's test. All categories presented matrices with one piece missing. In the "Level 0" category, the missing piece was identical to all the presented pieces. In the "Level 1" category, the missing piece represented a single feature change along the horizontal or the vertical. For example, the top row showed two white squares, the bottom row showed one black square, and so the missing piece should have been another black square. In the "Level 2" category, the missing piece represented the integration of joint feature changes across the horizontal and the vertical. For example, the top row showed a white square and a white triangle, the bottom row showed one black square, and so the missing piece should have been a black triangle. PFC patients, temporal patients, and healthy controls scored equally on Levels 0 and 1 problems (all between $80 \%$ and $100 \%$ correct). However, on Level 2 problems, PFC patients scored below chance, at approximately $10 \%$ correct, whereas temporal patients and controls performed equivalently, at approximately $90 \%$ correct. Thus, when relations among stimuli demanded integration - perhaps accomplished through WM maintenance-PFC patients were markedly impaired in a Gf-loaded task of induction. Indeed, a computational model of performance on such matrix-reasoning tasks indicates that integration of multiple stimulus dimensions relies on WM capacity (Carpenter, Just, \& Shell, 1990).

The Duncan et al. (1995) and Waltz et al. (1999) findings are consistent with the few imaging studies that have been conducted to examine the neural substrates of nonverbal, fluid reasoning in healthy adults. Early stud- 
ies measured regional cerebral blood flow (rCBF) during the performance of Raven's matrices test (Risberg \& Ingvar, 1973; Risberg, Maximilian, \& Prohovnik, 1977). Although these rCBF techniques had rather poor spatial resolution, they indicated that performance of Raven's test caused blood flow increases in frontal, parietal, and occipital cortex as compared with a resting condition. More recently, an fMRI study examined cortical activation patterns during the performance of different subtypes of Raven's problems (Prabhakaran, Smith, Desmond, Glover, $\&$ Gabrieli, 1997). Some problems required only visuospatial analysis, and others additionally required nonspatial, abstract/analytical reasoning (see Carpenter et al., 1990). Relative to a no-delay, matching-to-sample baseline, spatial reasoning activated right dorsolateral areas (Brodmann 9, 46) along with other right hemisphere regions such as anterior cingulate (32), parietal areas $(7,40)$, and temporal areas (37). Analytical reasoning versus baseline, however, elicited broader prefrontal activation bilaterally in dorsolateral areas $(9 / 10,45,46)$, as well as bilaterally in other PFC areas $(6,44)$, parietal areas $(7$, $39,40)$, temporal areas $(37,21,19)$, and occipital areas $(18,19,37)$. These findings indicate dPFC involvement in all kinds of Raven's items (along with PFC-networked regions posteriorly), but with greater bilateral dorsolateral involvement when abstract, fluid reasoning is necessary for item solution.

Similar findings under PET were reported by Esposito et al. (1999) and Duncan et al. (2000). Esposito et al. found bilateral dPFC activity (areas 9/46) during Raven's problems compared with a no-delay, matching-to-sample baseline, along with activity in anterior cingulate and some parietal, temporal, and occipital areas. Duncan et al. (2000) tested subjects on figural and verbal tests with high Gf loadings versus low Gf loadings (based on behavioral pilot testing). The figural tests were based on the Cattell test, and verbal tests were based on the Letter Sets Test (Ekstrom, French, Harman, \& Dermen, 1976). In comparison with the low-Gf tasks, the high-Gf tasks activated dPFC area 46, the figural task eliciting bilateral activation and the verbal task activating only left dPFC. (The figural task also demonstrated activation in anterior cingulate and in parietal and occipital areas.) The bilateral dPFC activation found during figural reasoning is consistent with the studies reviewed above. The more lateralized activation evidenced by the verbal task is intriguing and merits further investigation.

The evidence discussed in this section is clearly limited by the small number of studies conducted, and by the small samples in each. However, we are optimistic that further patient and imaging work with matrix-reasoning tests, such as the Cattell test and Raven's test, will confirm a prominent role for the $\mathrm{dPFC}$ in novel reasoning that loads highly onto a psychometric Gf factor. Indeed, the limited neuropsychological and neuroimaging research on other forms of $g$-loaded analytical reasoning, such as deductive reasoning, provides converging evidence for an important role for WM and dPFC. For example, patients with focal PFC damage performed worse than those with focal anterior temporal damage on deductive reasoning tasks that required integrating information across statements (Waltz et al., 1999). When propositions were chained, such as Dave is taller than Gary; Gary is taller than Bart; Is Dave taller than Bart?, patient groups and controls performed equivalently (all group $M \mathrm{~s}>86 \%$ correct). However, when propositions were scrambled and so required integration, such as Mona is taller than Kim; Stef is taller than Mona; Is Stef taller than Kim?, PFC patients performed at chance $(M=20 \%$ correct $)$, whereas temporal patients and controls performed equivalently $(M \mathrm{~s}=$ $87 \%$ and $86 \%$, respectively). Thus, PFC damage severely limited patients' ability to make transitive inferences when two relations had to be simultaneously maintained and integrated for solution.

Imaging studies using PET and fMRI also suggest dPFC involvement in deductive, syllogistic reasoning (e.g., All men are mortal; Socrates is a man; therefore, Socrates is mortal.), also a highly Gf-loaded task (Carroll, 1993; Snow, Kyllonen, \& Marshalek, 1984). Left dPFC areas, along with left temporal and anterior cingulate areas, are rather consistently active over baseline during syllogistic reasoning (Goel, Gold, Kapur, \& Houle, 1997), even when the syllogisms involve spatial relations (e.g., Officers are standing next to generals; privates are standing behind generals; Goel, Gold, Kapur, \& Houle, 1998). Moreover, right dPFC regions appear to be uniquely called upon when the contents of the syllogisms conflict with known facts (e.g., All pets are poodles; all poodles are vicious), and between the presentations of propositions to be integrated when they are free of real-world content (e.g., All B are $K$; all $K$ are $X$; Goel, Buchel, Frith, $\&$ Dolan, 2000). Whereas left PFC appears important for general reasoning (and integrative?) processes here, right PFC appears specialized for blocking the effect of prior knowledge and maintaining abstract information.

As with the study of prototypical Gf tests involving inductive reasoning such as Raven's and Cattell tests, then, a small body of work on deductive reasoning indicates that $\mathrm{dPFC}$ regions are involved in, and may be critical to, formal deduction. This is particularly true when propositions or arguments must be integrated in order to solve the problem, suggesting that the dPFC contribution here may be in active memory maintenance (for related imaging findings from a mathematical reasoning test, see Prabhakaran, Rypma, \& Gabrieli, 2001).

\section{Working Memory Functions and the Prefrontal Cortex: Conclusions and Criticisms}

In our review of research on the dPFC and its WMcapacity/executive-attentionfunctions, we have examined empirical work with varied methodologies and subject populations, and we are encouraged by the tremendous breadth and consistency of the evidence reviewed here. Clearly, more work is needed to understand some of the behaviors we have emphasized-for example, the role of the dPFC in set switching, and the role of specific dPFC 
areas in maintaining object versus spatial information and in different components of reasoning. However, some consistent patterns are certainly observable across diverse subject populations and tasks. The data are particularly clear regarding WM capacity. Damage to dPFC areas selectively reduces performance to chance levels on memory tasks in which interference is high and some source of distraction challenges the effective maintenance of the target information. Furthermore, dPFC areas, in conjunction with the posterior areas to which they are networked, are highly active during the performance of these WM-capacity tasks. Perhaps most importantly from our perspective, these dPFC cells, unlike the memory-relevant cells in posterior brain areas, persist in firing across memory delays even when distracting events occur before responding is permitted.

By generally linking WM/executive-attentionprocesses to the PFC, however, we do not preclude the involvement of PFC structures in other cognitive, or noncognitive, functions (see D'Esposito, Ballard, et al., 1998). The PFC is a very large, anatomically complex area of the primate brain, and so it is likely to be involved in additional aspects of information processing, motor performance, motivation, and/or emotional regulation. Indeed, just within the cognitive domain, patients with PFC damage have difficulty learning new associations, discriminating recent events from distant ones, and remembering the sources of learned information, among other tasks (e.g., Janowsky, Shimamura, \& Squire, 1989; Petrides, 1985, 1990; Petrides \& Milner, 1982; Shimamura, Janowsky, \& Squire, 1990). These memory and timing functions may be influenced by WM and attention-control processes, but they also may not be. For many of these behaviors, current models are too underspecified to clearly implicate executive attention involvement (but see Kimberg \& Farah, 1993; Zakay \& Block, 1997).

Because WM-capacity/executive-attention functions appear to map onto dPFC (and networked) structures, we propose that normal individual differences in WM capacity are mediated by individual differences in dPFC functioning. Of course, we recognize that the dPFC is not uniquely important to WM capacity or executive control. The dPFC clearly supports WM functions but cannot embody them by itself. To restate this important point, the dPFC is a necessary structure in executiveattention processes, but it is not a sufficient structure. As we have emphasized in our own work (see Engle, 2001; Engle, Kane, \& Tuholski, 1999; Engle, Tuholski, et al., 1999), even simple cognitive tasks involve multiple processes. It is therefore likely that these various processes map onto multiple functional mechanisms, which in turn map onto multiple biological structures.

However, with such caution in mind, we want to emphasize that PFC cells differ from memory-sensitive cells outside of the PFC, in that only the PFC cells maintain their delay-period activity in the presence of a distractor (di Pellegrino \& Wise, 1993a, 1993b; E. K. Miller et al.,
1996). Similarly, patients with dPFC damage show exaggerated brain potentials in auditory cortex to distractor tones presented during memory delays, suggesting that intact dPFC is critical to blocking distraction in the service of memory maintenance (Chao \& Knight, 1998; see also Bartus \& LaVere, 1977; Malmo, 1942). Together, these findings certainly suggest that the dPFC does have a unique function with respect to WM/executive-attention capabilities. More work is obviously needed, but we would argue that this unique function is to sustain the activation of memory representations even when attentional focus is drawn elsewhere due to distraction. This unique function will be particularly important in contexts in which LTM retrieval is made difficult due to interference from competing events or habit.

\section{GENERAL DISCUSSION}

Arguments for a strong relationship, or even an isomorphism, among WM capacity, executive attention, and fluid intelligence (see Engle, Kane, \& Tuholski, 1999; Engle, Tuholski, et al., 1999) are strengthened by the evidence that they also share a neurological substrate. Experimental work with brain-damaged primates (both human and nonhuman), as well as imaging research with healthy humans, indicates that the PFC - and perhaps the dorsolateral area in particular-is necessary for effective WM capacity and aspects of executive attention. Monkeys and human patients with lesions to the dPFC exhibit marked impairments in WM tasks and in many indices of focusing, dividing, and shifting attention. This should be particularly true, in our view, insofar as these tasks require that information be maintained in memory in the presence of interference. Damage to posterior and subcortical brain areas to which the dPFC is anatomically linked also impairs WM-capacity/attention-control capabilities. Single-unit recording and brain-imaging techniques further suggest that when healthy monkeys and humans engage in behaviors requiring WM capacity/ executive attention, they selectively activate dPFC and dPFC-linked brain regions. Finally, limited evidence from human studies suggests a corresponding reliance of psychometric Gf on the dPFC.

But how general are these WM-capacity/executiveattention capabilities? Do they really reflect a common construct, or are there multiple WM "capacities" associated with different stimulus modalities or processing domains? Of course, we do not suggest that all components of the WM system or all components of "attention" are domain-free. Clearly, the STM components, or "slave systems," of the WM system may be dissociated by the stimuli and representations on which they operate (see Baddeley \& Hitch, 1974; Baddeley \& Logie, 1999). We suggest here that an executive core of the WM system, which we label "WM capacity," reflects a general capability to control attention to maintain a limited amount of information in an active state, particularly in the presence 
of interference. Moreover, this domain-free capability reflects the shared variance among WM-capacity tests and tests of higher order cognition.

There is significant behavioral evidence for our position, reviewed in detail elsewhere (Conway \& Kane, 2001; Engle, 2001, 2002; Engle, Kane, \& Tuholski, 1999). Briefly, we note here that WM-capacity measures, requiring a variety of processing skills and presenting a variety of stimulus types, correlate substantially with fluid ability tasks across verbal, mathematical, and spatial domains (see, e.g., Crawford \& Stankov, 1983; Daneman \& Merikle, 1996; Engle et al., 1992; Kyllonen \& Christal, 1990; Larson \& Saccuzzo, 1989; Law, Morrin, \& Pellegrino, 1995; Stankov \& Crawford, 1993; Turner \& Engle, 1989). They also predict performance in a variety of simple attentional tasks that make explicit demands neither on memory retrieval nor on one particular domain of processing (Bleckley, 2001; Conway et al., 2001; Conway, Tuholski, Shisler, \& Engle, 1999; Kane et al., 2001; Kane \& Engle, in press; Tuholski, Engle, \& Baylis, 2001).

Furthermore, in neuropsychological terms, dPFC injury or deactivation may impair recall equivalently on object, spatial, haptic, and cross-modal delayed-memory tasks, suggesting generality across stimulus domains (e.g., Bauer \& Fuster, 1976; Fuster \& Bauer, 1974; Quintana \& Fuster, 1993; Verin et al., 1993). Moreover, PET results suggest equivalent dPFC activation in $n$-back tasks using visual versus auditory stimuli (Schumacher et al., 1996), and single-cell recordings indicate $\mathrm{dPFC}$ cells tuned to rule-dependent combinations of stimulus modalities (Fuster, Bodner, \& Kroger, 2000; White \& Wise, 1999). Finally, several imaging studies show similar bilateral dPFC activation patterns during both object and spatial WM task performance (e.g., Braver et al., 1997; Cohen et al., 1994; D'Esposito, Ballard, et al., 1998; Smith et al., 1996), and this conclusion is supported by a recent metaanalysis (Owen, 1997; see also D'Esposito, Aguirre, et al., 1998).

However, some behavioral work does support the idea of multiple, domain-specific WM-capacity systems (e.g., Daneman \& Merikle, 1996; Daneman \& Tardif, 1987; Jurden, 1995; Shah \& Miyake, 1996). ${ }^{17}$ Moreover, with respect to neurology, the lateral PFC consists of several distinct subregions with different specialties: for example, the principal sulcus and inferior convexity regions in the macaque. These dorsolateral and ventrolateral subregions (i.e., areas $9 / 46$ and 12 , respectively) are anatomically networked to different posterior regions. Principal sulcus neurons are primarily linked to posterior parietal cortex, and inferior convexity neurons are linked to inferior temporal cortex. These two posterior areas are specialized for processing spatial and object information, respectively (e.g., Mishkin, Ungerleider, \& Macko, 1983; Pandya \& Barnes, 1987). Accordingly, delay tasks with spatial stimuli may rely more on principal sulcus neurons in the dPFC, and delay tasks with object stimuli may rely more on inferior convexity cells (see, e.g., Mishkin \& Manning, 1978; Passingham, 1975; Rosenkilde, 1979; F. A. W. Wilson et al.,
1993; but see also Boussaoud \& Wise, 1993), and on more dorsal areas as well (Petrides, 1995). Moreover, in imaging studies, humans sometimes show different lateralization patterns in PFC activation during spatial versus object memory tasks (Casey et al., 1998; Courtney et al., 1998; D’Esposito, Ballard, et al., 1998; McCarthy et al., 1994; McCarthy et al., 1996). Here, then, separate anatomical structures seem to subserve working memories that involve different stimulus domains (but see D'Esposito, Aguirre, et al., 1998; D’Esposito, Postle, Ballard, \& Lease, 1999; Owen, 1997).

Despite these inconsistencies, we believe that WM capacity/executive attention/Gf reflects an entirely domainfree process or mechanism. At the same time, however, every task also involves the use of some domain-specific stimuli, processing, and skill, and so every measure of WM capacity/executive attention/Gf reflects both domainfree and domain-specific components. No individual test or small battery of tests will exclusively tap the executive component of WM capacity. For example, contradictory imaging findings with respect to $\mathrm{dPFC}$ laterality for spatial and object $n$-back tasks may reflect individual differences across the small samples of subjects in each study (D'Esposito, Ballard, et al., 1998; Postle, Stern, et al., 2000). The individual differences in these studies may represent the WM-capacity/executive-attention construct, or instead (or even also) may represent idiosyncratic strategies or skills adopted by subjects.

We suggest that a hierarchical view of the WM system is most appropriate, by analogy to the intelligence literature (e.g., Carroll, 1993, 1996; Kyllonen, 1993, 1996; Snow et al., 1984; see Engle, Kane, \& Tuholski, 1999). A domain-free central-executive component ("WM capacity"), like the second-order Gf factor of intelligence, works in concert with domain-specific storage and processing components, such as the first-order, domainspecific factors of intelligence.

Indeed, we view the neuroanatomic evidence as supporting a hierarchical view of WM. The specific factors correspond primarily to the domain or modality of to-bestored information, and therefore to the action of more posterior brain regions. The general factor transcends any specific domain or modality of processing, and therefore corresponds to the action of dPFC. As noted above, different subregions of the lateral PFC are generally networked to different posterior systems, and these separable pathways are suggestive of distinct WM systems. However, neural connections between these lateral PFC areas may allow them to coordinate their activity (Barbas \& Pandya, 1991; Pandya \& Barnes, 1987).

Moreover, a minority of neurons in each of these PFC subregions responds to the domain or modality that is typically reserved for the other subregion. That is, some principal sulcus neurons respond preferably to object, as opposed to spatial, information, and some inferior convexity neurons respond to spatial, as opposed to object, information (see, e.g., Boussaoud \& Wise, 1993; Funahashi et al., 1989, 1990; Kubota et al., 1980; Rosenkilde 
et al., 1981; F. A. W. Wilson et al., 1993; but see Niki, 1974b). Even within each specialized subregion, then, cross-domain activity is measurable. This suggests that lateral subregions of PFC have domain-specific firing preferences, or tuning curves, but they still contribute to WM performance in other nonpreferred domains or modalities (see Erickson, 1974, for parallel arguments in the neurobiology of coordinative perceptual coding, and see E. K. Miller, 2000, for evidence of similar tuning within the "what" and "where" visual pathways).

Even a single neuron may fire across delays in both spatial-and object-based discriminations within the very same task. Rao et al. (1997) created an ingenious delayed matching-to-sample task requiring monkeys to retain both object and spatial information across delays. The subject first viewed a sample object illustration in a neutral location, and then, after a blank delay, saw two test illustrations (each appearing in one of four possible test locations), one of which matched the sample. After another blank delay, the subject had to make an eye movement to the location where the matching sample had previously appeared. Thus, in making a delayed spatial response, object information also had to be maintained across delays. Seven percent of delay-sensitive cells fired only during the first, "object/what" delay, and $41 \%$ were uniquely tuned for the second, "location/where" delay. However, a majority (52\%) of delay neurons fired during both object- and location-based delays, and these "what-and-where" cells were distributed equally between dorsolateral and ventrolateral PFC areas. In similar studies, Rainer et al. (1998) found that $25 \%$ of dPFC delay cells were tuned to both object and location information, and White and Wise (1999) demonstrated that delay-period cells in dorsolateral and ventrolateral PFC were equally likely to be activated by cues for spatial or conditional (nonspatial) target-detection rules. Moreover, in the White and Wise study, individual cells in both dorsal and ventral areas changed preference for conditional versus spatial rules across different blocks of the task.

The generality of WM capacity is strongly supported by the human individual-differences research showing that WM-span measures predict performance in relatively low-level attention tasks bearing no surface similarity to the span tasks themselves, or to other "memory" tasks (for reviews, see Conway \& Kane, 2001; Engle, 2001, 2002; Engle, Kane, \& Tuholski, 1999). Unlike WM-span tasks, these attention tasks, such as antisaccade and Stroop, require no complex linguistic/arithmetic processing and no retention of stimulus lists. What they do require is that a goal-state be actively maintained in order to control behavior despite strong interference from habit and environmental events. They also appear to require intact dPFC functioning. Thus, our findings that low spans perform worse than do high spans on antisaccade tasks, Stroop tasks, dichotic-listeningtasks, verbal-fluency tasks, proactive-interference tasks, and Gf-loaded reasoning tasks strongly resemble the neuropsychological findings discussed at length in this review. Healthy individuals with low WM capacities, although obviously not as impaired as patients with dPFC damage, do show patterns of cognitive performance similar to those of dPFC patients. Moreover, healthy high-span subjects engaged in executive-attention tasks under a memory load come to resemble both low spans and dPFC patients in their performance (Bleckley, 2001; Kane \& Engle, 2000; Rosen \& Engle, 1997).

A hierarchical organization of WM capabilities seems the best way to account for the apparent generality and specificity in behavioral and neuroanatomical indices of WM capacity/executive attention. A general, domainfree factor certainly accounts for too much performance variance to be ignored. There are simply too many strong correlations among diverse WM-capacity tasks and diverse higher order tasks to deny that some general mechanism is involved. Yet, with respect to WM-capacity and higher order tasks, there typically remains some significant variance to be accounted for after the general-factor variance is removed (see, e.g., Daneman \& Merikle, 1996; Shah \& Miyake, 1996). Similarly, the dPFC appears to be critical to executive-attention capabilities across a variety of tasks and stimulus domains, and yet other posterior brain areas are variously and variably important to some of these tasks and stimuli, as well.

According to our framework, then, individual differences in WM capacity should best predict other capabilities when the WM-measure and the target-ability task both demand executive attention-that is, when neither task is too demanding in terms of a specialized skill in a particular domain. The correlations between WM-capacity and ability tasks will be highest when both tasks reflect the general WM-capacity factor ("Gwm") and neither is mediated too strongly by a specific lower level factor such as Baddeley's phonological loop or visuospatial sketchpad, or by other, more strategic mechanisms. Likewise, bilateral patterns of dPFC activation will be most likely during memory tasks that make the highest demands on executive attention regardless of the task domain. More differentiated activation patterns, and more variability in the participation of posterior brain areas, will be likely to appear during the performance of memory tasks that make particular demands on specific skills.

\section{CONCLUSIONS}

By definition, subjects in complex WM-capacity tasks must do more than just passively store information. These tasks make considerable demands on executive attention, we argue, by requiring that subjects maintain some information in an active state, and this is particularly critical under conditions of interference. The presence of interference puts a premium on this active maintenance of information, because without interference it is quite easy to retrieve inactive information from LTM. Not surprisingly, then, other cognitive tasks that demand executive attention for focusing or switching in the face of interference 
are also well predicted by individual differences in WM capacity. Moreover, performance on these executive-attention tasks is severely disrupted by imposing a simultaneous WM load.

But what does this WM capacity/executive attention construct ultimately reflect? We propose that the common factor among tasks that are sensitive to individual differences in WM capacity, tasks that are impacted by a secondary load, tasks that load highly onto a Gf factor, and tasks that selectively require $\mathrm{dPFC}$ involvement is the degree to which the tasks require executive attention. More specifically, the capability to maintain a memory representation in an active state despite distractions, and in interference-rich contexts, is precisely the aspect of executive attention that is critical to predicting general success across higher order cognitive domains, and that is particularly reliant on cells of the dPFC.

\section{REFERENCES}

ACKERLY, S. (1937). Instinctive, emotional and mental changes following prefrontal lobe extirpation. American Journal of Psychiatry, 92, 717-729.

Ahola, K., Vilkki, J., \& Servo, A. (1996). Frontal tests do not detect frontal infarctions after ruptured intracranial aneurysm. Brain \& Cognition, 31, 1-16.

Alexander, G. E., \& Fuster, J. M. (1973). Effects of cooling prefrontal cortex on cell firing in the nucleus medialis dorsalis. Brain Research, 61, 93-105.

Allport, D. A., Styles, E. A., \& Hsieh, S. (1994). Shifting attentional set: Exploring the dynamic control of tasks. In C. Umiltà \& M. Moscovitch (Eds.), Attention and performance XV: Conscious and nonconscious information processing (pp. 421-452). Hillsdale, NJ: Erlbaum.

Anderson, S. W., Damasio, H., Jones, R. D., \& Tranel, D. (1991). Wisconsin Card Sorting Test performance as a measure of frontal lobe damage. Journal of Clinical \& Experimental Neuropsychology, 13, 909-922.

Arthur, W., Jr., Barrett, G. V., \& Doverspike, D. (1990). Validation of an information-processing-based test battery for the prediction of handling accidents among petroleum-product transport drivers. Journal of Applied Psychology, 75, 621-628.

Awh, E., Jonides, J., Smith, E. E., Schumacher, E. H., Koeppe, R. A., \& Katz, S. (1996). Dissociation of storage and rehearsal in verbal working memory: Evidence from positron emission tomography. Psychological Science, 7, 25-31.

BAdDEley, A. D. (1996). Exploring the central executive. Quarterly Journal of Experimental Psychology, 49A, 5-28.

Baddeley, A. D., Della Sala, S., Papagno, C., \& Spinnler, H. (1997). Dual-task performance in dysexecutive and nondysexecutive patients with a frontal lesion. Neuropsychology, 11, 187-194.

BADdEley, A. D., \& Hitch, G. (1974). Working memory. In G. A. Bower (Ed.), The psychology of learning and motivation (Vol. 8, pp. 47-89). New York: Academic Press.

BADDEley, A. D., \& Logie, R. (1999). Working memory: The multiple component model. In A. Miyake \& P. Shah (Eds.), Models of working memory: Mechanisms of active maintenance and executive control (pp. 28-61). New York: Cambridge University Press.

Baker, S. C., Frith, C. D., Frackowiak, R. S. J., \& Dolan, R. J. (1996). Active representation of shape and spatial location in man. Cerebral Cortex, 6, 612-619.

Baldo, J. V., \& Shimamura, A. P. (1998). Letter and category fluency in patients with frontal lobe lesions. Neuropsychology, 12, 259-267.

Baldo, J. V., \& Shimamura, A. P. (2000). Spatial and color working memory in patients with lateral prefrontal cortex lesions. Psychobiology, 28, 156-167.

Banich, M. T., Milham, M. P., Atchley, R. A., Cohen, N. J., Webb, A., Wszalek, T., Kramer, A. F., Liang, Z. P., Wright, A., Shenker, J.,
\& Magin, R. (2000). fMRI studies of Stroop tasks reveal unique roles of anterior and posterior brain systems in attentional selection. Journal of Cognitive Neuroscience, 12, 988-1000.

Barbas, H., \& Mesulam, M. M. (1981). Organization of afferent input to subdivisions of area 8 in the rhesus monkey. Journal of Comparative Neurology, 200, 407-431.

Barbas, H., \& Mesulam, M. M. (1985). Cortical afferent input to the principalis region of the rhesus monkey. Neuroscience, 15, 619-637.

Barbas, H., \& Pandya, D. N. (1991). Patterns of connections of the prefrontal cortex in the rhesus monkey associated with cortical architecture. In H. S. Levin, H. M. Eisenberg, \& A. L. Benton (Eds.), Frontal lobe function and dysfunction (pp. 35-58). Oxford: Oxford University Press.

Barch, D. M., Braver, T. S., Nyström, L. E., Forman, S. D., Noll, D. C., \& Cohen, J. D. (1997). Dissociating working memory from task difficulty in human prefrontal cortex. Neuropsychologia, 35, 1373-1380.

Bartus, R. T., \& LaVere, T. E. (1977). Frontal decortication in rhesus monkeys: A test of the interference hypothesis. Brain Research, 119, 233-248.

Battersby, W. S., Krieger, H. P., Pollack, M., \& Bender, M. B. (1953). Figure-ground discrimination and the "abstract attitude" in patients with cerebral lesions. Archives of Neurology \& Psychiatry, 70, 703-712.

Battig, K., Rosvold, H. E., \& Mishinin, M. (1960). Comparison of the effects of frontal and caudate lesions on delayed response and alternation in monkeys. Journal of Comparative \& Physiological Psychology, 53, 400-404.

Batuev, A. S., Shaefer, V. I., \& Orlov, A. A. (1985). Comparative characteristics of unit activity in the prefrontal and parietal areas during delayed performance in monkeys. Behavioural Brain Research, 16, 57-70.

BAUER, R. H., \& Fuster, J. M. (1976). Delayed-matching and delayedresponse deficit from cooling dorsolateral prefrontal cortex in monkeys. Journal of Comparative \& Physiological Psychology, 90, 293302.

BAylis, G. C., \& Rolls, E. T. (1987). Responses of neurons in the inferior temporal cortex in short term and serial recognition memory tasks. Experimental Brain Research, 65, 614-622.

Bechara, A., Damasio, H., Tranel, D., \& Anderson, S. W. (1998). Dissociation of working memory from decision making within the human prefrontal cortex. Journal of Neuroscience, 18, 428-437.

Bench, C. J., Frith, C. D., Grasbi, P. M., Friston, K. J., Paulesu, E., Frackowiak, R. S. J., \& Dolan, R. J. (1993). Investigations of the functional anatomy of attention using the Stroop test. Neuropsychologia, 31, 907-922.

Benedict, R. H. B., Lockwood, A. H., Shucard, J. L., Shucard, D. W., WACK, D., \& MurPHY, B. W. (1998). Functional neuroimaging of attention in the auditory modality. NeuroReport, 9, 121-126.

Benton, A. L. (1968). Differential behavioral effects in frontal lobe disease. Neuropsychologia, 6, 53-60.

BERG, E. A. (1948). A simple objective technique for measuring flexibility in thinking. Journal of General Psychology, 39, 15-22.

Berman, K. F., Ostrem, J. L., Randolph, C., Gold, J., Goldberg, T. E., Coppola, R, Carson, R. E., Herscovitch, P., \& Weinberger, D. R. (1995). Physiological activation of a cortical network during performance of the Wisconsin Card Sorting Test: A positron emission tomography study. Neuropsychologia, 33, 1027-1046.

Berman, K. F., Zec, R. F., \& Weinberger, D. R. (1986). Physiological dysfunction of dorsolateral prefrontal cortex in schizophrenia: II. Role of neuroleptic treatment, attention, and mental effort. Archives of General Psychiatry, 43, 126-135.

BLECKLEY, M. K. (2001). Individual differences in visual attention and working memory capacity: Further distinctions between where and what. Unpublished doctoral dissertation, Georgia Institute of Technology.

Bolter, J. F., Long, C. J., \& Wagner, M. (1983). The utility of the Thurstone Word Fluency Test in identifying cortical damage. Clinical Neuropsychology, 5, 77-82.

Boone, K. B. (1999). Neuropsychological assessment of executive functions: Impact of age, education, gender, intellectual level, and vas- 
cular status on executive test scores. In B. L. Miller \& J. L. Cummings (Eds.), The human frontal lobes: Functions and disorders (pp. 247260). New York: Guilford.

BorkowSKI, J. G. (1965). Interference effects in short-term memory as a function of level of intelligence. American Journal of Mental Deficiency, 70, 458-465.

BoussaOud, D., \& Wise, S. P. (1993). Primate frontal cortex: Neuronal activity following attentional versus intentional cues. Experimental Brain Research, 95, 15-27.

Braver, T. S., Barch, D. M., Kelley, W. M., Buckner, R. L., Cohen, N. J., Miezin, F. M., Snyder, A. Z, Ollinger, J. M., Akbudak, E., Conturo, T. E., \& Petersen, S. E. (2001). Direct comparison of prefrontal cortex regions engaged by working and long-term memory tasks. NeuroImage, 14, 48-59.

Braver, T. S., \& Cohen, J. D. (2000). On the control of control: The role of dopamine in regulating prefrontal function and working memory. In S. Monsell \& J. Driver (Eds.), Attention and performance XVIII: Control of cognitive processes (pp. 713-737). Cambridge, MA: MIT Press.

Braver, T. S., Cohen, J. D., Nyström, L. E., Jonides, J., Smith, E. E., \& Noll, D. C. (1997). A parametric study of prefrontal cortex involvement in human working memory. Neurolmage, 5, 49-62.

BrodmAnn, K. (1925). Vergleichende Lokalisationslehre der Grosshirnrinde. Leipzig, Germany: Barth.

Butters, M. A., Kaszniak, A. W., Glisky, E. L., Eslinger, P. J., \& Schacter, D. L. (1994). Recency discrimination deficits in frontal lobe patients. Neuropsychology, 8, 343-353.

Callicott, J. H., Mattay, V. S., Bertolino, A., Finn, K., Coppola, R, Frank, J. A., Goldberg, T. E., \& Weinberger, D. R. (1999). Physiological characteristics of capacity constraints in working memory as revealed by functional MRI. Cerebral Cortex, 9, 20-26.

Carpenter, P. A., Just, M. A., \& Shell, P. (1990). What one intelligence test measures: A theoretical account of the processing in the Raven Progressive Matrices test. Psychological Review, 97, 404-431.

Carroll, J. B. (1993). Human cognitive abilities: A survey of factoranalytic studies. New York: Cambridge University Press.

Carroll, J. B. (1996). A three-striatum theory of intelligence: Spearman's contribution. In I. Dennis \& P. Tapsfield (Eds.), Human abilities: Their nature and measurement (pp. 1-17). Mahwah, NJ: Erlbaum.

Casey, B. J., Cohen, J. D., O'Craven, K., Davidson, R. J., Irwin, W., Nelson, C. A., Noll, D. C., Hu, X., Lowe, M. J., Rosen, B. R., TruwitT, C. L., \& TuRSKI, P. A. (1998). Reproducibility of fMRI results across four institutions using a spatial working memory task. NeuroImage, 8, 249-261.

Chao, L. L., \& KNight, R. T. (1998). Contribution of human prefrontal cortex to delay performance. Journal of Cognitive Neuroscience, $\mathbf{1 0}$, $167-177$.

Chorover,S. L., \& Cole, M. (1966). Delayed alternation performance in patients with cerebral lesions. Neuropsychologia, 4, 1-7.

Chow, T. W., \& Cummings, J. L. (1999). Frontal-subcortical circuits. In B. L. Miller \& J. L. Cummings (Eds.), The human frontal lobes: Functions and disorders (pp. 3-26). New York: Guilford.

Cicerone, K. D., Lazar, R. M., \& Shapiro, W. R. (1983). Effects of frontal lobe lesions on hypothesis sampling during concept formation. Neuropsychologia, 21, 513-524.

Cohen, J. D., Braver, T. S., \& O' ReILly, R. C. (1996). A computational approach to prefrontal cortex, cognitive control and schizophrenia: Recent developments and current challenges. Philosophical Transactions of the Royal Society of London: Series B, 351, 1515-1527.

Cohen, J. D., Braver, T. S., \& O'Reilly, R. C. (1998). A computational approach to prefrontal cortex, cognitive control and schizophrenia: Recent developments and current challenges. In A. C. Roberts, T. W. Robbins, \& L. Weiskrantz (Eds.), The prefrontal cortex: Executive and cognitive functions (pp. 195-220). Oxford: Oxford University Press.

Cohen, J. D., Dunbar, K., \& McClelland, J. L. (1990). On the control of automatic processes: A parallel distributed processing account of the Stroop effect. Psychological Review, 97, 332-361.

Cohen, J. D., Forman, S. D., Braver, T. S., Casey, B. J., Servan-
Schreiber, D., \& Noll, D. C. (1994). Activation of the prefrontal cortex in a nonspatial working memory task with functional MRI. Human Brain Mapping, 1, 293-304.

Cohen, J. D., Perlstein, W. M., Braver, T. S., Nyström, L. E., Noll, D. C., Jonides, J., \& Smith, E. E. (1997). Temporal dynamics of brain activation during a working memory task. Nature, 386, 604608.

Cohen, J. D., \& Servan-Schreiber, D. (1992). Context, cortex, and dopamine: A connectionist approach to behavior and biology in schizophrenia. Psychological Review, 99, 45-77.

Constantinidis, C., \& Steinmetz, M. A. (1996). Neuronal activity in posterior parietal area 7a during the delay periods of a spatial memory task. Journal of Neurophysiology, 76, 1352-1355.

Conway, A. R. A., Cowan, N., \& Bunting, M. F. (2001). The cocktail party phenomenon revisited: The importance of working memory capacity. Psychonomic Bulletin \& Review, 8, 331-335.

Conway, A. R. A., Cowan, N., Bunting, M. F., Therriault, D., \& Minkoff, S. (2002). A latent variable analysis of working memory capacity, short term memory capacity, processing speed, and general fluid intelligence. Intelligence, 30, 163-183.

Conway, A. R. A., \& ENGLE, R. W. (1994). Working memory and retrieval: A resource-dependent inhibition model. Journal of Experimental Psychology: General, 123, 354-373.

Conway, A. R. A., \& Engle, R. W. (1996). Individual differences in working memory capacity: More evidence for a general capacity theory. Memory, 4, 577-590.

Conway, A. R. A., \& Kane, M. J. (2001). Capacity, control and conflict: An individual differences perspective on attentional capture. In C. Folk \& B. Gibson (Eds.), Attraction, distraction and action: Multiple perspectives on attention capture (pp. 349-372). Amsterdam: Elsevier.

Conway, A. R. A., Tuholski, S. W., Shisler, R. J., \& Engle, R. W. (1999). The effect of memory load on negative priming: An individual differences investigation. Memory \& Cognition, 27, 1042-1050.

Corbetta, M., Miezin, F. M., Dobmeyer, S., Shulman, G. L., \& PeTERSON, S. E. (1991). Selective and divided attention during visual discriminations of shape, color, and speed: Functional anatomy by positron emission tomography. Journal of Neuroscience, 11, 2383-2402.

Corcoran, R., \& Upton, D. (1993). A role for the hippocampus in card sorting? Cortex, 29, 293-304.

Coslett, H. B., Bowers, D., Verfaellie, M., \& Heilman, K. M. (1991). Frontal verbal amnesia: Phonological amnesia. Archives of Neurology, 48, 949-955.

Courtney, S. M., Petit, L., Maisog, J. M., Ungerleider, L. G., \& НАХвY, J. V. (1998). An area specialized for spatial working memory in human frontal cortex. Science, 279, 1347-1351.

Courtney, S. M., Ungerleider, L. G., Keil, K., \& Haxby, J. V. (1996). Object and spatial working memory activate separate neural systems in human cortex. Cerebral Cortex, 6, 39-49.

Courtney, S. M., Ungerleider, L. G., Keil, K., \& Haxby, J. V. (1997). Transient and sustained activity in a distributed neural system for human working memory. Nature, 386, 608-611.

Cowan, N. (1995). Attention and memory: An integrated framework. Oxford: Oxford University Press.

Cowan, N. (1999). An embedded-process model of working memory. In A. Miyake \& P. Shah (Eds.), Models of working memory: Mechanisms of active maintenance and executive control (pp. 62-101). New York: Cambridge University Press.

Crawford, J. D., \& STankov, L. (1983). Fluid and crystallized intelligence and primacy/recency components of short-term memory. Intelligence, 7, 227-252.

Cuenod, C. A., Bookheimer, S. Y., Hertz-Pannier, L., Zeffiro, T. A. Theodore, W. H., \& Le Bihan, D. (1995). Functional MRI during word generation, using conventional equipment: A potential tool for language localization in the clinical environment. Neurology, 45, 1821-1827.

DAmasio, H. C. (1991). Neuroanatomy of frontal lobe in vivo: A comment on methodology. In H. S. Levin, H. M. Eisenberg, \& A. L. Benton (Eds.), Frontal lobe function and dysfunction (pp. 92-121). Oxford: Oxford University Press. 
D’ Амato, M. R. \& O'Neill, W. (1971). Effect of delay-interval illumination on matching behavior in the capuchin monkey. Journal of the Experimental Analysis of Behavior, 15, 327-333.

Daneman, M., \& CARPenter, P. A. (1980). Individual differences in working memory and reading. Journal of Verbal Learning \& Verbal Behavior, 19, 450-466.

Daneman, M., \& Merikle, P. M. (1996). Working memory and language comprehension: A meta-analysis. Psychonomic Bulletin \& Review, 3, 422-433.

DANEMAN, M., \& TARDIF, T. (1987). Working memory and reading skill reexamined. In M. Coltheart (Ed.), Attention and performance XII: The psychology of reading (pp. 491-508). Hove, U.K.: Erlbaum.

Dehaene, S., \& Changeux, J. P. (1989). A simple model of prefrontal cortex function in delayed-response tasks. Journal of Cognitive Neuroscience, 1, 244-261.

De Jong, R. D., Berendsen, E., \& Cools, R. (1999). Goal neglect and inhibitory limitations: Dissociable causes of interference effects in conflict situations. Acta Psychologica, 101, 379-394.

Delis, D. C., Squire, L. R., Bihrle, A., \& Massman, P. (1992). Componential analysis of problem-solving ability: Performance of patients with frontal lobe damage and amnesic patients on a new sorting test. Neuropsychologia, 30, 683-697.

DeMPSTER, F. N. (1991). Inhibitory processes: A neglected dimension in intelligence. Intelligence, 15, 157-173.

DeMPSTER, F. N. (1992). The rise and fall of the inhibitory mechanism: Toward a unified theory of cognitive development and aging. Developmental Review, 12, 45-75.

Dempster, F. N., \& CORKILl, A. J. (1999). Individual differences in susceptibility to interference and general cognitive ability. Acta Psychologica, 101, 395-416.

Desimone, R., \& Duncan, J. (1995). Neural mechanisms of selective visual attention. Annual Review of Neuroscience, 18, 193-222.

D'Esposito, M., Aguirre, G. K., Zarahn, E. K., Ballard, D., Shin, R. K., \& LEASE, J. (1998). Functional MRI studies of spatial and nonspatial working memory. Cognitive Brain Research, 7, 1-13.

D'Esposito, M., Ballard, D., Aguirre, G. K., \& Zarahn, E. (1998). Human prefrontal cortex is not specific for working memory: A functional MRI study. NeuroImage, 8, 274-282.

D'Esposito, M., Ballard, D., Zarahn, E., \& Aguirre, G. K. (2000). The role of prefrontal cortex in sensory memory and motor preparation: An event-related fMRI study. NeuroImage, 11, 400-408.

D'Esposito, M., Detre, J. A., Alsop, D. C., Shin, R. K., Atlas, S., \& Grossman, M. (1995). The neural basis of the central executive system of working memory. Nature, 378, 279-281.

D’Esposito, M., Post le, B. R., Ballard, D., \& Lease, J. (1999). Maintenance versus manipulation of information held in working memory: An event-related f MRI study. Brain \& Cognition, 41, 66-86.

D’Esposito, M., Post Le, B. R., Jonides, J., \& Smith, E. E. (1999). The neural substrate and temporal dynamics of interference effects in working memory as revealed by event-related functional MRI. Proceedings of the National Academy of Sciences, 96, 7514-7519.

Diamond, A. (1990). Developmental time course in human infants and infant monkeys, and the neural bases of, inhibitory control of reaching. In A. Diamond (Ed.), The development and neural bases of higher cognitive functions (Annals of the New York Academy of Sciences, Vol. 608, pp. 637-676). New York: New York Academy of Sciences.

DiAmond, A. (1991). Frontal lobe involvement in cognitive changes during the first year of life. In K. R. Gibson \& A. C. Peterson (Eds.), Brain maturation and cognitive development: Comparative and cross-cultural perspectives (pp. 127-180). New York: de Gruyter.

Dias, R., Robbins, T. W., \& RoberTs, A. C. (1996a). Dissociation in prefrontal cortex of affective and attentional shifts. Nature, 380, 69-72.

Dias, R., Robbins, T. W., \& Roberts, A. C. (1996b). Primate analogue of the Wisconsin Card Sorting Test: Effects of excitotoxic lesions of the prefrontal cortex in the marmoset. Behavioral Neuroscience, $\mathbf{1 1 0}$, $872-886$.

Dias, R, Robbins, T. W., \& Roberts, A. C. (1997). Dissociable forms of inhibitory control within prefrontal cortex with an analog of the Wisconsin Card Sort Test: Restriction to novel situations and independence from "on-line" processing. Journal of Neuroscience, 17, 9285-9297.

Di Pellegrino, G., \& Wise, S. P. (1993a). Effects of attention on visuo- motor activity in the premotor and prefrontal cortex of a primate. Somatosensory \& Motor Research, 10, 245-262.

di Pellegrino, G., \& Wise, S. P. (1993b). Visuospatial versus visuomotor activity in the premotor and prefrontal cortex of a primate. Journal of Neuroscience, 13, 1227-1243.

Diwadkar, V. A., Carpenter, P. A., \& Just, M. A. (2000). Collaborative activity between parietal and dorso-lateral prefrontal cortex in dynamic spatial working memory revealed by fMRI. NeuroImage, 12, 85-99.

Dolan, R. J., \& Fletcher, P. C. (1997). Dissociating prefrontal and hippocampal function in episodic memory encoding. Nature, $\mathbf{3 8 8}$, 582-585.

Dove, A., Pollmann, S., Schubert, T., Wiggins, C. J., \& von CraMON, D. Y. (2000). Prefrontal cortex activation in task switching: An event-related fMRI study. Cognitive Brain Research, 9, 103-109.

Drewe, E. A. (1974). The effect of type and area of brain lesion on Wisconsin Card Sorting Test performance. Cortex, 10, 159-170.

Dubois, B., Levy, R., Verin, M., Teixeira, C., Agid, Y., \& Pillon, B. (1995). Experimental approach to prefrontal functions in humans. Annals of the New York Academy of Sciences, 769, 41-60.

Dunbar, K., \& Sussman, D. (1995). Toward a cognitive account of frontal lobe function: Simulating frontal lobe deficits in normal subjects. In J. Grafman, K. J. Holyoak, \& F. Butler (Eds.), Structure and functions of the human prefrontal cortex (Annals of the New York Academy of Sciences, Vol. 769, pp. 289-304). New York: New York Academy of Sciences.

Duncan, J. (1990). Goal weighting and the choice of behavior in a complex world. Ergonomics, 33, 1265-1279.

Duncan, J. (1993). Selection of input and goal in the control of behavior. In A. Baddeley \& L. Weiskrantz (Eds.), Attention: Selection, awareness, and control. A tribute to Donald Broadbent (pp. 53-71). Oxford: Oxford University Press, Clarendon Press.

Duncan, J. (1995). Attention, intelligence, and the frontal lobes. In M. S. Gazzaniga (Ed.), The cognitive neurosciences (pp. 721-733). Cambridge, MA: MIT Press.

Duncan, J., Burgess, P., \& EMslie, H. (1995). Fluid intelligence after frontal lobe lesions. Neuropsychologia, 33, 261-268.

Duncan, J., Emslie, H., Williams, P., Johnson, R, \& Freer, C. (1996). Intelligence and the frontal lobe: The organization of goal-directed behavior. Cognitive Psychology, 30, 257-303.

Duncan, J., Johnson, R., Swales, M., \& Freer, C. (1997). Frontal lobe deficits after head injury: Unity and diversity of function. Cognitive Neuropsychology, 14, 713-741.

Duncan, J., Seitz, R. J., Kolodny, J., Bor, D., Herzog, H., Ahmed, A., Newell, F. N., \& EMSLIE, H. (2000). A neural basis for general intelligence. Science, 289, 457-460.

Dupont, P., Orban, G. A., Vogels, R., Bormans, G., Nuyts, J., Schiepers, C., De Roo, M., \& Mortelmans, L. (1993). Different perceptual tasks performed with the same visual stimulus attribute activate different regions of the human brain: A positron emission tomography study. Proceedings of the National Academy of Sciences, 90, 10927-10931.

Ekstrom, R. B., French, J. W., Harman, M. H., \& Dermen, D. (1976). Manual for kit of factor-referenced cognitive tests. Princeton, NJ: Educational Testing Service.

ElfGREN, C. I., \& RisberG, J. (1998). Lateralized frontal blood flow increases during fluency tasks: Influence of cognitive strategy. Neuropsychologia, 36, 505-512.

ENGLE, R. W. (1996). Working memory and retrieval: An inhibitionresource approach. In J. T. E. Richardson, R. W. Engle, L. Hasher, R. H. Logie, E. R. Stoltzfus, \& R. T. Zacks (Eds.), Working memory and human cognition (pp. 89-119). New York: Oxford University Press.

ENGLE, R W. (2001). What is working memory capacity? In H. L. Roediger III, J. S. Nairne, I. Neath, \& A. M. Surprenant (Eds.), The nature of remembering: Essays in honor of Robert G. Crowder (pp. 297-314). Washington, DC: American Psychological Association.

ENGLE, R. W. (2002). Working memory capacity as executive attention. Current Directions in Psychological Science, 11, 19-23.

Engle, R. W., Cantor, J., \& Carullo, J. J. (1992). Individual differences in working memory and comprehension: A test of four hypotheses. Journal of Experimental Psychology: Learning, Memory, \& Cognition, 18, 972-992. 
Engle, R. W., Kane, M. J., \& Tuholski, S. W. (1999). Individual differences in working memory capacity and what they tell us about controlled attention, general fluid intelligence and functions of the prefrontal cortex. In A. Miyake \& P. Shah (Eds.), Models of working memory: Mechanisms of active maintenance and executive control (pp. 102-134). New York: Cambridge University Press.

ENGLe, R. W., Nations, J. K., \& CANTOR, J. (1990). Is "working memory capacity" just another name for word knowledge? Journal of Educational Psychology, 82, 799-804.

ENGLE, R. W., \& ORANSKY, N. (1999). The evolution from short-term to working memory: Multi-store to dynamic models of temporary storage. In R. J. Sternberg (Ed.), The concept of cognition (pp. 515555). Cambridge, MA: MIT Press.

Engle, R. W., Tuholski, S. W., Laughlin, J. E., \& Conway, A. R. A. (1999). Working memory, short-term memory and general fluid intelligence: A latent variable approach. Journal of Experimental Psychology: General, 128, 309-331.

ERICKSON, R. P. (1974). Parallel "population" neural coding in feature extraction. In F. O. Schmitt \& F. G. Worden (Eds.), The neurosciences: Third study program (pp. 155-169). Cambridge, MA: MIT Press.

ERIKSEN, B. A., \& ERIKSEN, C. W. (1974). Effects of noise letters upon the identification of a target letter in a nonsearch task. Perception \& Psychophysics, 16, 143-149.

Eslinger, P. J., \& DAMASIO, A. R. (1985). Severe disturbance of higher cognition after bilateral frontal lobe ablation: Patient EVR. Neurology, 35, 1731-1741.

Esposito, G., Kirkby, B. S., Van Horn, J. D., Ellmore, T. M., \& Berman, K. F. (1999). Context-dependent, neural system-specific neurophysiological concomitants of ageing: Mapping PET correlates during cognitive activation. Brain, 122, 963-979.

Everling, S., \& Fischer, B. (1998). The antisaccade: A review of basic research and clinical findings. Neuropsychologia, 36, 885-899.

Ferreira, C. T., Verin, M., Pillon, B., Levy, R., Dubois, B., \& Agid, Y. (1998). Spatio-temporal working memory and frontal lesions in man. Cortex, 34, 83-98.

FERrIER, D. (1886). The functions of the brain (2nd ed.). London: Smith, Elder.

Fiez, J. A., Raife, E. A., Balota, D. A., Schwarz, J. P., Raichle, M. E., \& Peterson, S. E. (1996). A positron emission tomography study of the short-term maintenance of verbal information. Journal of Neuroscience, 16, 808-822.

Fletcher, P. C., Shallice, T., \& Dolan, R. J. (1998). The functional roles of prefrontal cortex in episodic memory. Brain, 121, 12391248.

Freedman, M., \& Cermak, L. S. (1986). Semantic encoding deficits in frontal lobe disease and amnesia. Brain \& Cognition, 5, 108-114.

Freedman, M., \& Oscar-Berman, M. (1986). Bilateral frontal lobe disease and selective delayed response deficits in humans. Behavioral Neuroscience, 100, 337-342.

Friedman, H. R. \& Goldman-RaKic, P. S. (1988). Activation of the hippocampus and dentate gyrus by working memory: A 2-deoxyglucose study of behaving rhesus monkeys. Journal of Neuroscience, 8, 46934706.

Frisk, V., \& Milner, B. (1990). The relationship of working memory to the immediate recall of stories following unilateral temporal or frontal lobectomy. Neuropsychologia, 28, 121-135.

Frith, C. D., Friston, K. J., Liddle, P. F., \& Frackowiak, R. S. J. (1991). A PET study of word finding. Neuropsychologia, 29, 11371148.

Funushima, J., Fukushima, K., Miyasaka, K., \& Yamashita, I. (1994). Voluntary control of saccadic eye movement in patients with frontal cortical lesions and Parkinsonian patients in comparison with that in schizophrenics. Biological Psychiatry, 36, 21-30.

Funahashi, S., Bruce, C. J., \& Goldman-Rakic, P. S. (1989). Mnemonic coding of visual space in the monkey's dorsolateral prefrontal cortex. Journal of Neurophysiology, 61, 331-349.

Funahashi, S., Bruce, C. J., \& Goldman-Rakic, P. S. (1990). Visuospatial coding in primate prefrontal neurons revealed by oculomotor paradigms. Journal of Neurophysiology, 63, 814-831.

Funahashi, S., Bruce, C. J., \& Goldman-Rakic, P. S. (1993). Dorso- lateral prefrontal lesions and oculomotor delayed-response performance: Evidence for mnemonic "scotomas." Journal of Neuroscience, 13, 1479-1497.

FunAHASHI, S., \& Kubota, K. (1994). Working memory and prefrontal cortex. Neuroscience Research, 21, 1-11.

FUSTER, J. M. (1973). Unit activity in prefrontal cortex during delayedresponse performance: Neuronal correlates of transient memory. Journal of Neurophysiology, 36, 61-78.

FUSTER, J. M. (1980). The prefrontal cortex. New York: Raven.

FUSTER, J. M. (1988). The prefrontal cortex: Anatomy, physiology, and neuropsychology of the frontal lobe. New York: Raven.

Fuster, J. M. (1989). The prefrontal cortex (2nd ed.). New York: Raven. Fuster, J. M. (1996, July). Emerging solutions to the problem of the frontal lobe. Paper presented at the James S. McDonnell Foundation Summer Institute in Cognitive Neuroscience, Hanover, NH.

Fuster, J. M., \& Alexander, G. E. (1973). Firing changes in cells of the nucleus medialis dorsalis associated with delayed response behavior. Brain Research, 61, 79-91.

Fuster, J. M., \& BAUER, R. H. (1974). Visual short-term memory deficit from hypothermia of frontal cortex. Brain Research, 81, 393-400.

Fuster, J. M., Bauer, R. H., \& Jervey, J. P. (1985). Functional interactions between inferotemporal and prefrontal cortex in a cognitive task. Brain Research, 330, 299-307.

Fuster, J. M., Bodner, M., \& Kroger, J. (2000). Cross-modal and cross-temporal association in neurons of frontal cortex. Nature, $\mathbf{4 0 5}$, 347-351.

Goel, V., Buchel, C., Frith, C., \& Dolan, R. J. (2000). Dissociation of mechanisms underlying syllogistic reasoning. NeuroImage, 12, 504-514.

Goel, V., Gold, B., Kapur, S., \& Houle, S. (1997). The seats of reason? An imaging study of deductive and inductive reasoning. NeuroReport, 8, 1305-1310.

Goel, V., Gold, B., Kapur, S., \& Houle, S. (1998). Neuroanatomical correlates of human reasoning. Journal of Cognitive Neuroscience, 10, 293-302.

Gold, J. M., Berman, K. F., Randolph, C., Goldberg, T. E., \& WeinBERGER, D. R. (1996). PET validation of a novel prefrontal task: Delayed response alternation. Neuropsychology, 10, 3-10.

Goldberg, T. E., Berman, K. F., Fleming, K., Ostrem, J., Van Horn, J. D., Esposito, G., Mattay, V. S., Gold, J. M., \& Weinberger, D. R. (1998). Uncoupling cognitive workload and prefrontal cortical physiology: A PET rCBF study. NeuroImage, 7, 296-303.

Goldberg, T. E., Berman, K. F., Randolph, C., Gold, J. M., \& WeinBERGER, D. R. (1996). Isolating the mnemonic component in spatial delayed response: A controlled PET ${ }^{15} \mathrm{O}-$ labeled water regional cerebral blood flow study in normal humans. NeuroImage, 3, 69-78.

Goldman, P. S., \& Rosvold, H. E. (1970). Localization of function within the dorsolateral prefrontal cortex of the rhesus monkey. $E x$ perimental Neurology, 27, 291-304.

Goldman, P. S., Rosvold, H. E., Vest, B., \& Galkin, T. W. (1971). Analysis of the delayed-alternation deficit produced by dorsolateral prefrontal lesions in the rhesus monkey. Journal of Comparative \& Physiological Psychology, 77, 212-220.

GOLDMAN-RAKIC, P. S. (1987). Circuitry of primate prefrontal cortex and regulation of behavior by representational memory. In F. Plum (Ed.), Handbook of physiology: The nervous system (Vol. 5, pp. 373417). Bethesda, MD: American Physiological Society.

Goldman-RaKic, P. S. (1995). Cellular basis of working memory. Neuron, 14, 477-485.

GoldMAN-RAKIC, P. S. (2000). Localization of function all over again. NeuroImage, 11, 451-457.

Goldstein, K. (1936). The significance of the frontal lobes for mental performance. Journal of Neurology \& Psychopathology, 17, 27-40. GolDSTEIN, K. (1944). The mental changes due to frontal lobe damage. Journal of Psychology, 17, 187-208.

Gopher, D., Armony, L., \& Greenshran, Y. (2000). Switching tasks and attention policies. Journal of Experimental Psychology: General, 129, 308-339.

Grady, C. L., McIntosh, A. R., Bookstein, F., Horwitz, B., Rapoport, S. I., \& HAXBY, J. V. (1998). Age-related changes in regional cerebral blood flow during working memory for faces. NeuroImage, 8, 409-425. 
Grafman, J., Jonas, B., \& Salazar, A. (1990). Wisconsin Card Sorting Test performance based on location and size of neuroanatomical lesion in Vietnam veterans with penetrating head injury. Perceptual \& Motor Skills, 71, 1120-1122.

Grant, A. D., \& Berg, E. A. (1948). A behavioral analysis of degree of reinforcement and ease of shifting to new responses in a Weigltype card-sorting problem. Journal of Experimental Psychology, 38, 404-411.

Grueninger, W. E., \& Pribram, K. H. (1969). Effects of spatial and nonspatial distractors on performance latency of monkeys with frontal lesions. Journal of Comparative \& Physiological Psychology, 68, 203-209.

Guitton, D., Buchtel, H. A., \& Douglas, R. M. (1985). Frontal lobe lesions in man cause difficulties in suppressing reflexive glances and in generating goal-directed saccades. Experimental Brain Research, $\mathbf{5 8}, 455-472$.

HalsteAd, W. C. (1947). Brain and intelligence: A quantitative study of the frontal lobes. Chicago: University of Chicago Press.

Harlow, H. F., \& Dagnon, J. (1943). Problem solution by monkeys following bilateral removal of the prefrontal areas: I. The discrimination and discrimination-reversal problems. Journal of Experimental Psychology, 32, 351-356.

Harlow, H. F., Davis, R. T., Settlage, P. H., \& Meyer, D. R. (1952). Analysis of frontal and posterior association syndromes in braindamaged monkeys. Journal of Comparative \& Physiological Psychology, 45, 419-429.

Harlow, H. F., \& Settlage, P. H. (1948). Effect of extirpation of frontal areas upon learning performance of monkeys. Research Publications for Research in Nervous \& Mental Disease, 27, 446-459.

Harlow, J. M. (1848). Passage of an iron bar through the head. Publications of the Massachusetts Medical Society, 2, 327-347.

Harper, D. N., \& White, K. G. (1997). Retroactive interference and rate of forgetting in delayed matching-to-sample performance. Animal Learning \& Behavior, 25, 158-164.

Hartley, A. A., Speer, N. K., Jonides, J., Reuter-Lorenz, P. A., \& Smith, E. E. (2001). Is the dissociability of working memory systems for name identity, visual-object identity, and spatial location maintained in old age? Neuropsychology, 15, 3-17.

Haxby, J. V., Petit, L., Ungerleider, L. G., \& Courtney, S. M. (2000). Distinguishing the functional roles of multiple regions in distributed neural systems for visual working memory. NeuroImage, 11, 98-110.

Haxby, J. V., Ungerleider, L. G., Horwitz, B., Rapoport, S. I., \& GRADY, C. L. (1995). Hemispheric differences in neural systems for face working memory: A PET rCBF study. Human Brain Mapping, 3, 68-82.

Heaton, R. (1981). A manual for the Wisconsin Card Sorting Test. Odessa, FL: Psychological Assessment Resources.

HeBB, D. O. (1939). Intelligence in man after large removals of cerebral tissue: Report of four left frontal lobe cases. Journal of General Psychology, 21, 73-87.

Hebi, D. O. (1945). Man's frontal lobes: A critical review. Archives of Neurology \& Psychiatry, 54, 10-24.

HebB, D. O., \& Penfield, W. (1940). Human behavior after extensive bilateral removal from the frontal lobes. Archives of Neurology \& Psychiatry, 44, 421-438.

Honey, G. D., Bullmore, E. T., \& Sharma, T. (2000). Prolonged reaction time to a verbal working memory task predicts increased power of posterior parietal cortical activation. NeuroImage, 12, 495503.

indaka, T., Anderson, N. D., Kapur, S., Cabeza, R. \& Craik, F. I. M. (2000). The effect of divided attention on encoding and retrieval in episodic memory revealed by Positron Emission Tomography. Journal of Cognitive Neuroscience, 12, 267-280.

Institute For Personality AND Ability Testing (1973). Measuring intelligence with culture fair tests. Champaign, IL: Author.

JACOBSEN, C. F. (1935). Functions of the frontal association area in primates. Archives of Neurology \& Psychiatry, 33, 558-569.

JACOBSEN, C. F. (1936). Studies of cerebral function in primates: I. The functions of the frontal association area in monkeys. Comparative Psychology Monographs, 13, 1-68.
Janowsky, J. S., Shimamura, A. P., Kritchevsky, M., \& Squire, L. R. (1989). Cognitive impairment following frontal lobe damage and its relevance to human amnesia. Behavioral Neuroscience, 103, 548-560.

Janowsky, J. S., Shimamura, A. P., \& Seuire, L. R. (1989). Source memory impairment in patients with frontal lobe lesions. Neuropsychologia, 27, 1043-1056.

JANSma, J. M., RAmSEY, N. F., Coppola, R. \& Kahn, R. S. (2000). Specific versus nonspecific brain activity in a parametric $n$-back task. NeuroImage, 12, 688-697.

JERSILD, A. T. (1927). Mental set and shift. Archives of Psychology [Whole No. 89].

Jetter, W., Poser, U., Freeman, R. B., Jr., \& Markowitsch, H. J. (1986). A verbal long term memory deficit in frontal lobe damaged patients. Cortex, 22, 229-242.

JHA, A. P., \& McCARThy, G. (2000). The influence of memory load upon delay-interval activity in a working-memory task: An event-related functional MRI study. Journal of Cognitive Neuroscience, 12(Suppl.), 90-105.

Joanette, Y., \& Goulet, P. (1986). Criterion-specific reduction of verbal fluency in right brain-damaged right-handers. Neuropsychologia, 24, 875-879.

Johannsen, P., Jakobsen, J., Bruhn, P., Hansen, S. B., Gee, A., StøDKILDE-Jørgensen, H., \& GJEDDE, A. (1997). Cortical sites of sustained and divided attention in normal elderly humans. NeuroImage, 6, 145-155.

Jones-Gotman, M., \& Milner, B. (1977). Design fluency: The invention of nonsense drawings after focal cortical lesions. Neuropsychologia, 15, 653-674.

Jonides, J., Marshuetz, C., Smith, E. E., Reuter-Lorenz, P. A., \& Koepre, R. A. (2000). Age differences in behavior and PET activation reveal differences in interference resolution in verbal working memory. Journal of Cognitive Neuroscience, 12, 188-196.

Jonides, J., Reuter-Lorenz, P. A., Smith, E. E., Awh, E., Barnes, L. L., Drain, M., Glass, J., Lauber, E J., Patalano, A. L., \& Schumacher, E. H. (1996). Verbal and spatial working memory in humans. Psychology of Learning \& Motivation, 35, 43-88.

Jonides, J., Schumacher, E. H., Smith, E. E., Lauber, E. J., Awh, E., Minoshima, S., \& Koeppe, R. A. (1997). Verbal working memory load affects regional brain activation as measured by PET. Journal of Cognitive Neuroscience, 9, 462-475.

Jonides, J., Smith, E. E., Koeppe, R. A., Awh, E., Minoshima, S., \& Mintun, M. A. (1993). Spatial working memory in humans as revealed by PET. Nature, 363, 623-625.

Jonides, J., Smith, E. E., Marshuetz, C., \& Koeppe, R. A. (1998). Inhibition in verbal-working memory revealed by brain activation. Proceedings of the National Academy of Sciences, 95, 8410-8413.

JuRdEN, F. H. (1995). Individual differences in working memory and complex cognition. Journal of Educational Psychology, 87, 93-102.

Kahneman, D., Ben-Ishai, R, \& Lotan, M. (1973). Relation of a test of attention to road accidents. Journal of Applied Psychology, 58, 113-115.

KAIL, R, \& HALL, L. K. (2001). Distinguishing short-term memory from working memory. Memory \& Cognition, 29, 1-9.

Kane, M. J., Bleckley, M. K., Conway, A. R. A., \& Engle, R. W. (2001). A controlled-attention view of working-memory capacity. Journal of Experimental Psychology: General, 130, 169-183.

KANE, M. J., \& ENGLE, R. W. (2000). Working memory capacity, proactive interference, and divided attention: Limits on long-term memory retrieval. Journal of Experimental Psychology: Learning, Memory, \& Cognition, 26, 333-358.

KANE, M. J., \& ENGLE, R. W. (in press). Working-memory capacity and the control of attention: The contributions of goal neglect, response competition, and task set to Stroop interference. Journal of Experimental Psychology: General.

Kane, M. J., Peterman, M., Bleckley, M. K., \& Engle, R. W. (2002). The attentional and intellectual demands of verbal and figural fluency: A dual-task approach. Unpublished manuscript.

Kane, M. J., Sanchez, A., \& Engle, R. W. (1999, November). Working memory capacity, intelligence, and goal neglect in the Stroop task. Poster presented at the annual meeting of the Psychonomic Society, Los Angeles. 
Kikuchi-Yorioka, Y., \& Sawaguchi, T. (2000). Parallel visuospatial and audiospatial working memory processes in the monkey dorsolateral prefrontal cortex. Nature Neuroscience, 3, 1075-1076.

Kimberg, D. Y., Aguirre, G. K., \& D'Esposito, M. (2000). Modulation of task-related neural activity in task-switching: An fMRI study. Cognitive Brain Research, 10, 189-196.

Kimberg, D. Y., D'Esposito, M., \& FARAh, J. (1997). Effects of bromocriptine on human subjects depend on working memory capacity. Cognitive Neuroscience, 8, 3581-3585.

KimberG, D. Y., \& FARAH, M. J. (1993). A unified account of cognitive impairments following frontal lobe damage: The role of working memory in complex, organized behavior. Journal of Experimental Psychology: General, 4, 411-428.

Kindt, M., Bierman, D., \& Brosschot, J. F. (1996). Stroop versus Stroop: Comparison of a card format and a single-trial format of the standard color-word Stroop task and the emotional Stroop task. Personality \& Individual Differences, 21, 653-661.

Kirchner, W. K. (1958). Age differences in short-term retention of rapidly changing information. Journal of Experimental Psychology, $\mathbf{5 5}, 352-358$.

KLEIN, K., \& Fiss, W. H. (1999). The reliability and stability of the Turner and Engle working memory task. Behavior Research Methods, Instruments, \& Computers, 31, 429-432.

KLINGBerg, T. (1998). Concurrent performance of two working memory tasks: Potential mechanisms of interference. Cerebral Cortex, $\mathbf{8}$, 593-601.

KNIGHT, R. T. (1991). Evoked potential studies of attention capacity in human frontal lobe lesions. In H. S. Levin, H. M. Eisenberg, \& A. L. Benton (Eds.), Frontal lobe function and dysfunction (pp. 139-153). Oxford: Oxford University Press.

Knight, R. T., \& Grabowecky, M. (1995). Escape from linear time: Prefrontal cortex and conscious experience. In M. S. Gazzaniga (Ed.), The cognitive neurosciences (pp. 1357-1371). Cambridge, MA: MIT Press.

Knight, R. T., Hillyard, S. A., Woods, D. L., \& Neville, S. J. (1981). The effects of frontal cortex lesions on event-related potentials during auditory selective attention. Electroencephalography \& Clinical Neurophysiology, 52, 571-582.

Knight, R. T., Scabini, D., \& Woods, D. L. (1989). Prefrontal cortex gating of auditory transmission in humans. Brain Research, 504, 338342 .

Knight, R. T., Staines, W. R., Swick, D., \& Chao, L. L. (1999). Prefrontal cortex regulates inhibition and excitation in distributed neural networks. Acta Psychologica, 101, 159-178.

Koch, K. W., \& Fuster, J. M. (1989). Unit activity in monkey parietal cortex related to haptic perception and temporary memory. Experimental Brain Research, 76, 292-306.

KoJIma, S., \& Goldman-RAKIC, P. S. (1982). Delay-related activity of prefrontal neurons in rhesus monkeys performing delayed response. Brain Research, 248, 43-49.

KoJIma, S., \& Goldman-RAKIC, P. S. (1984). Functional analysis of spatially discriminative neurons in prefrontal cortex of rhesus monkey. Brain Research, 291, 229-240.

Kubota, K., \& NiKi, H. (1971). Prefrontal cortical unit activity and delayed alternation performance in monkeys. Journal of Neurophysiology, 34, 337-347.

Kubota, K., Tonoike, M., \& Mikami, A. (1980). Neuronal activity in the monkey dorsolateral prefrontal cortex during a discrimination task with delay. Brain Research, 183, 29-42.

Kyllonen, P. C. (1993). Aptitude testing inspired by information processing: A test of the four-sources model. Journal of General Psychology, 120, 375-405.

KY LLONEN, P. C. (1996). Is working memory capacity Spearman's $g$ ? In I. Dennis \& P. Tapsfield (Eds.), Human abilities: Their nature and measurement (pp. 49-75). Mahwah, NJ: Erlbaum.

Ky llonen, P. C., \& Christal, R. E. (1990). Reasoning ability is (little more than) working-memory capacity?! Intelligence, 14, 389-433.

Laiacona, M., De Santis, A., Barbaratto, R., Basso, A., Spagnoli, D., \& CAPITANi, E. (1989). Neuropsychological follow-up of patients operated for aneurysms of anterior communicating artery. Cortex, $\mathbf{2 5}$, 261-273.
Larson, G. E., \& Perry, Z A. (1999). Visual capture and human error. Applied Cognitive Psychology, 13, 227-236.

LARSON, G. E., \& SAccuzzo, D. P. (1989). Cognitive correlates of general intelligence: Toward a process theory of $g$. Intelligence, 13, 5-31.

LaW, D. J., Morrin, K. A., \& Pellegrino, J. W. (1995). Training effects and working memory contributions to skill acquisition in a complex coordination task. Learning \& Individual Differences, 7, 207 234.

Lee, S. L., Wild, K., Hollnagel, C., \& Grafman, J. (1999). Selective visual attention in patients with frontal lobe lesions or Parkinson's disease. Neuropsychologia, 37, 595-604.

Lehto, J. (1996). Are executive function tests dependent on working memory capacity? Quarterly Journal of Experimental Psychology, 49A, 29-50.

LeZAK, M. D. (1983). Neuropsychological assessment. New York: Oxford University Press.

Los, S. A. (1999). Identifying stimuli of different perceptual categories in pure and mixed blocks of trials: Evidence for stimulus-driven switch costs. Acta Psychologica, 103, 173-205.

Luciana, M., Depue, R. A., Arbisi, P., \& Leon, A. (1992). Facilitation of working memory in humans by a $\mathrm{D}_{2}$ dopamine receptor agonist. Journal of Cognitive Neuroscience, 4, 58-68.

LURIA, A. R. (1966). Higher cortical functions in man. New York: Basic Books.

LuRIA, A. R. (1971). Memory disturbances in local brain lesions. Neuropsychologia, 9, 367-375.

Luria, A. R. Karpov, B. A., \& Yarbuss, A. L. (1966). Disturbances of active visual perception with lesions of the frontal lobes. Cortex, $\mathbf{2}$, 202-212.

Luria, A. R. Pribram, K. H., \& Homskaya, E. D. (1964). An experimental analysis of the behavioral disturbance produced by a left frontal arachnoidal endothelioma (meningioma). Neuropsychologia, 2, 257-280.

MacDonald, A. W., Cohen, J. D., Stenger, V. A., \& Carter, C. S. (2000). Dissociating the role of the dorsolateral prefrontal and anterior cingulate cortex in cognitive control. Science, 288, 1835-1838.

Mackworth, J. F. (1959). Paced memorizing in a continuous task. Journal of Experimental Psychology, 58, 206-211.

MacLeod, C. M. (1991). Half a century of research on the Stroop effect: An integrative review. Psychological Bulletin, 109, 163-203.

MacLeod, C. M., \& MacDonald, P. A. (2000). Interdimensional interference in the Stroop effect: Uncovering the cognitive and neural anatomy of attention. Trends in Cognitive Sciences, 4, 383-391.

Malmo, R. B. (1942). Interference factors in delayed response in monkeys after removal of frontal lobes. Journal of Neurophysiology, $\mathbf{5}$, 295-308.

Martinkauppi, S., Rämä, P., Aronen, H. J., Korvenoja, A., \& CarlSON, S. (2000). Working memory of auditory localization. Cerebral Cortex, 10, 889-898.

Mayr, U., \& Keele, S. W. (2000). Changing internal constraints on action: The role of backward inhibition. Journal of Experimental Psychology: General, 129, 4-26.

McCARTHY, G. (1995). Functional neuroimaging of memory. The Neuroscientist, 1, 155-163.

McCarthy, G., Blamire, A. M., Puce, A., Nobre, A. C., Bloch, G., Hyder, F., Goldman-Rakic, P. S., \& Shulman, R. G. (1994). Functional magnetic resonance imaging of human prefrontal cortex activation during a spatial working memory task. Proceedings of the $\mathrm{Na}$ tional Academy of Sciences, 91, 8690-8694.

McCarthy, G., Puce, A., Constable, R. T., Krystal, J. H., Gore, J. C., \& Goldman-Rakic, P. S. (1996). Activation of human prefrontal cortex during spatial and nonspatial working memory tasks measured by functional MRI. Cerebral Cortex, 6, 600-611.

McIntosh, A. R., Grady, C. L., Haxby, J. V., Ungerleider, L. G., \& Horwitz, B. (1996). Changes in limbic and prefrontal functional interactions in a working memory task for faces. Cerebral Cortex, 6, 571584.

McKenna, F. P., Duncan, J., \& Brown, I. D. (1986). Cognitive abilities and safety on the road: A re-examination of individual differences in dichotic listening and search for embedded figures. $\mathrm{Er}$ gonomics, 29, 649-663. 
Meiran, N. (1996). Reconfiguration of processing mode prior to task performance. Journal of Experimental Psychology: Learning, Memory, \& Cognition, 22, 1423-1442.

Mesulam, M. M. (1981). A cortical network for directed attention and unilateral neglect. Annals of Neurology, 10, 309-325.

Metz, J. T., Yasillo, N. J., \& Cooper, M. (1987). Relationship between cognitive functioning and cerebral metabolism. Journal of Cerebral Blood Flow \& Metabolism, 7(Suppl. 1), S305.

Miceli, G., Caltagirone, C., Gainotti, G., Masullo, C., \& Silveri, M. C. (1981). Neuropsychological correlates of localized cerebral lesions in non-aphasic brain-damaged patients. Journal of Clinical Neuropsychology, 3, 53-63.

Miller, E. (1984). Verbal fluency as a function of a measure of verbal intelligence and in relation to different types of cerebral pathology. British Journal of Clinical Psychology, 23, 53-57.

Miller, E. K. (2000). The prefrontal cortex: No simple matter. NeuroImage, 11, 447-450.

Miller, E. K., \& Cohen, J. D. (2001). An integrative theory of prefrontal cortex function. Annual Review of Neuroscience, 24, 167-202.

Miller, E. K., \& Desimone, R. (1994). Parallel neuronal mechanisms for short-term memory. Science, 263, 520-522.

Miller, E. K., Erickson, C. A., \& Desimone, R. (1996). Neural mechanisms of visual working memory in prefrontal cortex of the macaque. Journal of Neuroscience, 16, 5154-5167.

Miller, E. K., Li, L., \& Desimone, R. (1993). Activity of neurons in anterior inferior temporal cortex during a short-term memory task. Journal of Neuroscience, 13, 1460-1478.

Miller, G. A. (1956). The magical number seven, plus or minus two: Some limits on our capacity for processing information. Psychological Review, 63, 81-97.

Milner, B. (1963). Effects of different brain lesions on card sorting. Archives of Neurology, 9, 90-100.

Milner, B. (1964). Some effects of frontal lobectomy in man. In J. M. Warren \& K. Akert (Eds.), The frontal granular cortex and behavior (pp. 313-334). New York: McGraw-Hill.

Mishkin, M., \& Manning, F. J. (1978). Non-spatial memory after selective prefrontal lesions in monkeys. Brain Research, 143, 313-323.

Mishrin, M., \& Pribram, K. H. (1955). Analysis of the effects of frontal lesions in monkey: I. Variations of delayed alternation. Journal of Comparative \& Physiological Psychology, 48, 492-495.

Mishrin, M., \& Pribram, K. H. (1956). Analysis of the effects of frontal lesions in monkey: II. Variations of delayed response. Journal of Comparative \& Physiological Psychology, 49, 36-45.

Mishkin, M., Ungerleider,L. G., \& MAcko, K. A. (1983). Object vision and spatial vision: Two cortical pathways. Trends in Neurosciences, 6, 414-417.

Miyake, A., Friedman, N. P., Emerson, M. J., Witzki, A. H., \& HowERTER, A. (2000). The unity and diversity of executive functions and their contributions to complex "frontal lobe" tasks: A latent variable analysis. Cognitive Psychology.

Moscovitch, M. (1994). Cognitive resources and dual-task interference effects at retrieval in normal people: The role of the frontal lobes and medial temporal cortex. Neuropsychology, 8, 524-534.

Mountain, M. A., \& SNow, W. G. (1993). Wisconsin Card Sorting Test as a measure of frontal pathology: A review. The Clinical Neuropsychologist, 7, 108-118.

Nagahama, Y., Fukuyama, H., Yamauchi, H., Matsuzaki, S., KonISHI, J., ShibASAKI, H., \& KimURA, J. (1996). Cerebral activation during performance of a card sorting test. Brain, 119, 1667-1675.

Nagahama, Y., Okada, T., Katsumi, Y., Hayashi, T., Yamauchi, H., Sawamoto, N., Toma, K., Nakamura, K., Hanakawa, T., Konishi, J., Fuy ukama, H., \& Shibasaki, H. (1999). Transient neural activity in the medial superior frontal gyrus and precuneus time locked with attention shift between object features. NeuroImage, 10, 193-199.

Nagahama, Y., Sadato, N., Yamauchi, H., Katsumi, Y., Hayashi, T., FukuYama, H., Kimura, J., ShibasaKi, H., \& Yonekura, Y. (1998). Neural activity during attention shifts between object features. NeuroReport, 9, 2633-2638.

NaUtA, W. J. H. (1964). Some efferent connections of the prefrontal cortex in the monkey. In J. M. Warren \& K. Akert (Eds.), The frontal granular cortex and behavior (pp. 397-407). New York: McGrawHill.
Nauta, W. J. H. (1972). Neural associations of the frontal cortex. Acta Neurobiologiae Experimentalis, 32, 125-140.

Nelson, H. E. (1976). A modified card sorting test sensitive to frontal lobe defects. Cortex, 12, 313-324.

Newcombe, F. (1969). Missile wounds of the brain: A study of psychological deficits. Oxford: Oxford University Press.

NIKI, H. (1974a). Differential activity of prefrontal units during right and left delayed response. Brain Research, 70, 346-349.

NIKI, H. (1974b). Prefrontal unit activity during delayed alternation in the monkey: I. Relation to the direction of response. Brain Research, 68, 185-196.

NIKI, H. (1974c). Prefrontal unit activity during delayed alternation in the monkey: II. Relation to absolute versus relative direction of response. Brain Research, 68, 197-204.

Niki, H., \& Watanabe, M. (1976). Prefrontal unit activity and delayed response: Relation to cue location versus direction of response. Brain Research, 105, 79-88.

Norman, D. A., \& Shallice, T. (1986). Attention to action: Willed and automatic control of behavior. In R. J. Davidson, G. E. Schwartz, \& D. Shapiro (Eds.), Consciousness and self-regulation: Advances in research and theory (Vol. 4, pp. 1-18). New York: Plenum.

Nyström, L. E., Braver, T. S., Sabb, F. W., Delgado, M. R., Noll, D. C., \& Cohen, J. D. (2000). Working memory for letters, shapes, and localizations: fMRI evidence against stimulus-based regional organization in human prefrontal cortex. NeuroImage, 11, 424-446.

O’ ReIlly, R. C., BraVer, T. S., \& CoHen, J. D. (1997, July). A biologicallybased computational model of working memory. Paper presented at the Models of Working Memory Symposium, Boulder, CO.

O’Reilly, R. C., Braver, T. S., \& Cohen, J. D. (1999). A biologicallybased computational model of working memory. In A. Miyake \& P. Shah (Eds.), Models of working memory: Mechanisms of active maintenance and executive control (pp. 375-411). New York: Cambridge University Press.

Oscar-Berman, M. (1975). The effects of dorsolateral-frontal and ventrolateral-frontal lesions on spatial discrimination learning and delayed response in two modalities. Neuropsychologia, 13, 237-246.

Owen, A. M. (1997). The functional organization of working memory processes within human lateral frontal cortex: The contribution of functional neuroimaging. European Journal of Neuroscience, 9, 1329-1339.

Owen, A. M., Downes, J. J., Sahakian, B. J., Polkey, C. E., \& RobBINS, T. W. (1990). Planning and spatial working memory following frontal lobe lesions in man. Neuropsychologia, 28, 1021-1034.

Owen, A. M., Evans, A. C., \& Petrides, M. (1996). Evidence for a two-stage model of spatial working memory processing within the lateral frontal cortex: A positron emission tomography study. Cerebral Cortex, 6, 31-38.

Owen, A. M., Roberts, A. C., Hodges, J. R., Summers, B. A., Polkey, C. E., \& Robbins, T. W. (1993). Contrasting mechanisms of impaired attentional set-shifting in patients with frontal lobe damage or Parkinson's disease. Brain, 116, 1159-1175.

Owen, A. M., Roberts, A. C., Polkey, C. E., Sahakian, B. J., \& RobBINS, T. W. (1991). Extra-dimensional versus intra-dimensional set shifting performance following frontal lobe excisions, temporal lobe excisions or amygdalo-hippocampectomy in man. Neuropsychologia, 29, 993-1006.

Pandy A, D. N., \& Barnes, D. L. (1987). Architecture and connections of the frontal lobe. In E. Perecman (Ed.), The frontal lobes revisited (pp. 41-72). New York: IRBN Press.

Pandya, D. N., \& Yeterian, E. H. (1990). Prefrontal cortex in relation to other cortical areas in rhesus monkey: Architecture and connections. Progress in Brain Research, 85, 63-93.

Pandya, D. N., \& Yeterian, E. H. (1999). Comparison of prefrontal architecture and connections. In A. C. Roberts, T. W. Robbins, \& L. Weiskrantz (Eds.), The prefrontal cortex: Executive and cognitive functions (pp. 51-66). Oxford: Oxford University Press.

Parasuraman, R. (1998). The attentive brain. Cambridge, MA: MIT Press.

Pardo, J. V., Pardo, P. J., Janer, K. W., \& Raichle, M. E. (1990). The anterior cingulate cortex mediates processing selection in the Stroop attentional conflict paradigm. Proceedings of the National Academy of Sciences, 87, 256-259. 
Parkin, A. J., Bindschaedler, C., Harsent, L., \& Metzler, C. (1996). Pathological false alarm rates following damage to the left frontal cortex. Brain \& Cognition, 32, 14-27.

Parkin, A. J., Leng, N. R. C., \& Stanhope, N. (1988). Memory impairment following ruptured aneurysm of the anterior communicating artery. Brain \& Cognition, 7, 231-243.

Parks, R. W., Loewenstein, D. A., Dodrill, K. L., Barker, W. W., Yoshit, F., Chang, J. Y., Emran, A., Apicella, A., Sheramata, W. A., \& DuARA, R. (1988). Cerebral metabolic effects of a verbal fluency test: A PET scan study. Journal of Clinical \& Experimental Neuropsychology, 10, 565-575.

Passingham, R. E. (1975). Delayed matching after selective prefrontal lesions in monkeys. Brain Research, 92, 89-102.

Pati, P., \& DAsh, A. S. (1990). Interrelationships between incidental memory, non-verbal intelligence and Stroop scores. Psycho-Lingua, 20, 27-31.

Paus, T., Kalina, M., Patockova, L., Angerova, Y., Cerny, R., Mecir, P., Bauer, J., \& Krabec, P. (1991). Medial vs lateral frontal lobe lesions and differential impairment of central-gaze fixation maintenance in man. Brain, 114, 2051-2067.

Pavlov, I. P. (1941). Conditioned reflexes and psychiatry (Vol. 2; W. H. Gantt, Trans.). New York: International Publishers.

Pendleton, M. G., Heaton, R. K., Lehman, R. A., \& Hulihan, D. (1982). Diagnostic utility of the Thurstone Word Fluency Test in neuropsychological evaluations. Journal of Clinical Neuropsychology, 4, 307-317.

Pennington, B. F. (1994). The working memory function of the prefrontal cortices. In M. M. Haith, J. B. Bensen, R. J. Roberts, \& B. F. Pennington (Eds.), The development of future-oriented processes. Chicago: University of Chicago Press.

Perret. E. (1974). The left frontal lobe of man and the suppression of habitual responses in verbal categorical behavior. Neuropsychologia, 12, 323-330.

Petrides, M. (1985). Deficits on conditional associative-learning tasks after frontal- and temporal-lobe lesions in man. Neuropsychologia, 23, 601-614.

Petrides, M. (1989). Frontal lobes and memory. In F. Boller \& J. Grafman (Eds.), Handbookofneuropsychology (Vol. 3, pp. 75-90). Amsterdam: Elsevier.

Petrides, M. (1990). Nonspatial conditional learning impaired in patients with unilateral frontal but not unilateral temporal lobe excisions. Neuropsychologia, 28, 137-149.

Petrides, M. (1995). Impairments in non-spatial self-ordered and externally ordered working memory tasks after lesions of the mid-dorsal part of the lateral frontal cortex in the monkey. Journal of Neuroscience, 15, 359-375.

Petrides, M., Alivisatos, B., Meyer, E., \& Evans, A. C. (1993). Functional activation of the human frontal cortex during the performance of verbal working memory tasks. Proceedings of the National Academy of Sciences, 90, 878-882.

Petrides, M., \& Milner, B. (1982). Deficits on subject-ordered tasks after frontal- and temporal-lobe lesions in man. Neuropsychologia, 20, 249-262.

Petrides, M., \& Pandya, D. N. (1994). Comparative architectonic analysis of the human and macaque frontal cortex. In F. Boller \& J. Grafman (Eds.), Handbookofneuropsychology (Vol. 9, pp. 17-58). Amsterdam: Elsevier.

Pfefferbaum, A., Desmond, J. E., Galloway, C., Menon, V., Glover, G. H., \& Sullivan, E. V. (2001). Reorganization of frontal systems used by alcoholics for spatial working memory: An fMRI study. NeuroImage, 14, 7-20.

Phillips, L. H. (1997). Do "frontal tests" measure executive function? Issues of assessment and evidence from fluency tests. In P. Rabbitt (Ed.), Methodology of frontal and executive function (pp. 191-213). Hove, U.K.: Psychology Press.

Phillips, L. H. (1999). Age and individual differences in letter fluency. Developmental Neuropsychology, 15, 249-267.

Pierrot-Deseilligny, C., Rivaud, S., Gaymard, B., \& Agid, Y. (1991). Cortical control of reflexive visually-guided saccades. Brain, 114, 1473-1485.
PoHL, W. (1973). Dissociation of spatial discrimination deficits following frontal and parietal lesions in monkeys. Journal of Comparative \& Physiological Psychology, 82, 227-239.

Pollmann, S. (2001). Switching between dimensions, locations, and responses: The role of left frontopolarcortex. NeuroImage, 14, S118S124.

Posner, M. I. (1988). Structures and functions of selective attention. In T. Boll \& B. Bryant (Eds.), Clinical neuropsychology and brain function: Research, measurement, and practice. Washington, DC: American Psychological Association.

Posner, M. I., \& Peterson, S. E. (1990). The attention system of the human brain. Annual Review of Neuroscience, 13, 25-42.

Posner, M. I., \& Raichle, M. E. (1994). Images of mind. New York: Freeman.

Postle, B. R., Berger, J. S., \& D'Esposito, M. (1999). Functional neuroanatomical double dissociation of mnemonic and executive control processes contributing to working memory performance. Proceedings of the National Academy of Sciences, 96, 12959-12964.

Postle, B. R., Berger, J. S., TAich, A. M., \& D'Esposito, M. (2000). Activity in human frontal cortex associated with spatial working memory and saccadic behavior. Journal of Cognitive Neuroscience, 12(Suppl.), 2-14.

Postle, B. R., \& D'Esposito, M. (1999). "What"-then-“where" in visual working memory: An event-related fMRI study. Journal of Cognitive Neuroscience, 11, 585-597.

Postle, B. R., \& D'Esposito, M. (2000). Evaluating models of the topographical organization of working memory function in frontal cortex with event-related fMRI. Psychobiology, 28, 132-145.

Postle, B. R., Stern, C. E., Rosen, B. R., \& Corkin, S. (2000). An fMRI investigation of cortical contributions to spatial and nonspatial visual working memory. NeuroImage, 11, 409-423.

Prabhakaran, V., Narayanan, K., Zhao, Z., \& Gabrieli, J. D. E. (2000). Integration of diverse information in working memory within the frontal lobe. Nature Neuroscience, 3, 85-90.

Prabhakaran, V., Rypma, B., \& Gabrieli, J. D. E. (2001). Neural substrates of mathematical reasoning: A functional magnetic resonance imaging study of neocortical activation during performance of the Necessary Arithmetic Operations Test. Neuropsychology, 15, 115-127.

Prabhakaran, V., Smith, J. A. L., Desmond, J. E., Glover, G. H., \& Gabrieli, J. D. E. (1997). Neural substrates of fluid reasoning: An fMRI study of neocortical activation during performance of the Raven's Progressive Matrices Test. Journal of Cognitive Psychology, 33, 43-63.

Pribram, K. H., \& Mishrin, M. (1956). Analysis of the effects of frontal lesions in monkey: III. Object alternation. Journal of Comparative \& Physiological Psychology, 49, 41-45.

Ptito, A., Crane, J., Leonard, G., Amsel, R., \& Caramanos, Z. (1995). Visual-spatial localization by patients with frontal-lobe lesions invading or sparing area 46. NeuroReport, 6, 1781-1784.

Quintana, J., \& Fuster, J. M. (1993). Spatial and temporal factors in the role of prefrontal and parietal cortex in visuomotor integration. Cerebral Cortex, 3, 122-132.

Quintana, J., Yajeya, J., \& Fuster, J. M. (1988). Prefrontal representation of stimulus attributes during delay tasks: I. Unit activity in cross-temporal integration of sensory and sensory-motor information. Brain Research, 474, 211-222.

Rafal, R., Gershberg, F., Egly, R., Ivry, R., Kingstone, A., \& Ro, T. (1996). Response channel activation and the lateral prefrontal cortex. Neuropsychologia, 34, 1197-1202.

Ragland, J. D., Gur, R. C., Glahn, D. C., Censits, D. M., Smith, R. J., Lazarev, M. G., Alavi, A., \& Gur, R. E. (1998). Frontotemporal cerebral blood flow change during executive and declarative memory tasks with schizophrenia: A positron emission tomography study. Neuropsychology, 12, 399-413.

RAICHLE, M. E. (1994). Images of the mind: Studies with modern imaging techniques. Annual Review of Psychology, 45, 333-356.

Rainer, G., AsaAd, W. F., \& Miller, E. K. (1998). Selective representation of relevant information by neurons in the primate prefrontal cortex. Nature, 393, 577-579.

Ramier, A. M., \& Hecaen, H. (1970). Role respectif des atteintes 
frontales et de la lateralisation lesionnelle dans les deficits de la "fluence verbal" [Respective role of frontal injuries and lesion lateralization in "verbal-fluency" deficits]. Revue Neurologique, 123, 2-22.

RaO, S. C., Rainer, G., \& Miller, E. K. (1997). Integration of what and where in the primate prefrontal cortex. Science, 276, 821-824.

Raz, N., Briggs, S. D., Marks, W., \& Acker, J. D. (1999). Age-related deficits in generation and manipulation of mental images: II. The role of dorsolateral prefrontal cortex. Psychology \& Aging, 14, 436-444.

Reitan, R. M., \& Wolfson, D. (1994). A selective and critical review of neuropsychological deficits and the frontal lobes. Neuropsychology Review, 4, 161-197.

Richer, F., Decary, A., Lapierre, M. F., Rouleau, I., Bouvier, G., \& Saint-Hilaire, J. M. (1993). Target detection deficits in frontal lobectomy. Brain \& Cognition, 21, 203-211.

Risberg, J., \& IngVAR, D. H. (1973). Patterns of activation in the grey matter of the dominant hemisphere during memorizing and reasoning. Brain, 96, 737-756.

Risberg, J., Maximilian, A. V., \& Prohovnik, I. (1977). Changes of cortical activity patterns during habituation to a reasoning test. Neuropsychologia, 15, 793-798.

Roberts, A. C., Robbins, T. W., \& Weiskrantz, L. (1998). The prefrontal cortex: Executive and cognitive functions. Oxford: Oxford University Press.

Roberts, R. J., Jr., Hager, L. D., \& Heron, C. (1994). Prefrontal cognitive processes: Working memory and inhibition in the antisaccade task. Journal of Experimental Psychology: General, 123, 374-393.

Roberts, R. J., Jr., \& Pennington, B. F. (1996). An interactive framework for examining prefrontal cognitive processes. Developmental Neuropsychology, 12, 105-126.

Rogers, R. D., Andrews, T. C., Grasby, P. M., Brooks, D. J., \& RobBINS, T. W. (2000). Contrasting cortical and subcortical activations produced by attentional-set shifting and reversal learning in humans. Journal of Cognitive Neuroscience, 12, 142-162.

Rogers, R. D., \& Monsell, S. (1995). The cost of a predictable switch between simple cognitive tasks. Journal of Experimental Psychology: General, 124, 207-231.

Rogers, R. D., Sahakian, B. J., Hodges, J. R., Polkey, C. E., KenNARD, C., \& RobBins, T. W. (1998). Dissociating executive mechanisms of task control following frontal lobe damage and Parkinson's disease. Brain, 121, 815-842.

Romo, R, Brody, C. D., Hernández, A., \& Lemus, L. (1999). Neuronal correlates of parametric working memory in the prefrontal cortex. Nature, 399, 470-473.

Rosen, V. M., \& ENGLe, R. W. (1997). The role of working memory capacity in retrieval. Journal of Experimental Psychology: General, 126, 211-227.

Rosen, V. M., \& Engle, R. W. (1998). Working memory capacity and suppression. Journal of Memory \& Language, 39, 418-436.

Rosenkilde, C. E. (1979). Functional heterogeneity of the prefrontal cortex in the monkey: A review. Behavioral \& Neural Biology, 25, 301-345.

Rosenkilde, C. E., Bauer, R. H., \& Fuster, J. M. (1981). Single cell activity in ventral prefrontal cortex of behaving monkeys. Brain Research, 209, 375-394.

Rosvold, H. E., \& Delgado, J. M. R. (1956). The effect on delayed alternation test performance of stimulating or destroying electrically structures within the frontal lobes of the monkey's brain. Journal of Comparative \& Physiological Psychology, 49, 365-372.

Rowe, J. B., Toni, I., Josephs, O., Frackowiak, R. S. J., \& Passingham, R. E. (2000). The prefrontal cortex: Response selection or maintenance within working memory? Science, 288, 1656-1660.

Rylander, G. (1939). Personality changes after operations on the frontal lobes. Copenhagen: Munksgaard.

Ry PMA, B., \& D'EsPosito, M. (1999). The roles of prefrontal brain regions in components of working memory: Effects of memory load and individual differences. Proceedings of the National Academy of Sciences, 96, 6558-6563.

Rypma, B., Prabhakaran, V., Desmond, J. E., Glover, G. H., \& Gabrieli, J. D. E. (1999). Load-dependent roles of frontal brain regions in the maintenance of working memory. NeuroImage, 9, 216226.
Salmon, D. P., \& D’Amato, M. R. (1981). Note on delay-interval illumination effects on retention in monkeys (Cebus apella). Journal of the Experimental Analysis of Behavior, 36, 381-385.

Sarter, M., Bernston, G. G., \& Cacioppo, J. T. (1996). Brain imaging and cognitive neuroscience: Toward strong inference in attributing function to structure. American Psychologist, 51, 13-21.

Schumacher, E. H., Lauber, E., Awh, E., Jonides, J., Smith, E. E., \& Koeppe, R. A. (1996). PET evidence for an amodal verbal working memory system. NeuroImage, 3, 79-88.

Seidman, L. J., Breiter, H. C., Goodman, J. M., Goldstein, J. M., Woodruff, P. W. R., O'Craven, K., Savoy, R., Tsuang, M. T., \& Rosen, B. R. (1998). A functional magnetic resonance imaging study of auditory vigilance with low and high information processing demands. Neuropsychology, 12, 505-518.

Sergent, J. (1994). Brain-imaging studies of cognitive functions. Trends in Neurosciences, 17, 221-227.

Settlage, P., Zable, M., \& Harlow, H. F. (1948). Problem solution by monkeys following bilateral removal of the prefrontal areas: VI. Performance on tests requiring contradictory reactions to similar and to identical stimuli. Journal of Experimental Psychology, 38, 50-65.

Shah, P., \& Miyake, A. (1996). The separability of working memory resources for spatial thinking and language processing: An individual differences approach. Journal of Experimental Psychology: General, 125, 4-27.

Shallice, T. (1988). From neuropsychology to mental structure. Cambridge: Cambridge University Press.

Shallice, T., \& Burgess, P. W. (1991a). Deficits in strategy application following frontal lobe damage in man. Brain, 114, 727-741.

Shallice, T., \& Burgess, P. W. (1991b). Higher-order cognitive impairments and frontal lobe lesions in man. In H. S. Levin, H. M. Eisenberg, \& A. L. Benton (Eds.), Frontal lobe function and dysfunction (pp. 125-138). Oxford: Oxford University Press.

Shimamura, A. P. (2000). The role of the prefrontal cortex in dynamic filtering. Psychobiology, 28, 207-218.

Shimamura, A. P., Janowsky, J. S., \& Squire, L. R. (1990). Memory for the temporal order of events in patients with frontal lobe lesions and amnesic patients. Neuropsychologia, 28, 803-813.

Shimamura, A. P., Jurica, P. J., Mangels, J. A., Gershberg, F. B., \& KNIGHT, R. T. (1995). Susceptibility to memory interference effects following frontal lobe damage: Findings from tests of paired-associate learning. Journal of Cognitive Neuroscience, 7, 144-152.

Shindy, W. W., Posley, K. A., \& Fuster, J. M. (1994). Reversible deficit in haptic delay tasks from cooling prefrontal cortex. Cerebral Cortex, 4, 443-450.

Simkins-Bullock, J., Brown, G. G., Greiffenstein, M., Malik, G. M., \& McGillicudd, J. (1994). Neuropsychological correlates of shortterm memory distractor tasks among patients with surgical repair of anterior communicating artery aneurysms. Neuropsychology, 8, 246-254.

Skinner, J. E., \& Yingling, C. D. (1977). Central gating mechanisms that regulate event-related potentials and behavior. Progress in Clinical Neurophysiology, 1, 30-69.

Smith, E. E, \& Jonides, J. (1997). Working memory: A view from neuroimaging. Cognitive Psychology, 33, 5-42.

Smith, E. E. Jonides, J., \& Koeppe, R. A. (1996). Dissociating verbal and spatial working memory using PET. Cerebral Cortex, 6, 11-20.

Smith, E. E., Jonides, J., Koeppe, R. A., Awh, E., Schumacher, E. H., \& Minoshima, S. (1995). Spatial versus object working memory: PET investigations. Journal of Cognitive Neuroscience, 7, 337-356.

Snow, R. E., Kyllonen, P. C., \& MarshaleK, B. (1984). The topography of ability and learning correlations. In R. J. Sternberg (Ed.), Advances in the psychology of human intelligence (Vol. 2, pp. 47103). Hillsdale, NJ: Erlbaum.

STAмm, J. S. (1961). Electrical stimulation of frontal cortex in monkeys during learning of an alternation task. Journal of Neurophysiology, 24, 414-426.

Stamm, J. S., \& Rosen, S. C. (1973). The locus and crucial time of implication of prefrontal cortex in the delayed response task. In K. H. Pribram \& A. R. Luria (Eds.), Psychophysiology of the frontal lobes (pp. 139-153). New York: Academic Press.

Stankov, L., \& Crawford, J. D. (1993). Ingredients of complexity in fluid intelligence. Learning \& Individual Differences, 5, 73-111. 
Stern, C. E., Owen, A. M., Tracey, I., Look, R. B., Rosen, B. R., \& Petrides, M. (2000). Activity in ventrolateral and mid-dorsolateral prefrontal cortex during nonspatial visual working memory processing: Evidence from functional magnetic resonance imaging. NeuroImage, 11, 392-399.

Stroop, J. R. (1935). Studies of interference in serial verbal reactions. Journal of Experimental Psychology, 18, 643-662.

Stuss, D. T., \& Benson, D. F. (1984). Neuropsychological studies of the frontal lobes. Psychological Bulletin, 95, 3-28.

Stuss, D. T., Floden, D., Alexander, M. P., Levine, B., \& Katz, D. (2001). Stroop performance in focal lesion patients: Dissociation of processes and frontal lobe lesion location. Neuropsychologia, 39, $771-786$.

Stuss, D. T., Levine, B., Alexander, M. P., Hong, J., Palumbo, C., Hamer, L., Murphy, K. J., \& Izukawa, D. (2000). Wisconsin Card Sorting Test performance in patients with focal frontal and posterior brain damage: Effects of lesion location and test structure on separable cognitive processes. Neuropsychologia, 38, 388-402.

Stuss, D. T., Shallice, T., Alexander,M. P., \& Picton, T. W. (1995). A multidisciplinary approach to anterior attentional functions. In J. Grafman, K. J. Holyoak, \& F. Boller (Eds.), Structure and functions of the human prefrontal cortex. (Annals of the New York Academy of Sciences, Vol. 769, pp. 191-211). New York: New York Academy of Sciences.

Süß, H.-M., Oberauer, K., Wittman, W. W., Wilhelm, O., \& Schulze, R. (2002). Working-memory capacity explains reasoning ability and a little bit more. Intelligence, 30, 261-288.

Swartz, B. E., Halgren, E., Fuster, J. M., \& Mandelkern, M. (1994). An 18FDG-PET study of cortical activation during a shortterm visual memory task in humans. NeuroReport, 5, 925-928.

Sweeney, J. A., Mintun, M. A., Kwee, S., Wiseman, M. B., Brown, D. L., Rosenberg, D. R., \& CARL, J. R. (1996). Positron emission tomography study of voluntary saccadic eye movements and spatial working memory. Journal of Neurophysiology, 75, 454-468.

Taylor, S. F., Kornblum, S., Lauber, E. J., Minoshima, S., \& KoEPPE, R. A. (1997). Isolation of specific interference processing in the Stroop task: PET activation studies. NeuroImage, 6, 81-92.

Teuber, H. L., Battersby, W. S., \& Bender, M. B. (1951). Performance of complex visual tasks after cerebral lesions. Journal of Nervous \& Mental Disease, 114, 413-429.

Teuber, H. L., \& Mishrin, M. (1954). Judgment of visual and postural vertical after brain injury. Journal of Psychology, 38, 161-175.

Teuber, H. L., \& Weinstein, S. (1956). Ability to discover hidden figures after cerebral lesions. Archives of Neurology \& Psychiatry, 76, 369-379.

Troyer, A. K., Moscovitch, M., Winocur, G., Alexander, M. P., \& STuss, D. (1998). Clustering and switching on verbal fluency: The effects of focal frontal- and temporal-lobe lesions. Neuropsychologia, 36, 499-504.

Tucha, O., Smely, C., \& Lange, K. W. (1999). Verbal and figural fluency in patients with mass lesions of the left or right frontal lobes. Journal of Clinical \& Experimental Neuropsychology, 21, 229-236.

Tuholski, S. W., Engle, R. W., \& BAYlis, G. C. (2001). Individualdifferences in working memory capacity and enumeration. Memory \& Cognition, 29, 484-492.

Turner, M. L., \& ENGLE, R. W. (1989). Is working memory capacity task dependent? Journal of Memory \& Language, 28, 127-154.

Uhl, F., Franzen, P., Serles, W., Lange, W., Lindinger, G., \& DEECKE, L. (1990). Anterior frontal cortex and the effect of proactive interference in paired associate learning: A DC potential study. Journal of Cognitive Neuroscience, 2, 373-382.

Uhl, F., Podreka, I., \& Deecke, L. (1994). Anterior frontal cortex and the effect of proactive interference in word pair learning-Results of Brain-SPECT. Neuropsychologia, 32, 241-247.

Upton, D., \& CoRCoran, R. (1995). The role of the right temporal lobe in card sorting: A case study. Cortex, 31, 405-409.

VAlentine, E. R. (1975). Performance on two reasoning tasks in relation to intelligence, divergence and interference proneness. British Journal of Educational Psychology, 45, 198-205.
Van der Linden, M., Bruyer, R, Roland, J., \& Schils, J. P. (1993). Proactive interference in patients with amnesia resulting from anterior communicating artery aneurysm. Journal of Clinical \& Experimental Neuropsychology, 15, 525-536.

VAn der Linden, M., Coyette, F., \& Seron, X. (1992). Selective impairment of the "central executive" component of working memory: A single case study. Cognitive Neuropsychology, 9, 301-326.

van Zomeren, A. H., \& Brouwer, W. H. (1994). Clinical neuropsychology of attention. Oxford: Oxford University Press.

Vendrell, P., Junque, C., Pujol, J., Jurado, M. A., Molet, J., \& Grafman, J. (1995). The role of prefrontal regions in the Stroop task. Neuropsychologia, 33, 341-362.

Verin, M., Partiot, A., Pillon, B., Malapani, C., Agid, Y., \& Dubois, B. (1993). Delayed response tasks and prefrontal lesions in man-Evidence for self generated patterns of behaviour with poor environmental modulation. Neuropsychologia, 31, 1379-1396.

Vilk ki, J., Holst, P., Ohman, J., Servo, A., \& Heiskanen, O. (1992). Cognitive test performances related to early and late computed tomography findings after closed-head injury. Journal of Clinical \& Experimental Neuropsychology, 14, 518-532.

Volpe, B. T., \& Hirst, W. (1983). Amnesia following the rupture and repair of an anterior communicating artery aneurysm. Journal of Neurology, Neurosurgery, \& Psychiatry, 46, 704-709.

Walker, R., Husain, M., Hodgson, T. L., Harrison, J., \& Kennard, C. (1998). Saccadic eye movements and working memory deficits following damage to human prefrontal cortex. Neuropsychologia, 36, 1141-1159.

Waltz, J. A., Knowlton, B. J., Holyoak, K. J., Boone, K. B., Mishin, F. S., De Menezes Santos, M., Thomas, C. R, \& Miller, B. L. (1999). A system for relational reasoning in human prefrontal cortex. Psychological Science, 10, 119-125.

Warkentin, S., Nilsson, A., Risberg, J., \& Karlson, S. (1989). Absence of frontal lobe activation in schizophrenia. Journal of Cerebral Blood Flow \& Metabolism, 9(Suppl. 1), S354.

Warrington, E. K., JAMES, M., \& MACIEJEWSKi, C. (1986). The WAIS as a lateralizing and localizing diagnostic instrument: A study of 656 patients with unilateral cerebral lesions. Neuropsychologia, 24, 223-239.

Watanabe, T., \& NiKi, H. (1985). Hippocampal unit activity and delayed response in the monkey. Brain Research, 325, 241-254.

WeIGL, E. (1941). On the psychology of so-called processes of abstraction. Journal of Abnormal \& Social Psychology, 36, 3-33.

Weinberger, D. R., Berman, K. F., \& Zec, R. F. (1986). Physiologic dysfunction of dorsolateral prefrontal cortex in schizophrenia. Archives of General Psychiatry, 43, 114-124.

WEST, R. L. (1996). An application of prefrontal cortex function theory to cognitive aging. Psychological Bulletin, 120, 272-292.

West, R. [L.], \& Alain, C. (1999). Event-related neural activity associated with the Stroop task. Cognitive Brain Research, 8, 157-174.

West, R. [L.], \& Alain, C. (2000a). Effects of task context and fluctuations of attention on neural activity supporting performance of the Stroop task. Brain Research, 873, 102-111.

WEST, R. [L.], \& AlAIN, C. (2000b). Evidence for the transient nature of a neural system supporting goal-directed action. Cerebral Cortex, 10, 748-752.

White, I. M., \& Wise, S. P. (1999). Rule dependent neuronal activity in the prefrontal cortex. Experimental Brain Research, 126, 315-335.

WiCKENS, D. (1970). Encoding categories of words: An empirical approach to memory. Psychological Review, 77, 1-15.

Wilson, F. A. W., O'Scalaidhe, S. P., \& Goldman-Rakic, P. S. (1993). Dissociation of object and spatial processing domains in primate prefrontal cortex. Science, 260, 1955-1958.

WILSON, W. A., JR. (1962). Alternation in normal and frontal monkeys as a function of response and outcome of the previous trial. Journal of Comparative \& Physiological Psychology, 55, 701-704.

Wise, S. P., Murray, E. A, \& Gerfen, C. R. (1996). The frontal cortexbasal ganglia system in primates. Critical Reviews in Neurobiology, 10, 317-356.

Woodrow, H. (1916). The faculty of attention. Journal of Experimental Psychology, 1, 285-318. 
Woods, D. L., \& Knight, R. T. (1986). Electrophysiological evidence of increased distractibility after dorsolateral prefrontal lesions. Neurology, 36, 212-216.

Woods, R. P. (1996). Modeling for intergroup comparisons of imaging data. NeuroImage, 4, S84-S94.

Worsham, R. W., \& D'Amato, M. R. (1973). Ambient light, white noise, and monkey vocalization as sources of interference in visual short-term memory of monkeys. Journal of Experimental Psychology, 99, 99-105.

YACOSYNSKI, G. K., \& DAVIES, L. (1945). An experimental study of the frontal lobes in man. Psychosomatic Medicine, 7, 97-107.

YAMAGUCHI, S., \& KNIGHT, R. T. (1990). Gating of somatosensory inputs by human prefrontal cortex. Brain Research, 521, 281-288.

Yingling, C. D., \& SKInNer, J. E. (1977). Gating of thalamic input to cerebral cortex by nucleus reticularis thalami. In J. E. Desmedt (Ed.), Progress in clinical neurophysiology (Vol. 1, pp. 70-96). Basel: Karger.

Zable, M., \& Harlow, H. F. (1946). The performance of rhesus monkeys on series of object-quality and positional discriminations and discrimination reversals. Journal of Comparative Psychology, 39, 13-23.

ZaKaY, D., \& Block, R. A. (1997). Temporal cognition. Current Directions in Psychological Science, 6, 12-16.

Zatorre, R. J., \& McEntee, W. J. (1983). Semantic encoding deficits in a case of traumatic amnesia. Brain \& Cognition, 2, 331-345.

Zola-Morgan, S., \& Seuire, L. R. (1985). Medial temporal lesions in monkeys impair memory on a variety of tasks sensitive to human amnesia. Behavioral Neuroscience, 99, 22-34.

Zysset, S., Müller, K., Lohman, G., \& von Cramon, D. Y. (2001). Color-word matching Stroop task: Separating interference and response conflict. NeuroImage, 13, 29-36.

\section{NOTES}

1. For example, Engle, Tuholski, et al. (1999) found correlations among individual WM-span tasks ranging between .32 and $.51(M=.43)$, and correlations between the STM and WM-span tasks ranging between .31 and $.43(M=.35)$.

2. See Kane et al. (2001) for a brief discussion of two recent failures to find a relation between WM measures and antisaccade performance (Larson \& Perry, 1999; R. J. Roberts, Hager, \& Heron, 1994).

3 . We recognize that such a caveat may render some claims about PFC functioning unfalsifiable, at least on the basis of data from braininjured patients. However, because we do not present a formal theory here, we are less concerned with testability than with raising potentially important interpretational issues.

4. In several of Baldo and Shimamura's (2000) experimental conditions, patients with PFC damage were impaired relative to healthy controls even on no-delay versions of the tasks, and so it is difficult to infer memory maintenance disturbances here.

5 . In a recent delayed matching-to-sample study using faces as stimuli and delays of 15 and $24 \mathrm{sec}$, substantial delay-period dPFC activity was found, but in both delay conditions the activation peaked 9 to $12 \mathrm{sec}$ into the delay (dropping to quite low levels by the 21 st second in the 24-sec delay condition; Jha \& McCarthy, 2000).

6. In a spatial matching-to-sample task with a 9.5-18.5-sec delay, Rowe et al. (2000) reported delay-period activity in PFC Brodmann area 8 and Petrides and Pandya's (1994) area 9/46, but no delay activity in Brodmann area 46 proper.

7. Sweeney et al. (1996) also showed significant dPFC activation during a delayed-memory task with a short delay. Although their task was not obviously "complex" in terms of memory requirements, it did differ from most other human imaging work in that it required a delayed eye-movement response to the peripheral location that had previously contained the target stimulus.

8. Courtney, Petit, Maisog, Ungerleider, and Haxby (1998) reported a more posterior dorsal PFC region, just anterior to frontal eye field (FEF) on the superior frontal sulcus, to be bilaterally active during memory delays, but particularly during spatial delays. The relative position of this region compared with FEF was consistent with the area in monkey cortex that may be especially active during spatial delayedmemory tasks (F. A. W. Wilson et al., 1993). However, others have failed to replicate this result (Postle, Berger, Taich, \& D'Esposito, 2000).

9. Because Hartley et al. (2001) did not report correlation coefficients, we estimated them from the factor loadings of each $n$-back task onto the latent variable comprised of the three $n$-back tasks (loadings for verbal, object, and location tasks were $.97, .68$, and .82 , respectively).

10. Benedict et al. (1998) also demonstrated no difference in PFC activation under PET between focused- and divided-attention conditions during a continuous performance task. However, it is not clear from their report to what extent the focused-attention condition recruited dPFCareas in comparison with a control condition. Because the focusedattention condition required ignoring potent distraction, we would expect that it evoked substantial dPFC activity, and so the lack of difference between divided-and focused-attention conditions seems to fit with our interpretation of the findings from other demanding tasks.

11. This study also addressed the role of the anterior cingulate in Stroop interference. Although many imaging studies have indicated anterior cingulate activation in Stroop tasks (e.g., Bench et al., 1993; Pardo et al., 1990; for a review, see MacLeod \& MacDonald, 2000), here there was no anterior-cingulate-delay activity related to task instructions. Instead, anterior cingulate was activated at the time of stimulus presentation, particularly for incongruent stimuli. In contrast to correlations between dPFC activity and performance, however, anterior cingulate activity at stimulus presentation was positively correlated with interference $(r=.38)$. Thus, the more interference subjects showed, the more anterior cingulate activity they showed. These findings indicate that anterior cingulate may not play a role in combatting Stroop interference, but rather that it may merely signal or recognize that conflict is present (see also West \& Alain, 1999, 2000a).

12. Elfgren and Risberg (1998) found only left hemisphere dPFC blood flow increases in a letter-fluency task in which subjects generated as many words as possible starting with each of eight different letters, for $1 \mathrm{~min}$ each. However, they found bilateral dPFC increases in a figural fluency task in which subjects generated as many unique, unnameable designs as possible in an 8-min period.

13. We note a recent finding that verbal fluency tasks did not differentially correlate with seemingly "executive" compared with seemingly "nonexecutive" tasks in a population of traumatic brain injury patients (Duncan et al., 1997). However, the degree to which active maintenance and interference contributed to performance of the "executive" or "nonexecutive" tasks employed is not obvious to us.

14. Metz, Yasillo, and Cooper (1987) found that performance of a computerized WCST produced no more frontal activation in PET than did performance of a computerized matching-to-sample "control" task. However, their written report is too brief to allow a critical analysis of their methods and data. Note, however, that the matching-to-sample "control" task that they used has been shown to rely on the PFC in humans and macaques (Goldman-Rakic, 1987; McIntosh et al., 1996; Verin et al., 1993). Thus, the lack of significant PFC activation differences between this "control" task and the WCST is not too surprising.

Ragland et al. (1998) used PET to test activation patterns in the WCST in comparison with a resting-state baseline. They found that healthy adults matched to schizophrenia patients on various variables showed significant WCST-linked activation only in inferior PFC areas and not in dorsolateral areas. However, dorsolateral, dorsomedial, and superior PFC activation was linked with some aspects of superior performance: The number of categories attained was correlated with dorsolateral PFC activity at $r=.48$, with dorsomedial activity at $r=.50$, and with superior frontal activity at $r=.69$.

15. But see Pollmann (2001) for evidence that frontopolar cortex is critically activated during extradimensional set-switching.

16. Duncan et al. (1997) failed to replicate these results in a study of patients with damage due to traumatic brain injury. Here, patterns of goal neglect were no more highly correlated with extent of frontal lobe damage by MRI $(r=.25)$ than with parietal damage $(r=.25)$ or with temporal damage $(r=.36)$. However, most patients in this study had rather diffuse damage, and so inferences regarding focal lesion effects here must be drawn very tentatively. 
17. We have technical concerns with some of this work. First, Jurden's (1995) contention that verbal and nonverbal working memory factors are separable depends largely on a reanalysis of Kyllonen and Christal's (1990, Experiment 1) data; however, Jurden's Table 3 (p. 99) shows that he transposed Kyllonen and Christal's data incorrectly. This may simply reflect typographical errors in the table, but it instead might indicate that the reanalyses were conducted on the wrong data. Second, in Daneman and Tardif (1987), ceiling effects in their spatial-task data probably limited the possibility that this task would correlate with verbal measures (see Engle et al., 1992). Finally, in Shah and Miyake's (1996) study of verbal versus spatial WM (Experiment 1), subjects' VSAT and QSAT scores were correlated at an unusually low $r=.28$. Perhaps with a wider range of ability (their undergraduate subjects were recruited from Carnegie Mellon University and the University of Pittsburgh) and a sample that showed more typically high correlations between VSAT and QSAT scores, Shah and Miyake would have found less separability between verbal and spatial WM measures. The authors themselves note that ". . . the use of a cognitively restricted sample may have the advantage of revealing domain-specific effects more clearly, which might otherwise be masked by general ability factors." (p. 21, italics added). Of course, in our view of WM capacity, such "general ability factors" are precisely what are most interesting.

(Manuscript received February 16, 2000; revision accepted for publication October 15, 2001.) 